\title{
Revised Technical Implementation Plan for the ShakeAlert System-An Earthquake Early Warning System for the West Coast of the United States
}

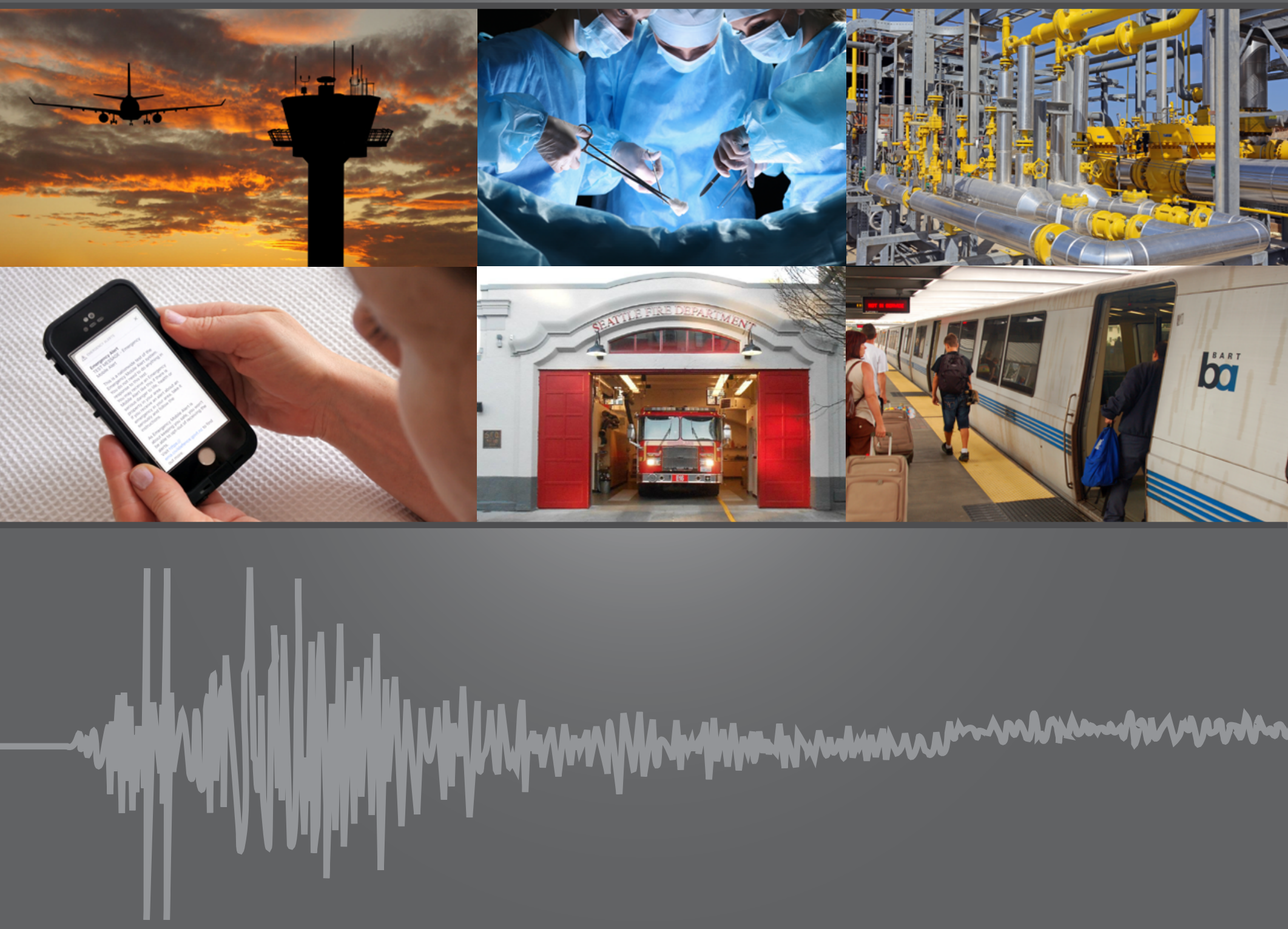

Open-File Report 2018-1155

Supersedes USGS Open-File Report 2014-1097

U.S. Department of the Interior

U.S. Geological Survey 
Cover images: Photographs showing potential beneficiaries of ShakeAlert, the earthquake early warning system for the West Coast of the United States. Clockwise from the upper left: ShakeAlert may provide enough warning (top left) to slow or stop taxiing planes (photograph from Ersin Ergin/ Shutterstock.com), (top middle) for surgeons or other medical professionals to stop delicate procedures (photograph from Andrei_R./Shutterstock. com), and (top right) for water companies to close valves and preserve precious water reserves (photograph from cpaulfell/Shutterstock.com). In addition, ShakeAlert may provide enough warning for (bottom left) people to drop, cover, and hold on (photograph from ChameleonsEye/Shutterstock. com); (bottom middle) first responders to open bay doors in advance of the shaking (photograph from Seattle Fire Department); and (bottom right) train operators to slow or stop trains (photograph from James Kirkikus/Shutterstock.com). 


\section{Revised Technical Implementation Plan for the ShakeAlert System-An Earthquake Early Warning System for the West Coast of the United States}

By Douglas D. Given, Richard M. Allen, Annemarie S. Baltay, Paul Bodin, Elizabeth S. Cochran, Kenneth Creager, Robert M. de Groot, Lind S. Gee, Egill Hauksson, Thomas H. Heaton, Margaret Hellweg, Jessica R. Murray, Valerie I.

Thomas, Douglas Toomey, and Thomas S. Yelin

Open-File Report 2018-1155

Supersedes USGS Open-File Report 2014-1097 


\title{
U.S. Department of the Interior \\ RYAN K. ZINKE, Secretary
}

\author{
U.S. Geological Survey \\ James F. Reilly II, Director
}

U.S. Geological Survey, Reston, Virginia: 2018
Supersedes USGS Open-File Report 2014-1097

For more information on the USGS - the Federal source for science about the Earth, its natural and living resources, natural hazards, and the environment-visit https://www.usgs.gov or call 1-888-ASK-USGS (1-888-275-8747)..

For an overview of USGS information products, including maps, imagery, and publications, visit https://store.usgs.gov.

Any use of trade, firm, or product names is for descriptive purposes only and does not imply endorsement by the U.S. Government.

Although this information product, for the most part, is in the public domain, it also may contain copyrighted materials as noted in the text. Permission to reproduce copyrighted items must be secured from the copyright owner.

Suggested citation:

Given, D.D., Allen, R.M., Baltay, A.S., Bodin, P., Cochran, E.S., Creager, K., de Groot, R.M., Gee, L.S., Hauksson, E., Heaton, T.H., Hellweg, M., Murray, J.R., Thomas, V.I., Toomey, D., and Yelin, T.S., 2018, Revised technical implementation plan for the ShakeAlert system-An earthquake early warning system for the West Coast of the United States: U.S. Geological Survey Open-File Report 2018-1155, 42 p., https://doi.org/10.3133/ofr20181155. [Supersedes USGS Open-File Report 2014-1097.]

ISSN 2331-1258 (online) 


\section{Contents}

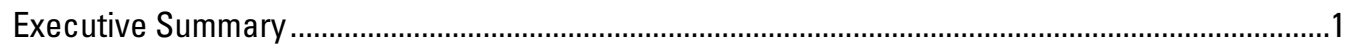

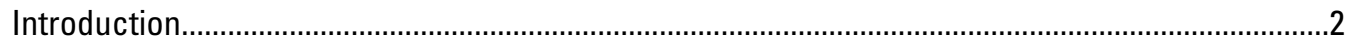

Vision

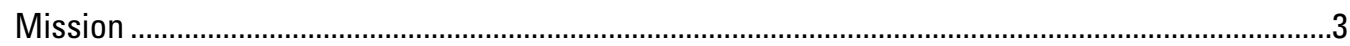

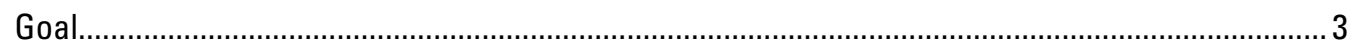

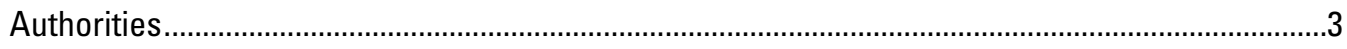

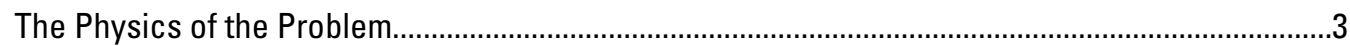

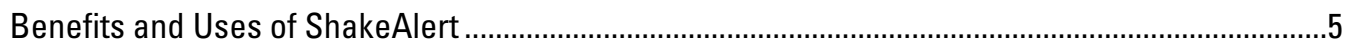

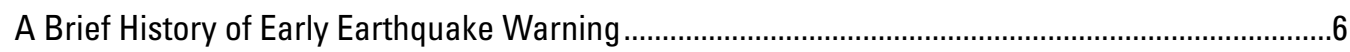

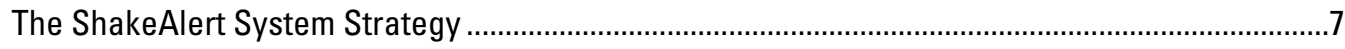

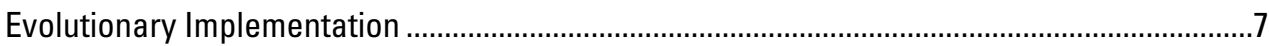

Other Partnerships and Collaboration...................................................................................

Phased Rollout Strategy ...........................................................................................................

Major System Components .............................................................................................................

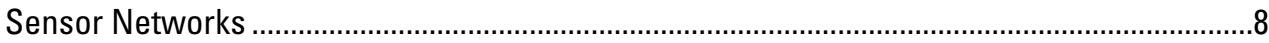

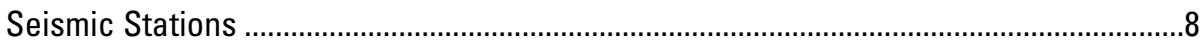

Global Navigation Satellite System Stations................................................................10

Required Station Distribution..............................................................................11

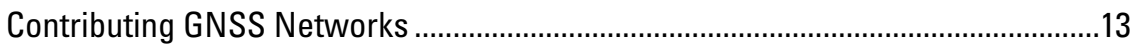

Goals for GNSS Network Upgrades .................................................................13

GNSS Network Upgrades in California ..............................................................14

GNSS Network Upgrades in Oregon and Washington..........................................14

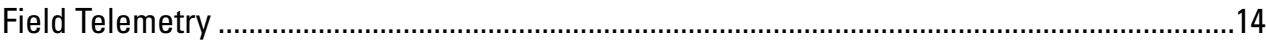

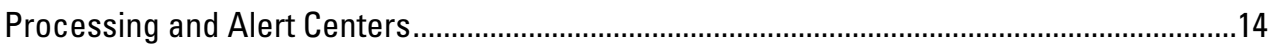

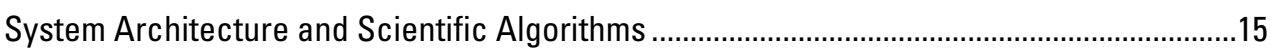

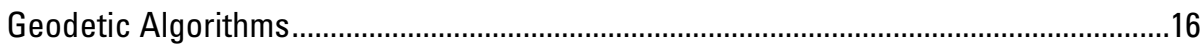

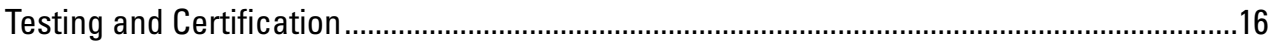

System Operation, Code Deployment, and Monitoring ………..............................................17

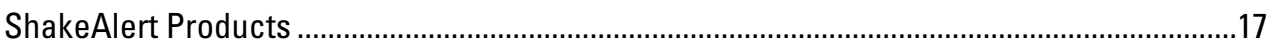

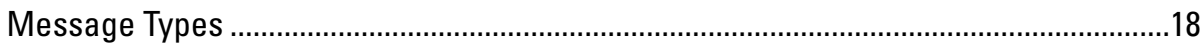

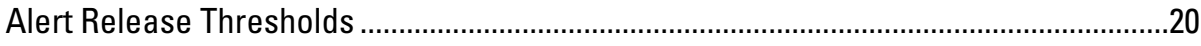

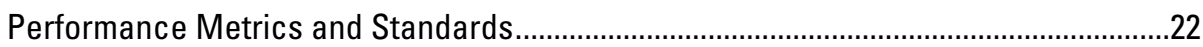

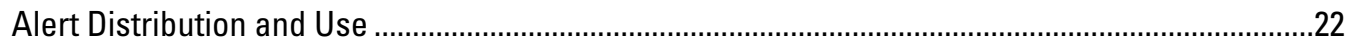

Alerts to Institutional Users_Pilot Projects ...................................................................22

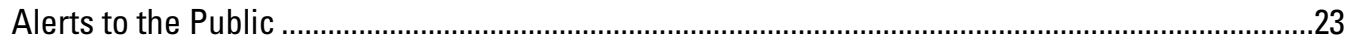

Mass Alerting via FEMA's Integrated Public Alert and Warning System and Cellular

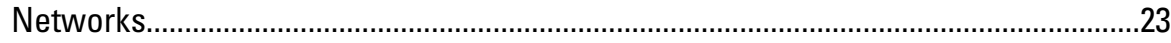

Push Notifications to Cell Phones..........................................................................................2

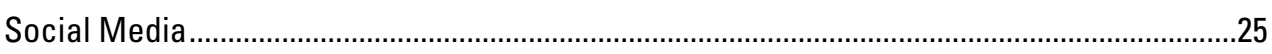

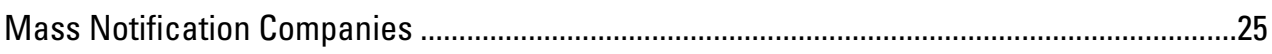

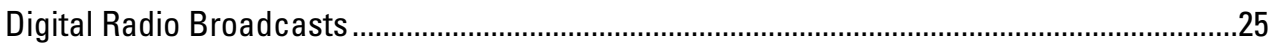

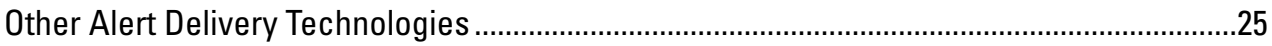

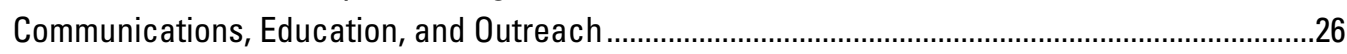

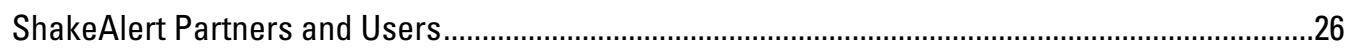




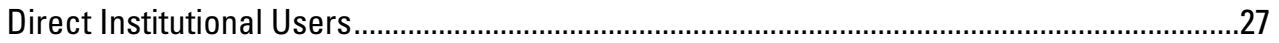

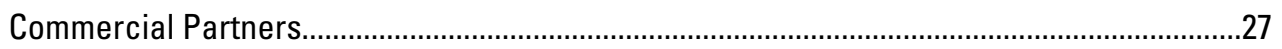

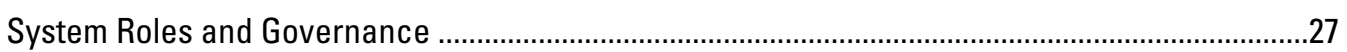

State Partners

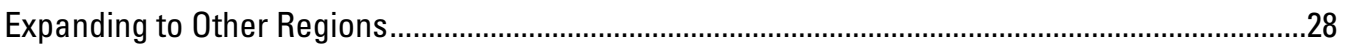

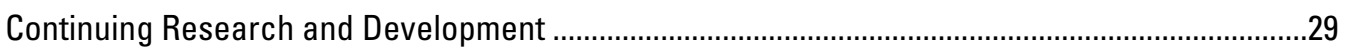

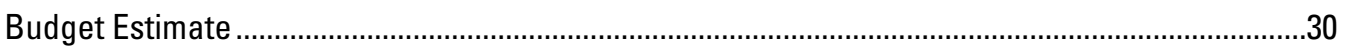

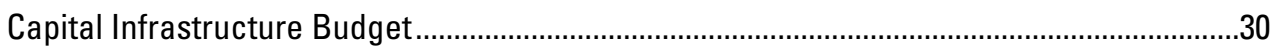

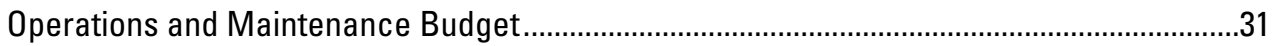

Timeline

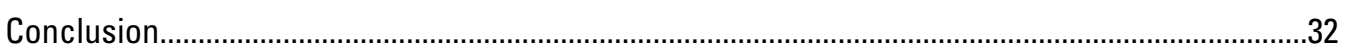

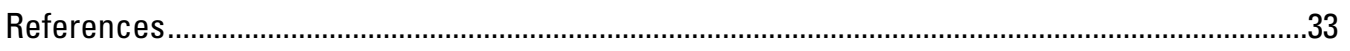

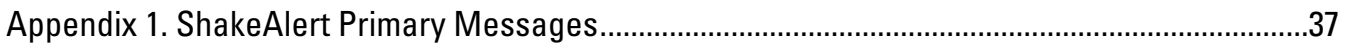

Appendix 2. ShakeAlert Reporting Region ..........................................................................39

Appendix 3. List of Current ShakeAlert Pilot Users and Technology Partners................................40

Appendix 4. Funding History....................................................................................................

Appendix 5. Telemetry Improvement Plan ................................................................................

\section{Figures}

1. Schematic cross section of the Cascadia Subduction Zone showing the three categories of earthquakes for which the ShakeAlert system must generate alerts ............4

2. Map of the western United States showing current and proposed locations of seismic

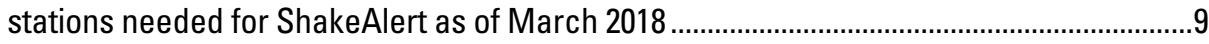

3. Schematic drawing of a typical seismic station used by the ShakeAlert system ...............10

4. Map of existing Global Navigation Satellite System stations in the geographic region of interest in California

5. Map of existing Global Navigation Satellite System stations in the geographic region

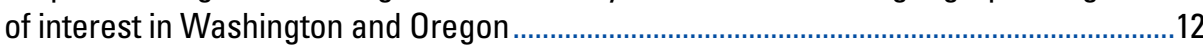

6. Schematic flowchart showing the architecture of the ShakeAlert system version $2.0 \ldots . . .16$

7. Screen shot image of the DMreview tool ......................................................................18

8. Two maps of the western United States showing examples of the shaking intensity contour and grid map ground-motion products distributed by ShakeAlert

9. Schematic drawing showing the architecture of the Federal Emergency Management Agency's Integrated Public Alert and Warning System.

\section{Appendix Figure}

2.1. Map of the ShakeAlert reporting region and Advanced National Seismic System regional network reporting areas in the western United States and Canada. 


\section{Tables}

1. Status of ShakeAlert seismic stations as of April 2018 ...

2. Summary of estimated capital and operation and maintenance budgets to complete and operate the ShakeAlert system

3. Summary of capital costs to complete buildout of ShakeAlert infrastructure by Advanced National Seismic System region.....

4. Summary of annual operations and maintenance budget for the ShakeAlert system by Advanced National Seismic System region

\section{Appendix Tables}

2.1. Vertices that define the ShakeAlert reporting region. ...39

4.1. Historical Federal funding for the ShakeAlert system. . .41

4.2. Historical Non-Federal funding for the ShakeAlert system. .. .41

5.1. Summary of capital and operation and maintenance budget estimates to complete the three-state telemetry improvement plan for the ShakeAlert system by Advanced National Seismic System region

\section{Key Terms, Abbreviations, and Symbols}

$\begin{array}{ll}\text { ActiveMO } & \begin{array}{l}\text { An open-source enterprise message broker service used to communicate } \\ \text { between ShakeAlert modules and data centers }\end{array} \\ \text { AMBER } & \text { America's Missing: Broadcast Emergency Response } \\ \text { ANSS } & \text { Advanced National Seismic System } \\ \text { APTS } & \text { America's Public Television Stations } \\ \text { AOMS } & \text { ANSS Quake Monitoring System } \\ \text { ATIS } & \text { Alliance for Telecommunications Industry Solutions } \\ \text { BARD } & \text { UC Berkeley's Bay Area Regional Deformation network } \\ \text { BART } & \text { Bay Area Rapid Transit } \\ \text { Cal OES } & \text { California Governor's Office of Emergency Services } \\ \text { Caltech } & \text { California Institute of Technology } \\ \text { CGS } & \text { California Geological Survey } \\ \text { CISN } & \text { California Integrated Seismic Network } \\ \text { ComCat } & \text { ANSS Comprehensive Earthquake Catalog } \\ \text { CREW } & \text { Cascadia Region Earthquake Workgroup } \\ \text { CWU } & \text { Central Washington University }\end{array}$

datalogger Field-hardened computer that accepts signals from a sensor, transforms them into digital data, and transmits them over a telemetry system to central processing sites 


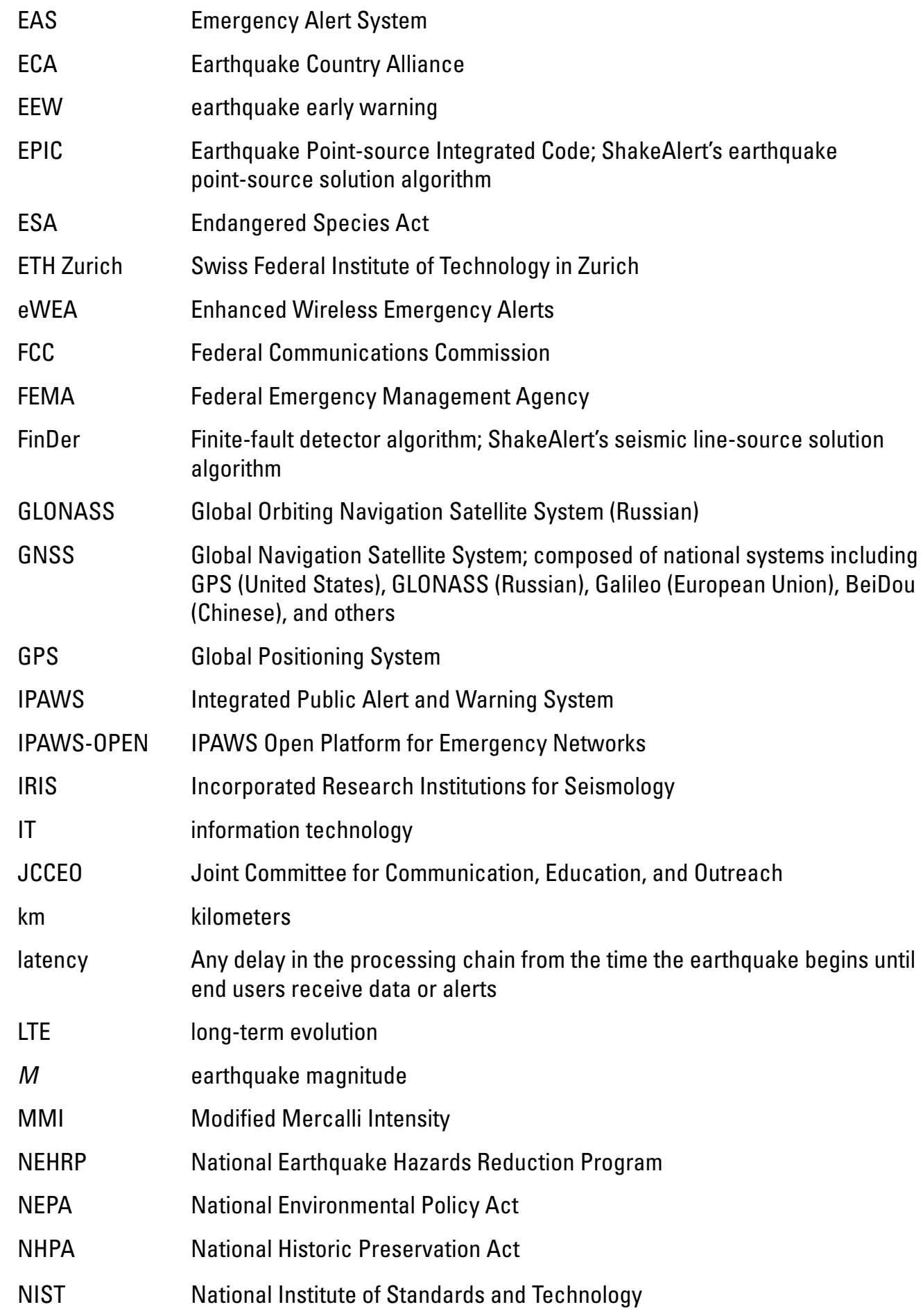




\begin{tabular}{|c|c|}
\hline NOAA & National Oceanic and Atmospheric Administration \\
\hline NSF & National Science Foundation \\
\hline PANGA & CWU's Pacific Northwest Geodetic Array \\
\hline PBO & Plate Boundary Observatory \\
\hline PGA & peak ground acceleration \\
\hline PGV & peak ground velocity \\
\hline PNSN & Pacific Northwest Seismic Network \\
\hline P-wave & $\begin{array}{l}\text { Primary wave; the faster moving compressional wave that arrives first during } \\
\text { an earthquake }\end{array}$ \\
\hline SCEC & Southern California Earthquake Center \\
\hline sensor & An instrument that measures ground motions \\
\hline seismic station & $\begin{array}{l}\text { A location with an installed datalogger, power system, telemetry, and sensors } \\
\text { that measures ground motions and transmits them to data processing centers }\end{array}$ \\
\hline SESAC & $\begin{array}{l}\text { Scientific Earthquake Studies Advisory Committee (for the USGS Earthquake } \\
\text { Hazards Program) }\end{array}$ \\
\hline SI & shindo seismic intensity scale (Japanese) \\
\hline SSL & secure sockets layer \\
\hline S-wave & $\begin{array}{l}\text { Secondary wave; the slower moving shear wave that arrives after the P-wave } \\
\text { during an earthquake }\end{array}$ \\
\hline telemetry & $\begin{array}{l}\text { Telecommunication capability that carries ground-motion data from sensor } \\
\text { stations in the field to central processing sites }\end{array}$ \\
\hline UC Berkeley & University of California, Berkeley \\
\hline UNR & University of Nevada, Reno \\
\hline URL & Uniform Resource Locator (a "web address") \\
\hline USGS & U.S. Geological Survey \\
\hline USGS EHP & U.S. Geological Survey's Earthquake Hazards Program\ \\
\hline UW & University of Washington \\
\hline VolP & Voice over Internet Protocol \\
\hline WEA & $\begin{array}{l}\text { Wireless Emergency Alerts; uses cellular broadcast technology in } \\
\text { commercial cell systems to send mass alerts to the public }\end{array}$ \\
\hline XML & extensible markup language \\
\hline
\end{tabular}





\title{
Revised Technical Implementation Plan for the ShakeAlert System-An Earthquake Early Warning System for the West Coast of the United States
}

\author{
By Douglas D. Given', Richard M. Allen², Annemarie S. Baltay', Paul Bodin³, Elizabeth S. Cochran', Kenneth \\ Creager $^{3}$, Robert M. de Groot ${ }^{1}$, Lind S. Gee ${ }^{1}$, Egill Hauksson ${ }^{4}$, Thomas H. Heaton ${ }^{4}$, Margaret Hellweg ${ }^{2}$, Jessica \\ R. Murray', Valerie I. Thomas ${ }^{1}$, Douglas Toomey ${ }^{5}$, and Thomas S. Yelin ${ }^{1}$
}

\section{Executive Summary}

The U.S. Geological Survey (USGS), along with partner organizations, has developed an earthquake early warning (EEW) system called ShakeAlert for the highest risk areas of the United States: namely, California, Oregon, and Washington. The purpose of the system is to reduce the impact of earthquakes and save lives and property by providing alerts that are transmitted to the public via mass notification technologies and more detailed data streams to institutional users and commercial service providers to trigger automated user-specific protective actions.

When an earthquake occurs, seismic waves radiate from the rupturing fault like waves on a pond. It is these waves people feel as earthquake shaking and which cause damage to structures. Using networks of ground-motion sensors and sophisticated computer algorithms, ShakeAlert can detect an earthquake seconds after it begins, calculate its location and magnitude, and estimate the resulting intensity of shaking. Alerts, including early warnings of impending shaking, can then be sent to people and systems that may experience damaging shaking, allowing them to take appropriate protective actions. Depending on the user's distance from the earthquake, alerts may be delivered before, during, or after the arrival of strong shaking. The ShakeAlert system can update its ground-motion estimates as an earthquake grows larger.

ShakeAlert is built on the foundation of the sensor networks and data processing infrastructure of the USGS-led Advanced National Seismic System (ANSS). However, these networks were not originally designed for EEW; old equipment needs to be updated and new stations need to be added to construct EEW-capable networks.

\footnotetext{
${ }^{1}$ U.S. Geological Survey.

${ }^{2}$ University of California, Berkeley.

${ }^{3}$ University of Washington.

${ }^{4}$ California Institute of Technology.

${ }^{5}$ University of Oregon.
}

This implementation plan calls for a total of 1,675 highquality, real-time EEW-capable ANSS seismic stations-1,115 in California and 560 in the Pacific Northwest. These seismic station numbers are based on a station spacing of 10 kilometers $(\mathrm{km})$ in urban areas, $20 \mathrm{~km}$ in seismic source areas that endanger population centers, and $40 \mathrm{~km}$ in other areas. About 865 seismic stations are currently contributing data to ShakeAlert and 250 more have funding and are currently being built. This plan would complete the buildout by upgrading or adding 560 seismic stations: 283 in California and 277 in Oregon and Washington. This budget also includes the one-time capital cost to make geodetic networks in California and the Pacific Northwest EEW-capable by upgrading about 475 Global Navigation Satellite System (GNSS) geodetic stations in USGS and cooperator networks with modern GNSS receivers that incorporate clock corrections for onboard positioning and improving telemetry where needed.

ShakeAlert's mission requires fast, reliable telemetry to deliver sensor data to processing centers. The ANSS networks currently use both commercial and their own specialized telecommunication infrastructure. The networks also have collaborators that provide telemetry bandwidth, thereby reducing costs. However, existing data pathways can be fragile so this document includes estimates for telemetry infrastructure upgrades designed to survive strong ground shaking and the heavy telecommunications congestion that will come with a large earthquake.

The ShakeAlert data processing infrastructure includes redundant servers that are geographically distributed at the monitoring centers of tier 1 ANSS seismic networks in Seattle, Washington, as well as Menlo Park, Berkeley, and Pasadena in California. There are three data processing layers. The data layer handles raw ground-motion data from field stations and is part of the routine ANSS Quake Management System (AQMS) operated by the ANSS networks. The production layer analyzes these data using ShakeAlert algorithms to detect earthquakes, calculate their locations and magnitudes, and estimate the area and intensity of the resulting shaking. The alert layer checks these geophysical solutions against alert release criteria and creates and publishes alert products as appropriate. Users connect to alert layer servers to subscribe to alert and data streams. 
ShakeAlert currently has two independent algorithms to detect and characterize earthquakes using seismic data. The first is EPIC (earthquake point-source integrated code), which produces point-source solutions. EPIC measures several ground-motion parameters in small time windows and associates them to locate the earthquakes and estimate magnitudes. EPIC employs multiple checks to discriminate between random noise and earthquake shaking, including a "filter bank" check to reject large remote earthquakes, called teleseisms. The second algorithm is FinDer (finite-fault detector), which can produce either a point-source or, for larger earthquakes, a line-source solution. It estimates the fault's centroid location, orientation, and length using a pattern search technique to fit ground-motion observations to precalculated fault templates. EPIC and FinDer algorithms both update frequently as the earthquake grows and more data become available. Algorithms to utilize geodetic data are currently in development and will be added to ShakeAlert in the future.

ShakeAlert publishes several data and alert products to meet the needs of different users. All messages include the location of the earthquake, either as a point or a line, and its magnitude. Ground-shaking estimates are published in two forms, ground-motion contours or a map grid. Alert products are released to institutional users for events of magnitude 3.5 or greater. A lower threshold would result in more false alerts. The threshold for initial public alerting will be magnitude 5.0 or greater, but this alert threshold could be lowered as the system improves and public confidence in and familiarity with ShakeAlert increases.

To have the greatest benefit, EEW alerts, or "ShakeAlerts," will be delivered to institutional users and individuals by all practical pathways. The USGS alert layer can support thousands of institutional users and alert redistributors, but the USGS does not have the mission nor the infrastructure and expertise to perform mass notifications to the public. Although our strategy is to use existing Federal and private mass alerting systems, these message delivery technologies must be upgraded to be fast enough for effective EEW. Also, it is beyond the mission and abilities of the USGS to implement automatic actions for end users. To meet this need, we are recruiting private sector "technology enablers" that have the necessary expertise to develop end-user implementations with the goal of stimulating an EEW industry.

EEW alerts are useless if people do not know how to respond to them. Although the alert messages will include instructions about what to do (drop, cover, and hold on), alerts will be more effective if people have been trained in advance. Messages about ShakeAlert's capabilities, limitations, and benefits should be integrated with existing earthquake education programs, including State-run programs. Therefore, ShakeAlert will coordinate with both public and private partners and stakeholders through various partnerships and agreements to accomplish consistent and ongoing public education.

The estimated cost of completing the computing infrastructure and sensor networks for ShakeAlert is $\$ 39.4$ million. The annual operation and maintenance cost of the completed system is estimated to be $\$ 28.6$ million per year. This document also provides estimates of the added costs for a telemetry improvement plan. Building a highly reliable data telemetry infrastructure would cost another $\$ 20.5$ million; however, this cost could be reduced if project partners provide bandwidth on existing systems. Operating this highly reliable data telemetry would add another $\$ 9.8$ million per year of costs; but this also could be reduced by partners providing bandwidth at low or no cost to the project.

\section{Introduction}

Earthquakes are a national problem, with more than 143 million people exposed to potentially damaging shaking in the United States (Jaiswal and others, 2015). Most of our nation's earthquake risk is concentrated in the highly populated areas on the active plate tectonic boundary of the West Coast of the continental United States. The Federal Emergency Management Agency (FEMA) has estimated that the annualized loss from earthquakes nationwide is $\$ 6.1$ billion per year, with 73 percent of that figure ( $\$ 4.5$ billion per year) coming from California, Oregon, and Washington and 61 percent ( $\$ 3.7$ billion per year) from California alone (Federal Emergency Management Agency, 2017). This estimate is only for building-related losses, and does not include components such as utility and transportation losses, business interruption, and the losses associated with deaths and injuries. In the next 30 years, California has a 99.7 percent chance of a magnitude 6.7 or larger earthquake (Field and others, 2015) and the Pacific Northwest has a 10 percent chance of a magnitude 8 to 9 megathrust earthquake on the Cascadia Subduction Zone (Field and others, 2008).

An earthquake early warning (EEW) system detects earthquakes so quickly that an alert can reach some areas before strong shaking arrives so that protective actions can be taken. The earthquake's location and magnitude are rapidly estimated by measuring the first shaking with sensors near the source. The ground-shaking intensity expected across the affected region is then estimated and alerts sent to people or systems in those areas, in some cases before the larger, more damaging shaking arrives. As the earthquake grows, more data become available from additional sensors and the system revises these groundmotion estimates and updates its alerts. The area very close to the epicenter may not receive the alert before strong shaking begins but can still benefit from the information that a significant earthquake is occurring. The size of this area can be minimized by having dense networks with sensors close to the epicenter, fast detection algorithms and alerting software, and rapid alert-delivery technologies. More distant locations will have more time to act but will typically experience less intense shaking.

In 2006, the U.S. Geological Survey (USGS) began funding the development of EEW in collaboration with university, State, and private partners and has the goal of building a public system for three States of the West Coast of the United States: California, Oregon, and Washington. Built on three of the eleven regional seismic networks of the Advanced National Seismic System (ANSS), those efforts resulted in a demonstration system called ShakeAlert, which began sending test notifications to 
select users in January 2012. In February 2016, the ShakeAlert Production Prototype version 1.0 went live in California and began providing notifications to a small group of early pilot users. In April 2017, Production Prototype version 1.2 went live for some areas of the entire West Coast. In this phase, alerts were not sent to the general public, but pilot users were encouraged to develop and deploy functioning implementations to take automatic actions to protect their infrastructure and alert their employees. At the same time, commercial technology enablers began developing products to protect infrastructure and alert people. In 2016, the USGS announced its goal of rolling out the first phase of public alerting in 2018.

\section{Vision}

The vision of the USGS is to reduce the impact of earthquakes and save lives and property in the United States by developing and operating a public earthquake early warning capability for high-risk regions.

\section{Mission}

The USGS, along with partner organizations, will develop and operate an EEW system, called ShakeAlert, for the highest risk areas of the United States. The ShakeAlert system will leverage the current earthquake-monitoring capabilities of the ANSS (U.S. Geological Survey, 2017) and provide alerts free of charge to the public via all practical emergency-alert channels. ShakeAlert will also provide more information-rich alert streams to specialized users, including commercial service providers, for use in user-specific applications. The USGS will promote and help coordinate public education about the ShakeAlert system and its capabilities, limitations, and benefits to users. This mission will be accomplished in cooperation with both public and private partners and stakeholders through various partnerships and agreements.

\section{Goal}

The goal of the USGS and partners is to build and operate the ShakeAlert system in three States of the West Coast of the United States - California, Oregon, and Washington. The USGS will generate alerts of potentially damaging earthquakes (called ShakeAlerts) that will be served to the public, and will send rapid earthquake and ground-motion data to Government agencies and private users on a region-by-region basis as soon as the ShakeAlert system, its products, and its parametric data meet minimum quality and reliability standards in those geographic regions. ShakeAlert will subsequently expand geographically to other ANSS regions with high earthquake risk after the dense modern seismic instrumentation necessary to support EEW is installed and necessary operational funding is secured.

\section{Authorities}

The USGS was established by the Organic Act of March 3, 1879 (20 Stat. 394, 43 U.S.C. 31 et seq.). The Earthquake Hazards Reduction Act (P.L. 95-124) gives the USGS the Federal responsibility for providing notifications of earthquakes. The USGS is tasked with developing an EEW system in the United States in the Earthquake Hazards Reduction Act of 1977 (42 U.S.C. 7701 et seq.). Also, the most recent National Earthquake Hazards Reduction Program (NEHRP) authorization (P.L. 108-360) notes the loss-reduction value of early warning systems (sec. 7701), specifically calls for disseminating warnings of earthquakes (sec. 7702), and authorizes the USGS to establish and operate the ANSS "in order to enhance earthquake research and warning capabilities" (sec. 7707). FEMA has granted the USGS the authority to alert the public through its Integrated Public Alert and Warning System (IPAWS).

\section{The Physics of the Problem}

The ShakeAlert system must generate alerts for different types of potentially damaging earthquakes. Earthquakes on the West Coast of the United States fall into three broad categories - shallow crustal, plate interface, and intraslab events (fig. 1). Shallow crustal earthquakes are the most frequent and occur all along the West Coast. These events occur on faults in the cooler brittle zone of the Earth's crust from the surface down to a depth of about 35 kilometers $(\mathrm{km})$ (20 miles). Such earthquakes can reach magnitudes $(M)$ as high as 8.0. Wellknown faults that produce large shallow crustal earthquakes include the San Andreas, Hayward, and Seattle Faults.

The Cascadia Subduction Zone produces two additional types of earthquakes. Plate interface events occur where the oceanic plate is thrust under the overriding continental plate in a process known as subduction. A sudden slip at the interface between the two plates can generate megathrust earthquakes as large as $M 9.0$ or larger. Such an event occurred off the coast of the Pacific Northwest in 1700 and produced a large tsunami that caused damage as far away as Japan. In contrast, intraslab events occur within the down-going oceanic plate as it bends and breaks underneath the continent. As a result, these events are deep and typically produce less ground shaking than interface or crustal events of comparable magnitude. However, intraslab events can still cause damage when they are located under population centers, such as Portland, Oregon, or Seattle, Washington. The 2001 M6.8 Nisqually earthquake that damaged Seattle was an intraslab earthquake.

Large earthquakes are not simple. The slip or rupture on a fault begins at a point below the Earth's surface called the hypocenter and then propagates along a fault like a zipper. Rupture can grow in either one or both directions along the fault. The rupture front races down the fault at about 3 kilometers per second ( 2 miles per second) but may progress irregularly as it encounters 
strong and weak patches in the fault. The rupture can also jump from one fault to another before it stops. To correctly estimate the effects of the earthquake, ShakeAlert must track the progress of the fault rupture as it grows. As fault slip proceeds, more shaking energy is released, the magnitude increases, and a larger area is shaken. In addition, an earthquake may begin at some distance from a user's location but the rupture may get closer as it grows. For a given earthquake magnitude, the final intensity of shaking that a user experiences depends on their distance from the fault rupture rather than the earthquake's starting point.

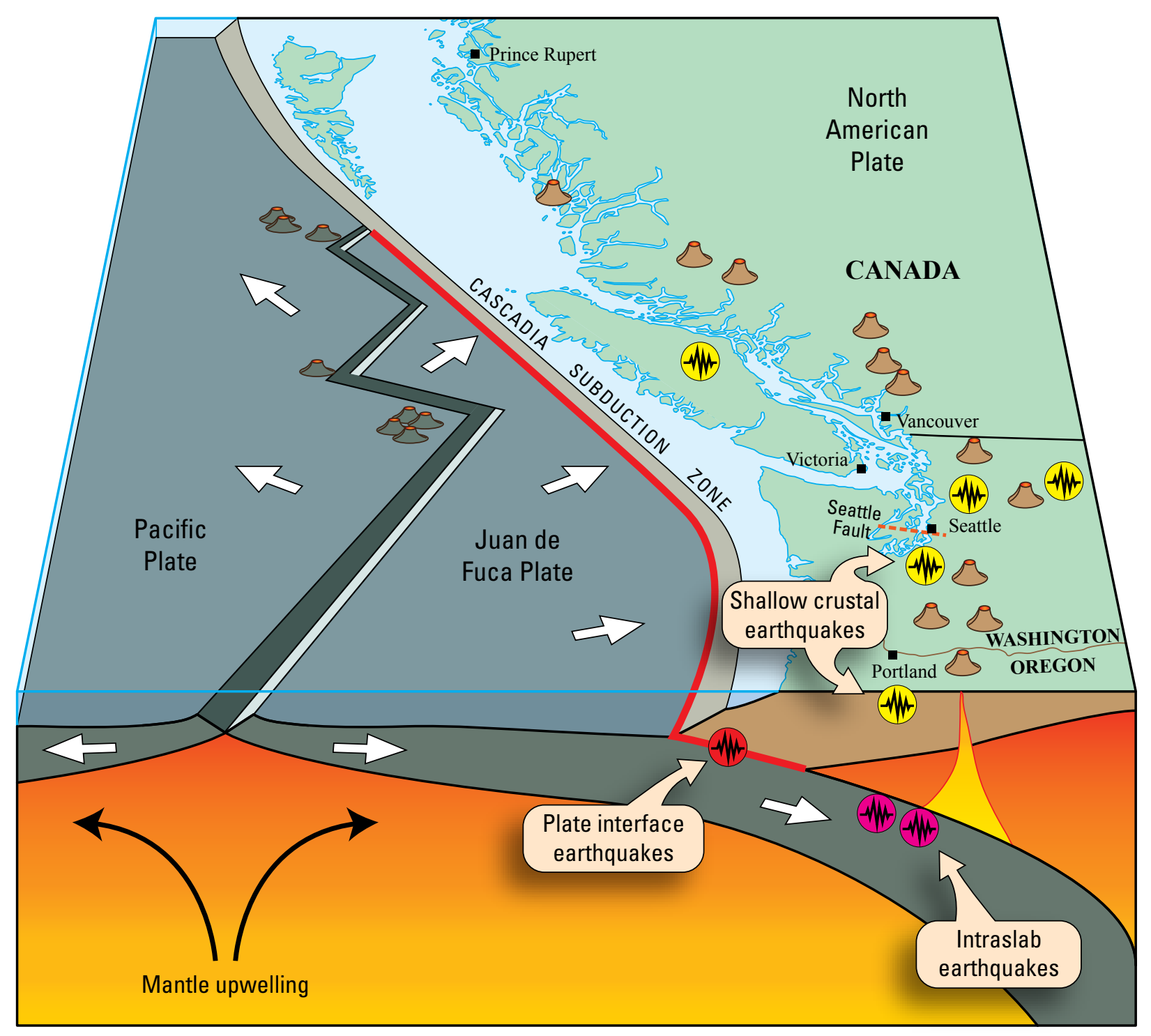

Figure 1. Schematic cross section of the Cascadia Subduction Zone showing the three categories of earthquakes for which the ShakeAlert system must generate alerts. West Coast earthquakes fall into three broad categories: shallow crustal earthquakes occur on faults in the cool brittle crust, plate interface earthquakes occur at the interface between the oceanic and continental tectonic plates, and intraslab earthquakes occur within the down-going oceanic plate. Shallow crustal earthquakes are most common and plate interface earthquakes generate the largest earthquakes. Because of their depth, intraslab earthquakes typically produce less shaking than either shallow crustal or plate interface earthquakes. 
In earthquake detection systems like ShakeAlert, a point-source solution describes an earthquake's location as a point in space with a latitude, longitude, and depth. A finite-fault solution describes an earthquake as slip on a length of fault, either as a line at the surface or a plane slicing through the Earth's crust. Finite-fault solutions are necessary to accurately predict the area and intensity of shaking for earthquakes greater than about $M 7.0$.

\section{Benefits and Uses of ShakeAlert}

A few seconds of warning may not seem like much, but ShakeAlert can trigger automated actions that can prevent injury or death, reduce immediate damage, and speed recovery from earthquakes. Fire station doors can be opened to prevent jamming, which traps equipment inside. Heavy equipment like trains, elevators, and cranes can automatically stop or park in safe positions. Pipeline valves can be shut and thus prevent surges and spills. A few seconds of warning is also sufficient for people to take protective actions, especially if they have been trained in advance. School children can drop, cover, and hold on, and crowds in theaters and sports venues can be forewarned and given instructions to prevent panic. Workers in factories, construction sites, and hospitals can evacuate from dangerous areas. ShakeAlert can be particularly valuable after a large earthquake, because aftershocks shake weakened structures and endanger rescue and repair workers that are in hazardous situations. Even if the alert arrives after strong shaking has begun at a location, it enhances situational awareness and can help people make better choices in the confusing moments after an earthquake. An added benefit is that public education about EEW raises public awareness of the overall earthquake threat and how to best react when an earthquake does occur.

EEW systems are in operation in several countries around the world. Public alerting is done nationwide in Japan and Taiwan, and in parts of Mexico, China, and Korea. Turkey, Italy, and Romania do more limited alerting to protect infrastructure. Several countries are actively working on systems, including India, Israel, and Chile.

Strauss and Allen (2016) enumerated many benefits of EEW: "Three lives saved, two semiconductor plants warned, one [Bay Area Rapid Transit] train slowed, a 1 percent reduction in nonfatal injuries, a 0.25 percent avoidance in gas-related fire damage, could each in theory save enough money to pay for one year of operation of the system for the entire U.S. West Coast. EEW could also reduce the number of injuries in earthquakes by more than 50 percent." Additionally, Porter and Jones (2018) concluded that for the case of a M7.0 event on the Hayward Fault, people taking drop, cover, and hold actions in response to EEW could prevent 1,500 out of 18,000 estimated nonfatal injuries. This would have a monetary benefit valued at about $\$ 300$ million.

A study by the U.S. Government Accountability Office concluded that "According to ShakeAlert stakeholders we spoke with, the implementation of an Earthquake Early Warning (EEW) system could have numerous benefits, including providing warnings to the general public" (U.S. Government Accountability Office, 2016). Another recent study conducted by the Pacific Earthquake Engineering Research Center for the State of California found that "there was strong consensus among interviewees that overall societal value can result from 14 different sectors of the State's economy and infrastructure having access to and making concrete use of a Statewide EEW [system] in different ways" (Johnson and others, 2016). This study further concluded that "the sectors unanimously perceived the overall societal benefits of having a Statewide EEW [system] as very high."

A poll of the Japanese public following the M9.0 Tohoku-Oki earthquake of March 11, 2011, indicated that 90 percent of the population thinks EEW is worth the investment (Fujinawa and Noda, 2013).

\section{Alert or warning?}

"The difference between alerts and warnings can be unclear because a warning can also serve as an alert, and an alert may be accompanied by some information about protective measures. Technology has further eroded the distinction. For example, on mobile devices, the Commercial Mobile Alert service will simultaneously deliver both a distinctive tone (the alert) and a brief message with additional information (a warning). Similarly, sirens have evolved to provide both a siren sound and a spoken message" (National Academies of Sciences, Engineering, and Medicine, 2018). 


\section{A Brief History of Early Earthquake Warning}

Suggestions to build EEW systems tend to follow destructive earthquakes. The earliest proposal to build an EEW system came after the M6.8 earthquake on the Hayward Fault, which wracked San Francisco on October 21, 1868. In an editorial titled "Earthquake Indicator" to the San Francisco Daily Evening Bulletin one month after the quake, Dr. J.D. Cooper described all the essential elements of an effective EEW system: the "simple mechanical contrivance" would be "self-acting" and use sensors outside the city connected by telegraph lines to an alarm of "peculiar sound, and known to everybody as the earthquake bell" (J.D. Cooper, San Francisco Daily Evening Bulletin, November 3, 1868). A similar suggestion was made in an Iranian newspaper in 1909 after a M7.4 event killed 8,000 people in Iran (Berberian, 2013).

In Japan, the 1964 M7.5 Niigata earthquake occurred just months before the inauguration of the first Shinkansen high-speed train and, in its first year of operation, a M6.1 quake damaged some structures of the new system, motivating the Japanese National Railways to build the first operational EEW system (Nakamura and Saita, 2007). In 1985, the M8.1 earthquake off the coast of Guerrero, Mexico killed as many as 10,000 people in the Greater Mexico City area, prompting the government of Mexico City to build the SASMEX system that began sending public alerts in 1993 (Lee and Espinosa-Aranda, 1998). Systems with varying coverage and functionality have also been built in Romania, Turkey, Italy, Taiwan, and China, primarily in response to deadly earthquakes.

The first serious proposal to implement an EEW system in the United States was made when Heaton (1985) described a "seismic computerized alert network" for California. Four years later, following the M6.9 Loma Prieta earthquake $90 \mathrm{~km}$ (60 miles) south of San Francisco, California, the USGS deployed an improvised EEW system in the epicentral area using the same analog sensors and radio telemetry that were used in the earthquake monitoring network. The system sent alarms via radio signal to Oakland, Calif., where emergency personnel were engaged in recovery operations at the collapsed Cypress Street Viaduct of Interstate 880. During its six months of operation, the system sent warnings for all 12 earthquakes between magnitudes 3.7 and 4.5 (Bakun and others, 1994).

As sensor, computer, and telecommunications technologies have improved, seismic monitoring networks have become more automated and capable of creating faster, more sophisticated post-earthquake products (Hutton and others, 2010). In 1999, the USGS began a project to unify the patchwork of regional research seismic networks in the United States into a coordinated Advanced National Seismic System (U.S. Geological Survey, 1999). That plan anticipated that the ANSS would ultimately be the foundation for EEW in the United States.

In 2006, the USGS began directly supporting EEW research through cooperative agreements with University of California, Berkeley (UC Berkeley), California Institute of Technology (Caltech), the Southern California Earthquake Center (SCEC), and the Swiss Federal Institute of Technology in Zurich (ETH Zurich). This effort resulted in three viable EEW techniques, which led to a second three-year phase of funding. This phase resulted in an end-to-end demonstration system called ShakeAlert. In January 2012, the ShakeAlert demonstration system began sending live test notifications to a limited group of "beta" users. These organizations were given access to the live alert stream and were asked to evaluate the potential of the system but take no actions based on its output. In a special project with UC Berkeley, the Bay Area Rapid Transit (BART) system began using EEW to slow down trains in 2012 (McPartland, 2013). That same year the Gordon and Betty Moore Foundation saw the value of the ShakeAlert project and awarded two consecutive three-year grants totaling \$10.3 million to support EEW research and development at Caltech, UC Berkeley, the University of Washington (UW), and the USGS.

In October 2013, the State of California enacted legislation that directed the California Governor's Office of Emergency Services (Cal OES) to develop and deploy a comprehensive statewide EEW system in collaboration with the USGS and its ShakeAlert partners, which the State refers to as the California Earthquake Early Warning System. In 2016, the State created an EEW advisory board and appropriated $\$ 10$ million to build or upgrade 183 stations and perform training and education about EEW. In 2018, Cal OES presented a business plan to the legislature for completing the system in California and recommending ways to fund its operation (Blue Sky Consulting Group, 2018). An additional $\$ 15.8$ million was allocated in fiscal year 2018-19 to support Cal OES's internal program and install the remaining sensors needed in California.

ShakeAlert Production Prototype version 1.0 began serving alert notifications to early adopters called "pilots" in California in February 2016. The West Coast-wide Production Prototype version 1.2 became operational in April 2017, when the Seattle alert center was created and connected with the California servers, extending the system to Washington and Oregon. The version 1.2 system did not alert the general public, but pilot users were encouraged to develop practical applications to alert employees and take automatic protective actions.

In 2016, the USGS set a goal to begin the first phase of public alerting in 2018. Although the system would neither be complete nor fully funded, it was considered important to show progress and results from the funding that had been invested to encourage additional investment and support. This commitment to public alerting also recognized that direct users in many sectors were committing resources to use the alerts and created opportunities to educate decisionmakers and the public about the practical uses and limitations of EEW. At the same time, commercial "technology enablers" began investing resources to create marketable applications, thus motivating others to follow and building a nascent EEW applications industry, which would serve the needs of public alerting as well as automatic (machineto-machine) earthquake safety systems. Setting a goal for the first phase of public alerting also motivated alert technology operators, like FEMA, cell carriers, and mass-notification companies, to take steps to speed up distribution systems to maximize warning times. 


\section{The ShakeAlert System Strategy}

\section{Evolutionary Implementation}

The ShakeAlert system leverages the existing earthquakemonitoring capability and expertise of two ANSS regional seismic networks. One, the California Integrated Seismic Network (CISN), is a collaboration among the USGS, Caltech, UC Berkeley, the California Geological Survey (CGS), and Cal OES. The other, the Pacific Northwest Seismic Network (PNSN), is a collaboration among the USGS, UW, and the University of Oregon. The ANSS tier 1 regional processing centers in the Pacific Northwest, northern California, and southern California are jointly staffed by both USGS and university personnel. These centers are funded by USGS internal funds and USGS external grants through cooperative agreements, along with additional funding by states, universities, or special projects. These same universities and other partners are developing ShakeAlert through additional EEWspecific cooperative agreements. The ShakeAlert Central group, located at the USGS office in Pasadena, Calif., manages systemwide operations, development, testing, and monitoring.

In addition to seismic networks, the USGS operates realtime Global Navigation Satellite System (GNSS) networks in southern and northern California and supports GNSS stations and data collection throughout the western United States through cooperative agreements with UC Berkeley, University of Nevada, Reno (UNR), and Central Washington University (CWU). The USGS also supports these institutions and UNAVCO (which operates the Plate Boundary Observatory geodetic stations that are currently supported by the National Science Foundation) to develop the geodetic component of ShakeAlert through EEWspecific cooperative agreements.

By evolving existing Federal- and State-supported capabilities, the USGS can build incrementally on the substantial government investment in sensor networks, data telemetry systems, data processing centers, and software for earthquake monitoring. It can also leverage the considerable institutional expertise and experience at these centers, which have demonstrated competence in the production of rapid, automatic earthquake products for emergency responders, scientists, engineers, policy makers, and the public. Algorithm development was done as part of a long-standing scientific research and development collaboration among university and USGS scientists.

\section{Other Partnerships and Collaboration}

Partnerships with many organizations are already important to the success of USGS earthquake monitoring networks. Data centers receive real-time ground-motion data from both public and private organizations that operate sensors. Other partners provide secure sensor locations at their facilities or bandwidth on their data communications infrastructure to bring field data to processing centers. These partnerships significantly improve the performance and reduce the cost of the system.

\section{Phased Rollout Strategy}

ShakeAlert capabilities are being rolled out in phases as the system is developed. The pace and level of progress are determined primarily by available funding for the project and the progress of external partners. As already described, the project has progressed through several phases, from research and development to demonstration to the current production prototype phase. Likewise, use of the system by public and private institutional users has incrementally expanded from beta users ("look but don't act") to pilot users ("act in error-tolerant ways"). These include emergency responders, schools, utilities, rail systems, and private companies (appendix 3).

The first phase of general public alerting will be regionally limited and will begin only when seismic network density and alert distribution technologies are far enough along to ensure timely and reliable EEW. This is because stations must be close to earthquake-generating faults to enable rapid alerts (especially when these faults are in urban areas) and because the technology to alert the general public via cell phones, radio, or television is currently too slow for effective earthquake alerts (discussed below). General public alerting using these technologies will occur in later phases when these alert distribution pathways are upgraded and tested and when the public is widely educated about the system and trained in alert response. The final step to full public alerting in all areas will only be prudent when the project is fully funded.

Despite incomplete funding, it is important to serve the public and begin to make ShakeAlert products available for use when they meet minimum quality and reliability standards. This strategy demonstrates that users in many sectors see the benefits of ShakeAlert and are committing resources to use it, and encourages additional users to follow their lead. This bandwagon includes commercial "technology enablers" who are investing to create commercial applications, thus creating a new ShakeAlert industry to bridge the gap between USGS-generated alerts and practical implementation at end-user locations. A phased rollout strategy that makes alerts partially available before the system is 100 percent complete is also motivating alert technology owners like FEMA, cellular carriers, and mass notification companies to speed up alerts, a process that can take years. In addition, concrete use cases are valuable in educating decisionmakers and the public about ShakeAlert and in gaining experience to improve both the human interface and the machine-to-machine interface. Finally, the protections afforded by ShakeAlert, even if limited, should be used as soon as possible because the next damaging earthquake can happen at any time.

\section{Major System Components}

ShakeAlert is designed as set of geographically distributed but interconnected components and sub-systems to detect earthquakes so quickly that alerts can be sent to people and machines allowing them to take protective actions before strong shaking arrives. The main components of the system include 
alert generation, supporting tasks, and alert services and user application, whose main components are summarized below and discussed in more detail in the following sections.

Alert generation includes all actions from detecting an earthquake to generating alerts:

- Sensor networks. - Integrated networks of seismic and geodetic sensors focused on potential earthquake source areas and population centers to record seismic and geodetic ground motions generated by earthquakes. Seismic stations use inertial sensors (masses and springs) to measure ground motion as velocity or acceleration, while geodetic stations use GNSS receivers to measure ground displacement.

- Field telemetry.-Data telecommunications systems to reliably transport data from field sensors to regional alert centers with minimal latency.

- Processing and alert centers.-Physical infrastructure with hardened, secure data processing capabilities to receive and manage ground-motion data and perform detection, decisionmaking, and alert-serving functions.

- Scientific algorithms.-Sophisticated scientific software algorithms to analyze seismic and geodetic data to rapidly detect earthquakes, reject non-earthquake signals, determine earthquake characteristics, and estimate the resulting ground-motion intensities.

- Alert generation.-Rules and software to evaluate and manage these scientific results, decide if alert or other data products should be created and to whom they should be served, create alerts, and serve them to technical users and public alert distribution providers.

Supporting tasks include steps to operate and improve the system:

- Testing and monitoring.-Facilities to continuously evaluate the performance of the system, refine and tune algorithms, and assess new methods and system changes.

- Research.-Ongoing research in seismology, geodesy, technology, and social science to improve the system's performance.

- Operations.-Reliable, continuous operation of the system and long-term maintenance of its hardware and software infrastructure.

Alert services and user application addresses serving alerts to and communication with end users:

- Alert services.-Facilities to provide rapid, reliable alert and data services and follow-up messaging to technical users and the public. Although ShakeAlerts and follow-up messages will be generated by the USGS, we depend on outside capabilities in other agencies and the private sector to distribute these alerts and messages to the public.

- Communication, education, and outreach.-Effective communication and education about the ShakeAlert system and its benefits, recruitment of end users and technology enablers, and outreach to stakeholders, decisionmakers and the public.

As the system is developed, work on each of these components of the system can proceed independently of progress on the others.

\section{Sensor Networks}

Existing ANSS regional monitoring networks serve multiple purposes and furnish ground-motion data for a variety of products used for science, engineering, situational awareness, and public safety, including ShakeAlert. Upgrades to these networks will not only benefit ShakeAlert, but will improve other USGS earthquake and situational awareness products.

\section{Seismic Stations}

This plan calls for a network of 1,675 high-quality, real-time seismic stations: 1,115 in California (operated by the CISN) and 560 in the Pacific Northwest (operated by the PNSN). This number is based on a study of optimal spacing of stations to maximize EEW alert speed by Kuyuk and Allen (2013). The target station density is $10 \mathrm{~km}$ spacing in urban areas, $20 \mathrm{~km}$ in seismic source areas that endanger population centers, and $40 \mathrm{~km}$ in lower risk areas. When possible, stations are placed within $5 \mathrm{~km}$ of major fault traces, but experience tells us that damaging earthquakes can occur even where faults have not been mapped. The greater density in urban areas speeds up alerts, provides ground-motion data for Seismic and geodetic stations ShakeMaps, and allows
Seismic stations use inertial sensors (masses and springs) to measure ground motion as velocity or acceleration, whereas geodetic stations use GNSS receivers to measure ground displacement. for some station outages without major impact on system performance. In practice, a uniformly spaced grid of sensors is impractical owing to the realities of land use and access to data telemetry infrastructure. Figure 2 shows the current distribution of contributing stations along with approximate locations of proposed new and upgraded stations. During the build-out phase, final station locations will be selected by scouting for places that are seismically quiet, where telecommunications are available, and where a land use permit can be obtained.

The ground-motion observations used for EEW currently come from broadband and strong-motion seismic sensors. The sensors are operated by the West Coast ANSS seismic networks and currently are not spaced closely enough in all areas to accomplish EEW without unacceptable delays. Therefore, new 


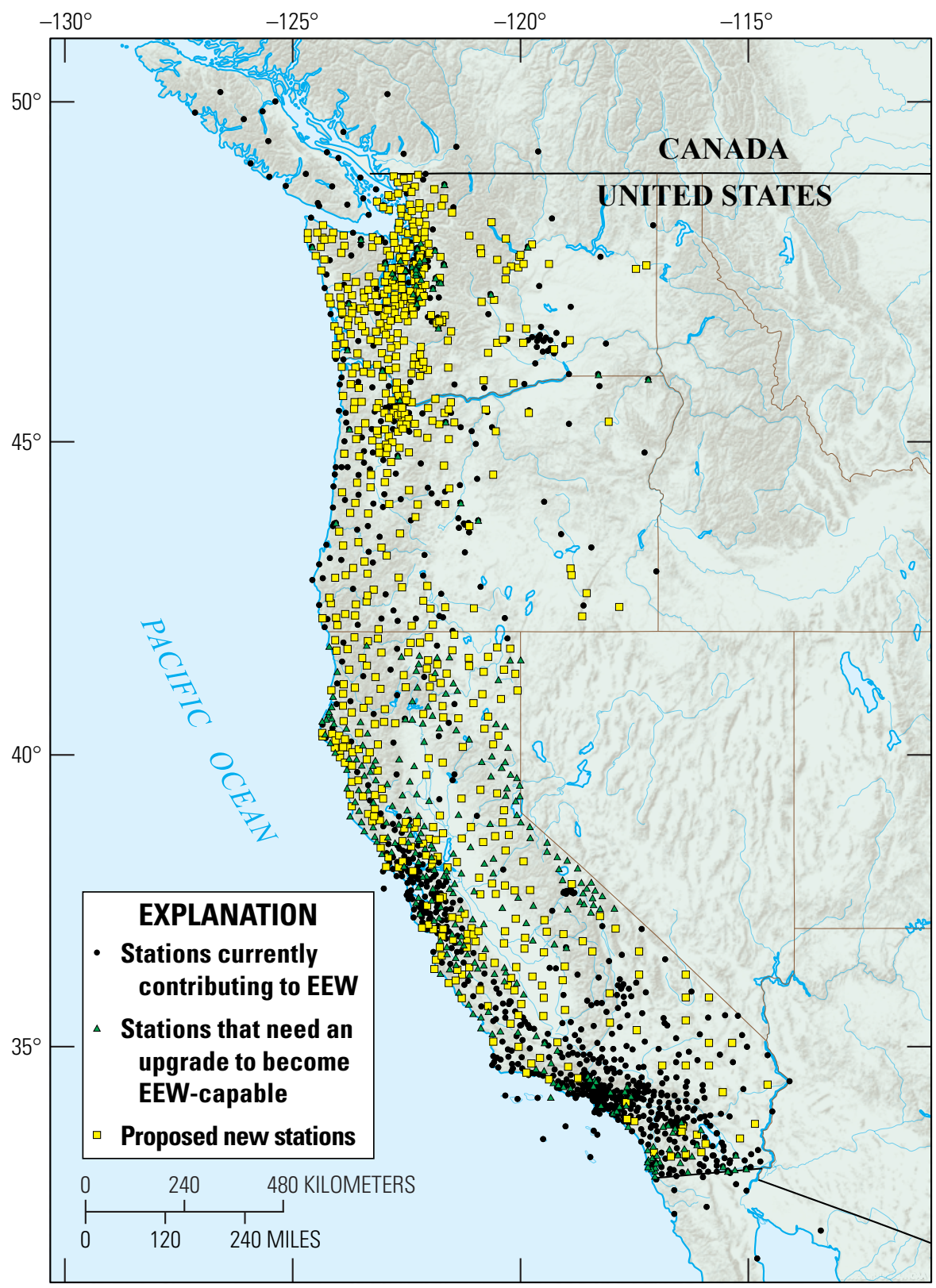

Figure 2. Map of the western United States showing current and proposed locations of seismic stations needed for ShakeAlert as of March 2018. Black dots show currently contributing stations (some may need upgrades), green triangles show currently active stations that must be upgraded to become earthquake early warning (EEW) capable, and yellow squares show approximate locations of proposed new stations.

Base from Esri (C) 2018 and its licensors

stations must be added and existing stations must be upgraded to achieve the needed density of EEW-capable stations.

ShakeAlert requirements identify two different types of seismic station to be used. All stations have strong-motion accelerometers that stay on scale for the largest shaking. About 25 percent of stations additionally have more sensitive broadband sensors installed. Stations with broadband sensors are always installed in the "free field," that is, away from the built environment where cultural noise and the response of structures to earthquake shaking may contaminate the groundmotion measurements. Strong-motion-only stations are also installed in the free field when possible, but may be placed in or near structures in urban settings where options are limited. Most free-field stations are solar powered with battery backup to last at least three days. A station schematic is shown in figure 3 .
This diversity of sensors improves the overall performance of the earthquake detection algorithms. For example, some strong-motion sensors are more prone to electronic noise that can cause false alerts. This can be reduced or eliminated by cross checking data with colocated broadband data. Where network coverage is less dense, the more sensitive broadband sensors can detect more distant events at the edges of the networks as well as smaller local events to continuously "exercise" the system.

Permitting presents a particular challenge for the buildout of ShakeAlert. Federal agencies control 27 percent of the land in Washington, 53 percent in Oregon, and 46 percent in California. These lands are subject to complex and stringent regulations, including those set by the National Environmental Policy Act (NEPA), Endangered Species Act (ESA), and National Historic 

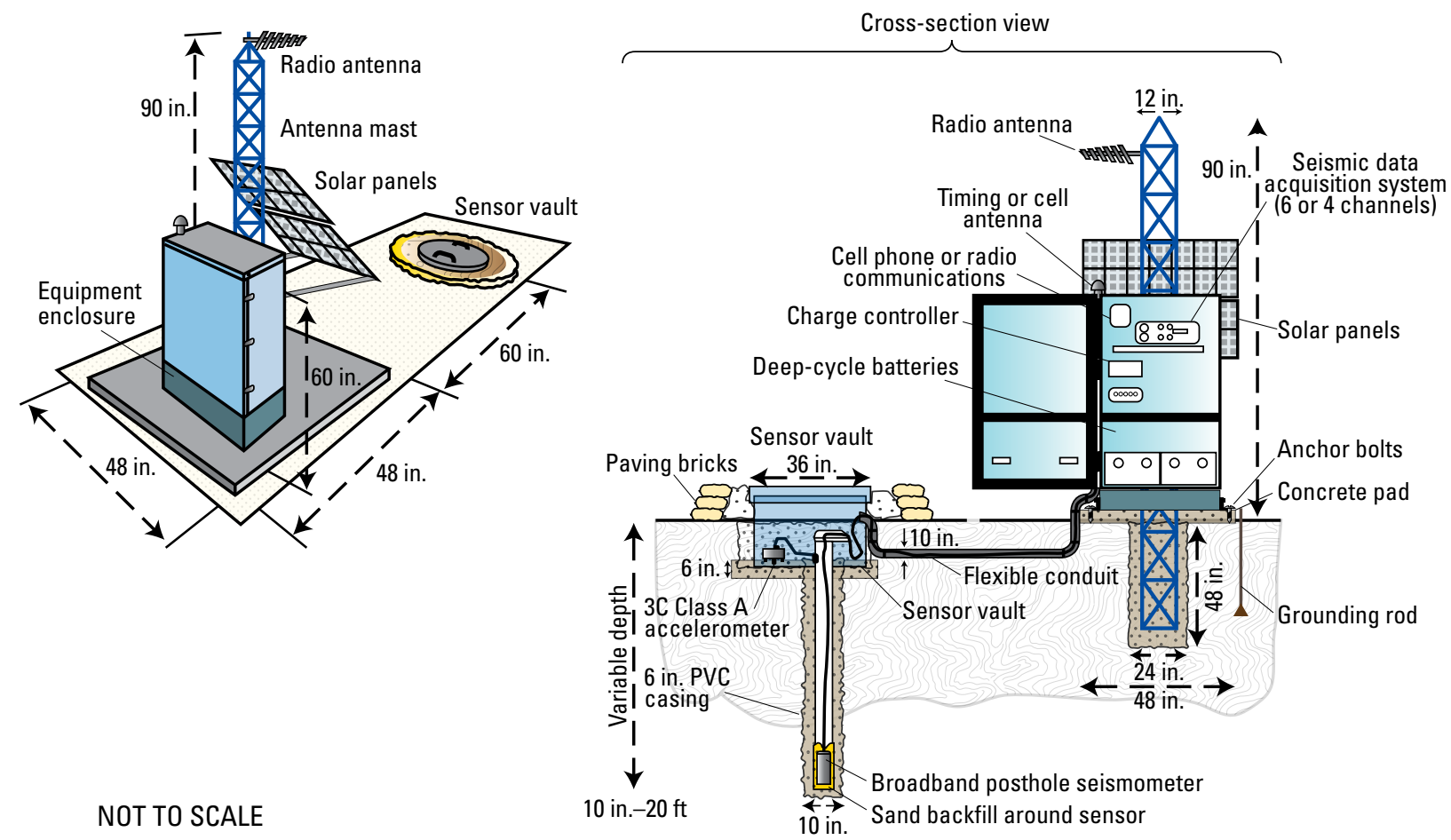

Figure 3. Schematic drawing of a typical seismic station used by the ShakeAlert system. Solar panels are on the enclosure that houses electrical and communications components. Seismic sensors are deployed in a shallow borehole. In some cases, a Global Navigation Satellite System (GNSS) receiver may be colocated at the site (not shown). All distances given are in inches (in.) or feet (ft).

Preservation Act (NHPA), which make obtaining permits to upgrade or install hundreds of permanent stations costly and time consuming. Even on private lands, NEPA, ESA, and NHPA requirements apply if Federal funds are used for the work. Similar State laws exacerbate the problem. The USGS is working with other Federal agencies to streamline the review and permitting process and obtain blanket permits or waivers wherever possible.

At the beginning of the project, many West Coast stations were antiquated and not suitable for EEW. Many had old sensors that went off scale for moderate events, did not cover the frequency range needed for EEW, or sent data too slowly or not at all. Many stations have been upgraded or added with new ShakeAlert funding, but the buildout is not complete (see table 1). Priority has been given to upgrading or adding stations in densely populated urban areas, and along the fault systems threatening those urban areas.

In mid-2018, about 865 of the 1,675 stations needed were contributing to the ShakeAlert system. Of these, 615 are in the CISN and 250 in the PNSN. A small fraction of these are owned and operated by contributing networks run by other organizations. In 2017, the State of California funded the upgrade or installation of 183 additional CISN stations over two years. Also in 2017, the USGS funded 34 new stations in the CISN and 33 in the PNSN to be completed in two years. When all funded stations are completed, the CISN will have 832 contributing stations and the PNSN will have 283 for a West Coast total of 1,115, which is 67 percent of the total planned stations. As shown in table 1, completing the seismic networks for ShakeAlert will require 560 additional stations: 283 in California and 277 in Oregon and Washington.
Table 1. Status of ShakeAlert seismic stations as of April 2018.

[Stations funded by California Governor's Office of Emergency Services (Cal OES) and the U.S. Geological Survey (USGS) in fiscal year 2017 (FY17) are still being installed and are not counted as contributing. CISN, California Integrated Seismic Network; PNSN, Pacific Northwest Seismic Network]

\begin{tabular}{lrrc}
\hline \multicolumn{1}{c}{ Seismic station status } & CISN & PNSN & $\begin{array}{c}\text { Total West } \\
\text { Coast stations }\end{array}$ \\
\hline $\begin{array}{l}\text { Number of contributing stations } \\
\begin{array}{l}\text { Number of Cal OES-funded } \\
\quad \text { stations (FY17) }\end{array}\end{array}$ & 1815 & 250 & 865 \\
$\begin{array}{l}\text { Number of USGS-funded } \\
\quad \text { stations (FY17) }\end{array}$ & 34 & 33 & 183 \\
\hline Subtotal & 832 & 283 & 67 \\
Number of unfunded stations & 283 & 277 & 560 \\
\hline Total & $\mathbf{1 , 1 1 5}$ & $\mathbf{5 6 0}$ & $\mathbf{1 , 6 7 5}$ \\
Target number & $\mathbf{1 , 1 1 5}$ & $\mathbf{5 6 0}$ & $\mathbf{1 , 6 7 5}$ \\
\hline
\end{tabular}

\section{Global Navigation Satellite System Stations}

Real-time, high-precision, high-rate GNSS stations can faithfully record the large, permanent ground displacements that accompany very large earthquakes ( $>M 7.0$ ), allowing better determination of the magnitude and fault rupture extent. These GNSS stations are particularly important to properly characterize large earthquakes on the San Andreas Fault Zone and megathrust (plate-boundary interface) events on the Cascadia Subduction Zone off the northwestern coast from northern California to Canada (Ruhl and others, 2017). 


\section{Required Station Distribution}

The geodetic algorithms being considered for use in the ShakeAlert system use several approaches to characterizing the earthquake source, from which shaking intensity can be predicted. Application of scaling relationships relating magnitude to observed peak ground displacement, implemented in the G-FAST code (Crowell and others, 2018), will be more robust with GNSS data from stations at a range of hypocentral distances, including near-source data and good azimuthal coverage where possible. Finite-fault algorithms, which are part of all geodetic methods currently being examined, require data within a couple of locking depths (that is, the depth at the base of the seismogenic zone), which is about $30 \mathrm{~km}$ from the fault for crustal events. The peak slip for subduction zone megathrust earthquakes is offshore; therefore, it is critical to have near-coast GNSS data with good coverage along the entire length of the subduction zone for geodetic algorithms to operate effectively.
A strength of geodetic data is its ability to record permanent ground displacements that result as fault slip occurs. These static offsets will be largest near the earthquake's slip centroid (where fault displacements are greatest), rather than the epicenter. As magnitude increases, so does the source-tostation distance for which displacements can be resolved, and networks with larger station spacing can still provide adequate observations for large earthquakes. In the Pacific Northwest, real-time GNSS data could contribute to EEW for earthquakes on crustal faults underlying metropolitan areas like Seattle; however, the most important application of real-time geodesy in the Cascadia region is for large megathrust events on the subduction zone interface. Accordingly, in planning GNSS network upgrades, we concentrate on the geographic region bracketing the San Andreas Fault Zone in California (fig. 4) and from the coast to the eastern edge of the Cascade Range in the Pacific Northwest (fig. 5) as the geographic region of interest for real-time geodetic data.

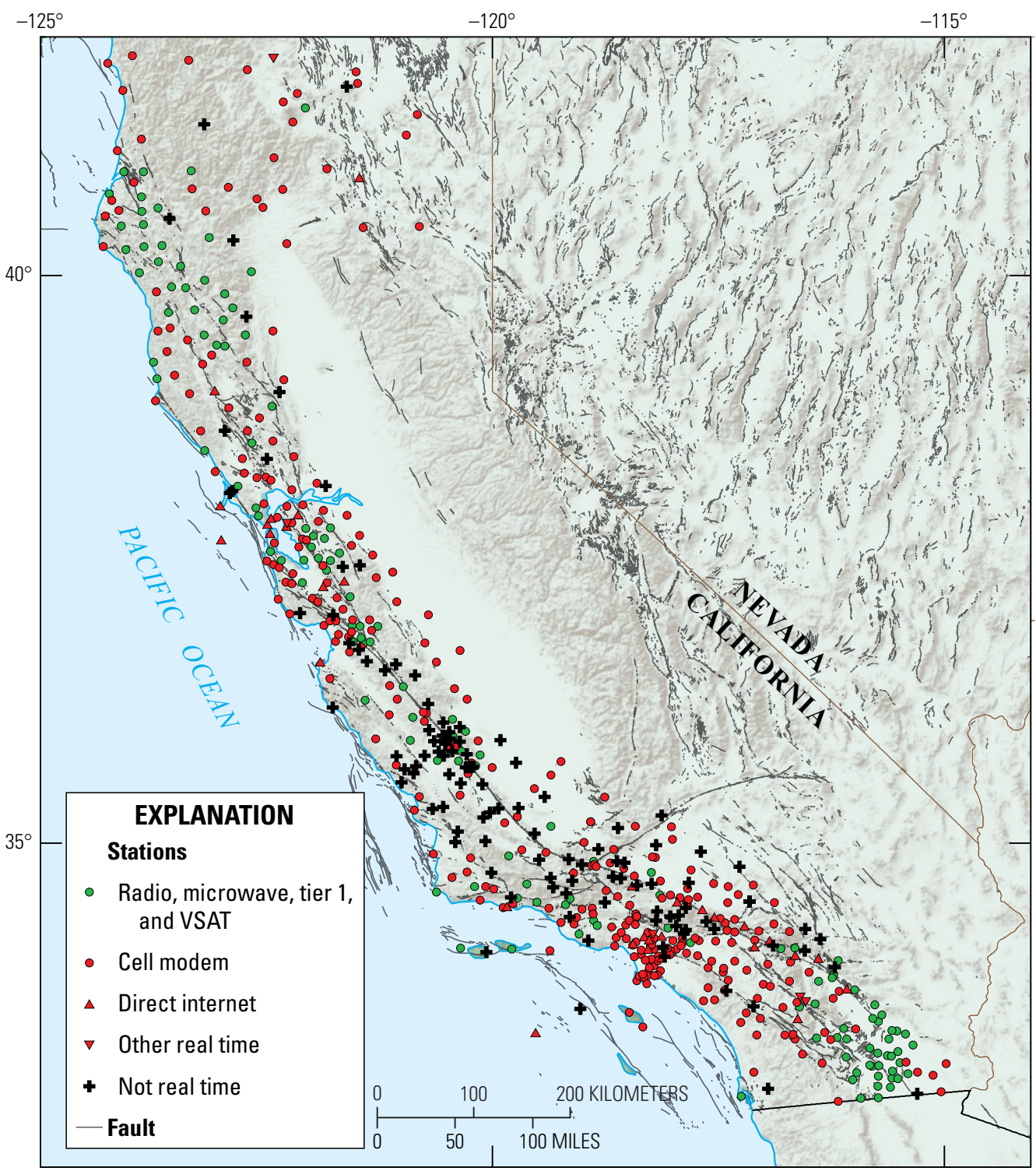

Base from Esri (C) 2018 and its licensors
Figure 4. Map of existing Global Navigation Satellite System (GNSS) stations in the geographic region of interest in California, categorized by type of data communications used. Stations are concentrated near the San Andreas Fault Zone and southern Cascade Range. Faults shown are from the Quaternary Fault and Fold Database of the United States, accessed on September 20, 2018, at https:// earthquake.usgs.gov/hazards/ qfaults/. VSAT, very small aperture terminal satellite. 


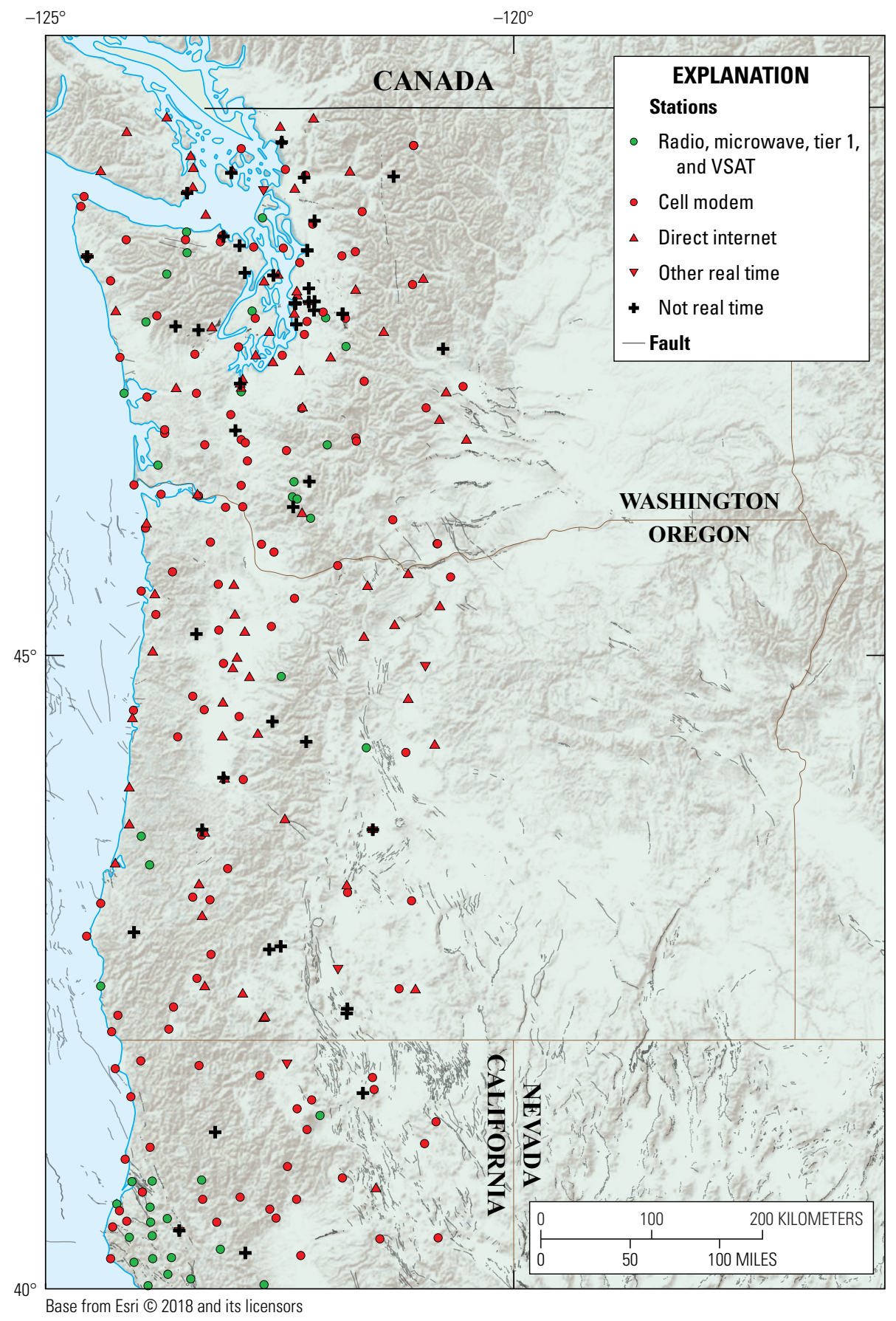

Figure 5. Map of existing Global Navigation Satellite System (GNSS) stations in the geographic region of interest in Washington and Oregon, categorized by type of data communications used. Stations are concentrated in the Cascade Range. Faults shown are from the Quaternary Fault and Fold Database of the United States, accessed on September 20, 2018, at https://earthquake.usgs.gov/hazards/qfaults/. VSAT, very small aperture terminal satellite. 
The optimal GNSS station spacing has only been evaluated for a few specific scenarios using a subset of the geodetic EEW methods (for example, Ruhl and others, 2017). This analysis suggests that if all existing permanent GNSS stations contributed data to ShakeAlert, adequate coverage would be achieved in most parts of the geographic region of interest, even though station coverage is less dense in Oregon and Washington than in California. However, not all existing stations currently operate in real time, and of those that do, only a subset is likely to provide data reliably and in a timely manner. Furthermore, we must consider future geodetic EEW methods, conceptualized but not yet implemented in algorithms, that may have different requirements; this includes algorithms that predict shaking intensity directly from displacement measurements through empirical earthquake magnitude scaling or other relationships.

\section{Contributing GNSS Networks}

Within the region of geodetic interest, there are 813 permanent geodetic stations: 580 in California and 233 in Oregon and Washington. These stations are operated by several organizations. The majority of permanent geodetic stations on the West Coast are part of the Plate Boundary Observatory (PBO), which is a National Science Foundation-supported facility operated by UNAVCO. Recently, UNAVCO has received USGS support to begin to improve parts of PBO for ShakeAlert. In California, the USGS Pasadena office operates about 140 stations along the southern San Andreas Fault and in the Los Angeles metropolitan area, and the USGS Menlo Park office operates 8 stations in the San Francisco Bay area. UC Berkeley's Bay Area Regional Deformation (BARD) network operates 32 stations with support from the USGS. The USGS does not operate permanent geodetic stations in Oregon or Washington. In addition to UNAVCO, GNSS stations in these States are operated by Central Washington University's Pacific Northwest Geodetic Array (PANGA) network, which receives partial funding from the USGS. Because the USGS operates fewer than 20 percent of the geodetic stations that could be used by ShakeAlert, and given that these stations are not distributed evenly over the ShakeAlert region, the geodetic component of ShakeAlert will leverage existing Federally supported partner networks.

Each of the collaborating GNSS data providers processes raw data in geodetic formats and makes real-time position streams available in the GeoJSON format using the RabbitMQ message protocol. ShakeAlert centers will connect to these streams and convert the data to Earthworm format for use by geodetic algorithms. Within this framework, a ShakeAlert working group is establishing operational real-time delivery of GNSS position streams to ShakeAlert centers using common data formats and transport protocols. Work required to complete development and testing of real-time GNSS data systems for ShakeAlert is described in the Continuing Research and Development section of this report.

\section{Goals for GNSS Network Upgrades}

In most parts of California, the existing station distribution is adequate to contribute to ShakeAlert for $>M 7$ earthquakes on the San Andreas Fault system. For that reason, this plan does not call for installing new permanent GNSS sites in California. Coverage is also good in most parts of Oregon and Washington, although sparse station spacing within $100 \mathrm{~km}$ of the central Oregon coast may negatively impact alerting capability. Accordingly, the vast majority of GNSS upgrades focus on improving the robustness and efficiency of network operations and data acquisition to ensure data flow from as many real-time GNSS stations as possible in the event of an earthquake. Specifically, these upgrades focus on two aspects: hardening telemetry and replacement of obsolete Global Positioning System (GPS) receivers with modern GNSS instrumentation, which are described in the following paragraphs. We also plan for installation of 10 new real-time GNSS sites in the Pacific Northwest, with an emphasis on the central Oregon coast.

The existing permanent GNSS networks utilize various communications systems to transmit data, and many sites use a combination of multiple communications systems. These include radio, direct internet, microwave, VSAT (very small aperture terminal) satellite, and cell modems, to name a few. Cell modems are the most widely used, but are vulnerable to failure owing to overloading in the event of an earthquake and aftershock sequence. Likewise, direct internet connections may not be resilient during an earthquake. Other systems, such as VSAT or radios, are often more robust, but may have higher data-transmission latency. The spatial distribution of GNSS telemetry methods is not uniform across the geographic region of interest (figs. 4, 5). Telemetry upgrades are intended to address vulnerabilities of specific methods as well as achieve a greater diversity of communications methods throughout the region.

Many of the receivers currently deployed at permanent GPS stations are reaching end-of-life and do not support more recently implemented technology that allows for efficient back-filling of data gaps without disrupting real-time data flow on shared seismic-geodetic telemetry systems. These older receivers also do not allow leveraging of other GNSS systems, such as the Russian Global Orbiting Navigation Satellite System (GLONASS), which, used in conjunction with GPS, provide improved position accuracy. Some modern receiver models also support onboard absolute positioning, in which raw data are processed on the receiver rather than being transmitted to a central processing center. This capability would shorten current data transmission paths and eliminate potential points of failure in going from raw observables recorded onsite to position streams needed by EEW algorithms. Given the advantages of onboard positioning, we see this capability as the new standard for real-time GNSS networks. In addition to having the appropriate receiver hardware, onboard positioning requires purchasing a subscription to real-time clock corrections for each station. The upgrades included in our budget cover conversion to onboard positioning of only a fraction of GNSS stations in the region of interest, and as such represent an initial step toward this longer term goal. 
As part of ongoing GNSS network upgrades, seismic and GNSS sensors are being colocated when possible to allow application of seismo-geodetic techniques, and to economize site permitting, construction, and maintenance costs. A VSAT telemetry system is being implemented to provide robust data acquisition from about 10 key Cascadia Subduction Zone GNSS sites.

\section{GNSS Network Upgrades in California}

Of the 580 GNSS stations in California, 264 were identified as candidates for some type of upgrade:

- Upgrade 65 of the 113 non-real time stations to real time, with 90 percent of these upgraded to provide onboard positions. These upgrades will target stations that are not within $10 \mathrm{~km}$ of an existing real-time station.

- Upgrade telemetry at 40 stations in the Cape Mendocino area to address high data latency at sites in this region; 90 percent of these would include upgrading the receiver to onboard positioning.

- Upgrade telemetry at 16 stations along the San Andreas and Rodgers Creek Faults north of the San Francisco Bay area to reduce reliance on cellular communications infrastructure; 50 percent of these would include upgrading the receiver to onboard positioning.

- Upgrade 43 obsolete receivers in northern California to modern GNSS receivers with onboard positioning (without telemetry upgrade).

- Upgrade 100 obsolete receivers in southern California with modern GNSS receivers with onboard positioning (without telemetry upgrade).

We also include purchase of the clock-correction subscriptions needed for onboard positioning for 130 stations that have the required hardware but no subscription. Selection of these stations will prioritize those near the southern San Andreas Fault and those with robust telemetry.

By upgrading stations to more robust and lower latency communication systems, we anticipate that at least 275 of the 580 stations in California, or nearly 50 percent, will be able to provide timely GNSS data for ShakeAlert. Another 150 stations that will not be upgraded could still contribute to ShakeAlert but their telemetry paths are more prone to damage by a major earthquake. The number of GNSS stations actually reporting resolvable displacements for any particular earthquake will depend on the source-to-station distance.

\section{GNSS Network Upgrades in Oregon and Washington}

There are 233 GNSS stations in the region of interest in Oregon and Washington; 190 of these operate in real time. Within this region, 79 stations have receivers capable of onboard positioning but they lack a subscription for the required clock corrections needed to calculate them.
A total of 232 GNSS stations were identified as candidates for some type of upgrade in Oregon and Washington:

- Upgrade 20 non-real-time sites to real-time operations.

- Upgrade real-time telemetry at 80 sites.

- Upgrade obsolete receivers at 122 stations (in some cases these coincide with telemetry upgrades).

- Install 10 new real-time GNSS sites on the Pacific Northwest coast.

The receiver upgrades will bring the number of stations capable of onboard positioning to 211. We also budget for purchasing clock-correction subscriptions for half of these stations, prioritizing sites near the coast. Following these upgrades, at least 140 stations (about 58 percent) regionwide will be able to provide robust, timely GNSS data for ShakeAlert. Approximately 105 of these stations will produce onboard position streams.

\section{Field Telemetry}

ShakeAlert's public safety mission requires that sensor data be delivered with lower latency and higher per-station reliability than has been necessary for other ANSS seismic network tasks; therefore, the telemetry system design must extend and harden the current network telemetry infrastructure. It must be reliable, robust, and sustainable, particularly during strong ground shaking and the heavy telecommunications congestion that will come after a large earthquake. The ANSS networks will use existing telecommunication resources when practical and, as they have done in the past, will seek collaborations that can build capacity and reduce costs.

The ShakeAlert project evaluated available and emerging telecommunications technologies and developed a plan for robust data return (see the telemetry improvement plan described in appendix 5). The final mix and distribution of telemetry technologies will be determined by funding as well as the cost, capability, and geographical availability of the various telemetry options. There will also be regional adaptations owing to differences in topography, vegetation, population, and available infrastructure.

\section{Processing and Alert Centers}

The ShakeAlert data processing infrastructure consists of redundant servers that are geographically distributed in Seattle, Menlo Park, Berkeley, and Pasadena (fig. 6). The processing architecture has three processing layers. The data layer imports and handles raw ground-motion data from the field stations. This is part of routine regional seismic monitoring function and is done within the ANSS Quake Management System (AQMS) framework. Next, live data streams are forked from AQMS to ShakeAlert's production layer as Earthworm TraceBuf messages, where they are analyzed, seismic signals are detected, and EEW-specific parameters are calculated. These parameters are 
passed to scientific algorithms that detect earthquakes, calculate their location and magnitude, and estimate the area and intensity of the resulting shaking. Finally, the alert layer examines these geophysical solutions, decides if an alert should be issued, and creates alert products. All interprocess communication is done using ActiveMQ, an open-source, enterprise-level messaging middleware that has wide support in the information technology (IT) community.

All production and alert infrastructure, computers, and networking have been engineered to the greatest extent possible to fulfill their alerting functions during and after disasters, including strong shaking (as much as 2.0 times gravitational acceleration $[g])$, loss of commercial electrical power for as long as one week, and collapse of commercial telecommunications systems.

The ShakeAlert system must comply with the Federal Government's cybersecurity assessment and accreditation process as required by the Federal Information Security Management Act of 2002. ShakeAlert completed this process and received a conditional authority-to-operate in March 2018. Exceptions identified in the assessment and accreditation process are noted in a plan of action and milestones and will be addressed as quickly as available resources will allow. We expect that ShakeAlert will operate with waivers under a conditional authority-to-operate for the foreseeable future, because full compliance, with no exceptions or waivers, would require operating within existing Government data centers. This would cause unacceptable delays for incoming data streams and outgoing alerts. User connections to the servers of the ShakeAlert alert layer require user authentication with credentials issued by the USGS. All interactions use secure sockets layer (SSL) certificates and data streams are encrypted.

\section{System Architecture and Scientific Algorithms}

The earlier ShakeAlert Production Prototype version 1.2 is described by Kohler and others (2018). That version of the system used two point-source algorithms, ElarmS and OnSite (a third algorithm, VirtualSeismologist was deprecated in 2016). An evaluation and streamlining process in 2017 resulted in a single unified point-source algorithm, EPIC, short for earthquake point-source integrated code, which is based primarily on ElarmS (Kuyuk and Allen, 2014). This was done for several reasons. First, having multiple detection algorithms with different strengths and weaknesses was originally thought to improve the robustness of the system, but actually degraded the total system performance by creating more false alerts. Second, the research prototype code and documentation needed to evolve to reliable, tested production quality. Third, removing very similar algorithms simplifies the overall system and focuses our limited programming staff on fewer core modules. Other improvements were also added, most notably techniques that significantly reduce false alerts owing to remote earthquakes (or teleseisms).

As part of ShakeAlert Production Prototype version 2.0, the server architecture was rearranged to create two independent layers, the production layer for earthquake processing and the alert layer to make alerting decisions and serve alerts to users. The production layer analyzes sensor data, characterizes earthquake sources, and predicts the resulting ground motions, while the alert layer makes the decision to issue alert products. This new alert layer is subject to rigorous cyber security controls, particularly because it is public facing.

ShakeAlerts are generated as the end product of a set of intercommunicating modules, each with a unique function (fig. 6). These modules are described here:
Earthquake solutions

A "point-source" solution describes an earthquake's location as a point in space with a latitude, longitude, and depth. A "finite-fault" solution describes the earthquake as slip on a length of fault, either as a line at the surface or a plane slicing through the Earth's crust. Finite-fault solutions are necessary to accurately predict the area and intensity of shaking for events greater than about $M 7.0$.

- Event source solution algorithms.- In 2018, two earthquake detection algorithms are in operation. The first is EPIC, which produces point-source solutions and associated event magnitudes. In EPIC, the first of two modules measures displacement, velocity, and acceleration, and EEW-specific parameters from the seismograms in small time windows. These measured parameters are passed to a second module that associates these parameters into events, locates the earthquake, and estimates its magnitude. EPIC employs checks to discriminate between random noise and earthquake shaking including a "filter bank" check to reject teleseisms. EPIC updates many times per second as more ground-motion data becomes available. The second earthquake detection algorithm is FinDer, short for finite-fault detector. The FinDer algorithm can produce either a point-source or line-source solution. It estimates the fault's centroid location, orientation, and length using a pattern search technique to fit ground-motion observations to pre-calculated fault templates using "matching by correlation" (Böse and others, 2012). It updates as the fault grows and more data become available.

- Solution aggregator.-This module reviews the results of the contributing event-source algorithms and aggregates them into a single unified solution. This becomes the basis of various alert and information products.

- Ground motion estimation.-The EQinfo2GM module uses source solutions and ground-motion prediction equations to estimate the distribution and intensity of shaking that the earthquake will cause. The estimates are represented in two forms: contour maps and grid maps. The contour maps contain polygons that define areas of Modified Mercalli Intensity (MMI; see pg. 21). The grid maps specify MMI, peak ground acceleration (PGA) and peak ground velocity (PGV) values at grid points with a spacing of 0.2 degrees $(22 \mathrm{~km})$. The grid size is scaled to the earthquake's magnitude to a maximum of 6,000 grid points. EQinfo2GM currently 


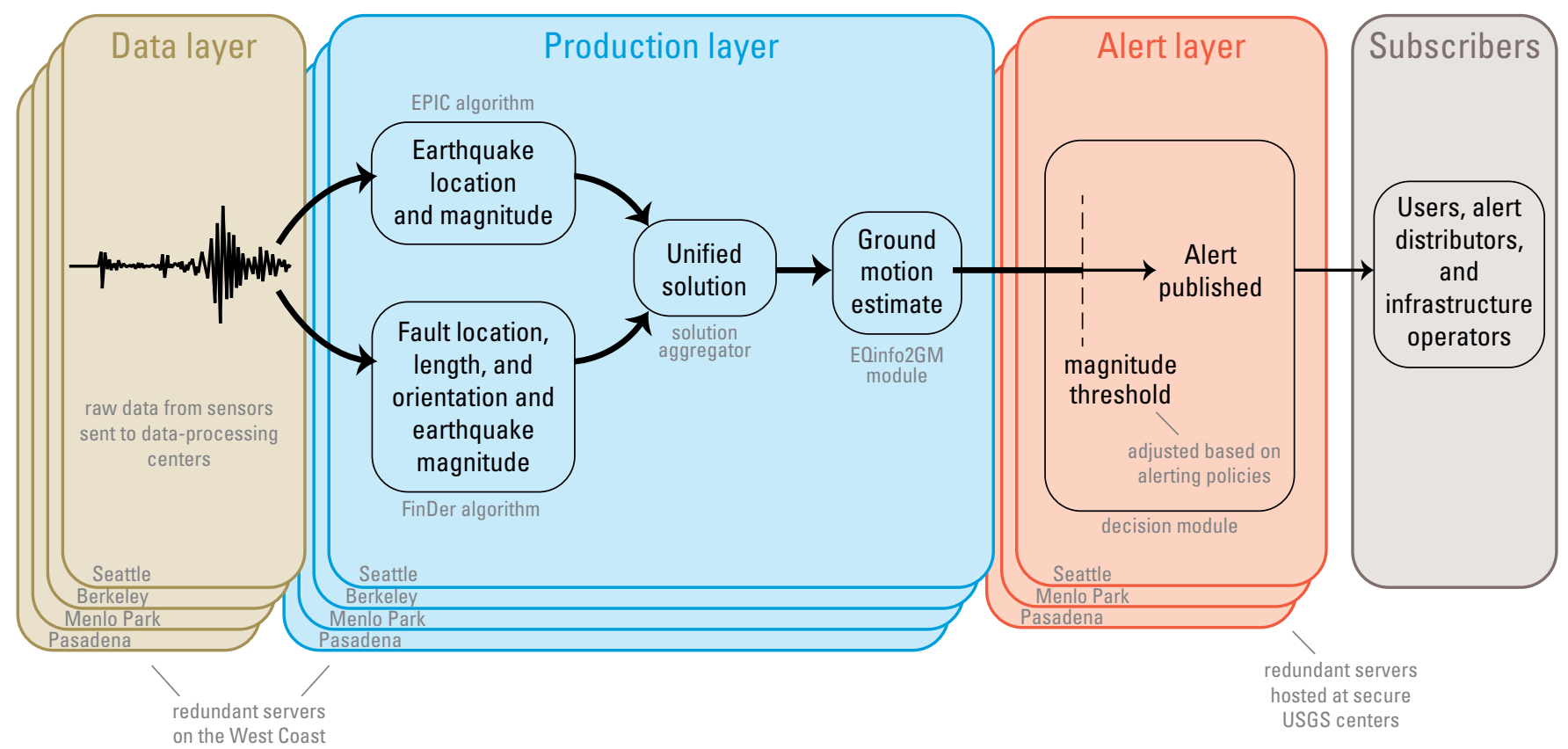

Figure 6. Schematic flowchart showing the architecture of the ShakeAlert system version 2.0. Data processing flows from the data layer, through the production layer to the alert layer, which publishes alerts for subscribers. Redundant data processing centers in Washington, northern California, and southern California protect the system against power losses, hardware failures, and loss of connectivity owing to earthquakes or other causes. The alert layer is subject to several security measures: it has achieved Federal cybersecurity assessment and accreditation under the Federal Information Security Management Act, has secure public-facing servers, requires user authentication, encrypts data streams, and is hosted exclusively on U.S. Geological Survey (USGS) servers. All communication between layers occurs through ActiveMQ messaging.

uses the same region-specific ground-motion prediction equations that are used by ShakeMap implementations in California, Oregon, and Washington.

- Decision module.-This module reviews the results of the solution aggregator and EQinfo2GM. If an event meets predefined alert thresholds it will publish the appropriate products as alert topics, making them available to users and alert distributors.

- Heartbeat aggregator.-This module collects system heartbeat and state-of-health messages and summarizes them into an overall system health message for other system components.

These algorithms are always being improved and new techniques are being explored as described below in the Continuing Research and Development section. These are developed both by the USGS and universities under USGSsupported cooperative agreements in a computer development environment that mimics the ShakeAlert production system. All code is managed and version controlled through a GitLab repository workflow. Once mature, an operation-ready code is run on integration servers at each alert center, which are identical to the real-time production systems. If they promise to improve the system in some way, codes are submitted as candidates for production to the testing and certification team.

\section{Geodetic Algorithms}

Three geodetic algorithms are currently under consideration for ShakeAlert: BEFORES (Minson and others, 2014), G-FAST (Crowell and others, 2018), and G-larmS (Grapenthin and others, 2014). These geodetic algorithms do not detect events, rather they are triggered by ShakeAlert event messages (which are generated by seismic algorithms) and use geodetic data, in some cases combined with strong ground-motion observations, to improve real-time finite source and magnitude estimates for large earthquakes. The evaluation and streamlining of these geodetic algorithms for use in ShakeAlert is described in the Continuing Research and Development section.

\section{Testing and Certification}

The ShakeAlert testing and certification platform provides quantitative assessment of algorithm and system performance and is a platform for testing modifications and improvements to the algorithms and their run-time configurations (Cochran and others, 2018b). The testing and certification platform has two main components: real-time testing and off-line testing. New or modified code modules or configuration changes are submitted as candidates for use in the production system. 
In the real-time test, candidates are run in an environment that is identical to the actual production environment. In the off-line test, a suite of about 120 historically recorded waveform sets are replayed in a realistic pseudo-production environment. The off-line test suite includes 47 historic local, regional, and teleseismic earthquakes, as well as anomalous and potentially problematic signals like station recentering and calibration events. Results are recorded and compared to the baseline performance of the current production system. If changes pass these tests and improve the system's performance then they are deployed to the production systems.

System results for point-source solutions, including magnitude, epicentral location, origin time, and time to first alert, are computed for each event and compared to the ANSS Comprehensive Earthquake Catalog (ComCat). These are then aggregated into cumulative measures of algorithm performance across the historic event test suite. Furthermore, ground-motion predictions are compared to predicted and historic ShakeMaps for a given event using a threshold-based approach that assesses how often end users would initiate the appropriate actions based on their ground-shaking thresholds. The testing and certification platform is a convenient, streamlined procedure for objectively testing algorithms and has been designed with flexibility to accommodate significant changes in how algorithms are being modified and developed.

The testing and certification methodology is imperfect because there are few historical large earthquakes that were recorded with the type and density of sensors available today. Techniques to produce synthetically generated seismograms that faithfully simulate P-waves from natural earthquakes are not mature and thus do not yet provide a realistic test of the system. Research is being done in this area, as well as on broadband synthetics that can also be useful for testing geodetic techniques. Recordings of large events from Japan, which has a dense seismic network, have been adapted for testing ShakeAlert; however, geologic conditions and sensor distributions are not identical to those on the West Coast of the United States.

\section{System Operation, Code Deployment, and Monitoring}

ShakeAlert computers are geographically distributed and each alert center is staffed by USGS and university personnel. As funds become available, additional staff will be added to make operations more robust. Staff employ IT industry best practices. For example, all system operations, code and configuration changes, and monitoring are done using documented standard operating procedures and enterprise-level tools. All critical servers are clones of one another, having consistent hardware, Linux operating system configurations, and support libraries. Servers are virtualized when appropriate. The ShakeAlert system is operated and monitored in the context of the regional ANSS West Coast seismic networks, which supply the ground-motion data. The stateof-health of stations and field telemetry systems, the timeliness of data delivery, and the quality of the data returned are monitored by the ANSS regional seismic networks; however, new monitoring tools are being added and all network monitoring capabilities will benefit because of the more demanding operational requirements of ShakeAlert. For example, station data quality is monitored and chronically problematic stations are not used by ShakeAlert algorithms until they are repaired.

All ShakeAlert servers are operated with identical operating system environments and revision levels (currently RedHat Linux 7) and are patched regularly. Compliance is maintained using the Puppet configuration management tool, which runs every 5 minutes to verify compliance of operating system components, application code, and configuration files. All system changes are tested before they are deployed using Puppet. All production servers are constantly monitored using industry best practices and standard tools to detect system faults, failures, resource usage, and security issues. System and application logs are archived. Port scans are performed monthly by the USGS Office of the Chief Information Officer using Nessus. The alert layer servers are administered exclusively by USGS personnel both to satisfy Federal Information Security Management Act controls and to insulate partner organizations from liability. Production layer servers are operated jointly by the USGS and university cooperators.

Likewise, all application-level code, including data processing algorithms and alerting modules are monitored with Puppet, which would detect and report any changes to the modules or their configuration files. When changes to code or configurations have passed the testing and certification process and are approved for production, then they are deployed to production servers using Puppet.

All critical systems are continuously monitored using a variety of tools. Nagios is used to monitor system resources and Puppet is used to define and enforce the state of the operating system and all installed software. The graphical DMreview tool allows operators to monitor and review system results for earthquakes and alerts (fig. 7).

A description of where each station is located and how it detects and reports ground motions is called "station metadata". Accurate station metadata is critical to reducing errors in the system. All system modules use the same station metadata description files to ensure consistent behavior across systems. ANSS network operators and other data contributors are responsible for maintaining up-to-date metadata, which can change owing to station repairs, upgrades, or failures, and are expected to provide updates within 24 hours of change. When new stations are added, a station acceptance procedure ensures that new stations produce good quality data and that station metadata is correct.

\section{ShakeAlert Products}

ShakeAlert produces real-time information about an earthquake's source and the ground shaking that may result. This information is served as several data and alert products to meet the needs of a variety of users. Source solution and shaking estimates are revised in real time as the fault rupture evolves and as more ground-motion data become available from stations near the 


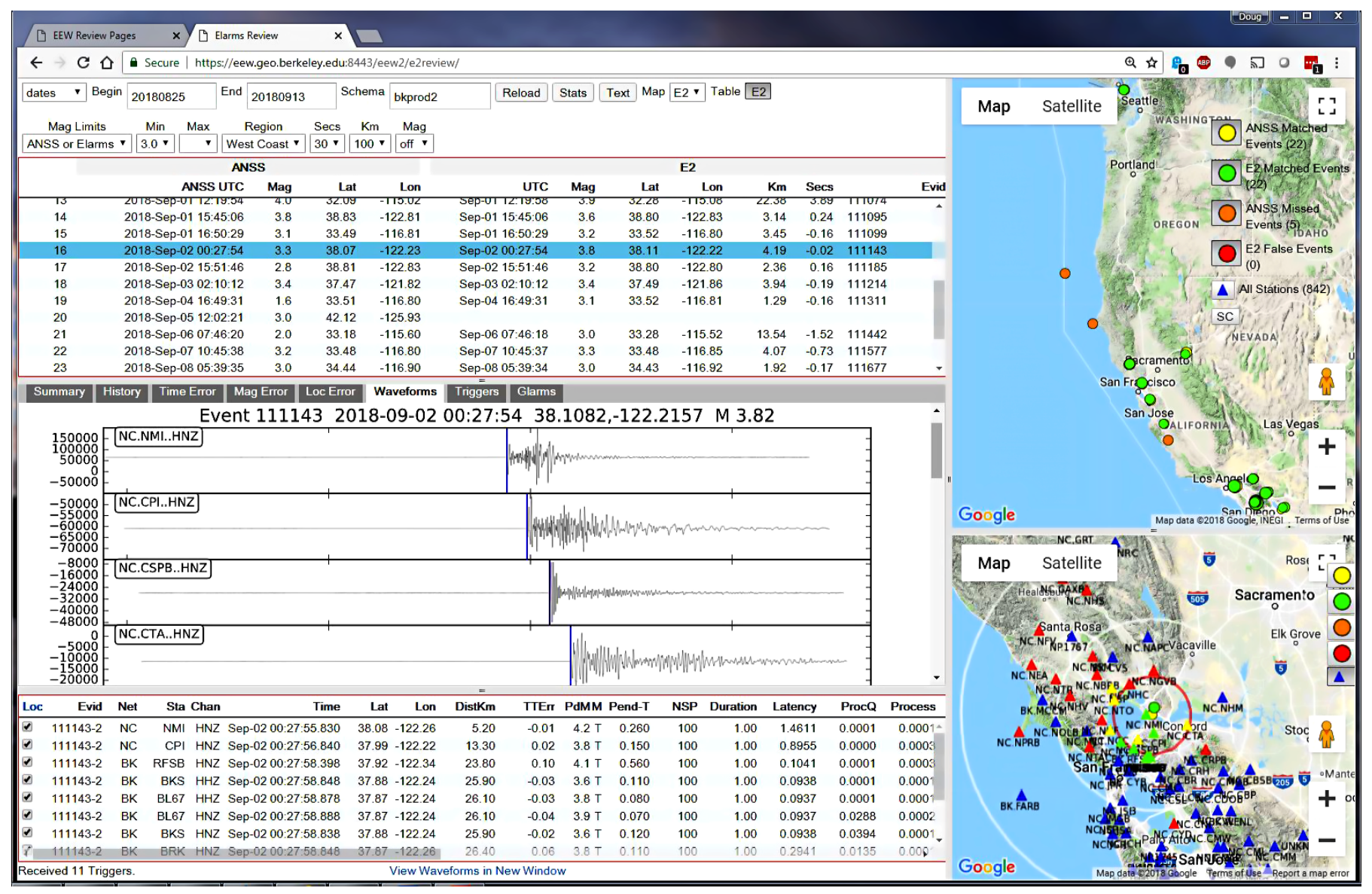

Figure 7. Screen shot image of the DMreview tool, a graphical interface used to review the performance of the ShakeAlert system.

rupture, and additional, more distant stations begin to report. For the largest events, this could continue for minutes.

The system's algorithms can produce two types of earthquake source solutions. The first is a point-source solution (EPIC) that describes the earthquake source as a hypocenter and a magnitude. The second is a line-source solution (FinDer) that portrays the evolving fault rupture as a line on the Earth's surface along with a magnitude. The source solutions are then used as input to a ground-motion prediction equation or ground motion to intensity conversion equation to estimate the ground shaking that will result from the event. The pointsource solution is adequate for estimating ground motions as large as approximately $M 6.5$. For larger events, the length and orientation of the fault rupture from the line-source solution is needed to accurately calculate the shaking area and intensity. The ground shaking estimate is presented in two formats:

(1) a contour message that contains polygons enclosing shaking levels and (2) a map message that contains a grid of shaking level values (fig. 8). These primary message types are the basis for various derived messages that have simplified, reformatted, or extended content customized for specific users.

As soon as possible after each true alert, ShakeAlert will automatically provide an easily understandable follow-up message containing a description of the earthquake that caused the alert. This will validate the alert and enhance people's situational awareness so they can plan their next actions. The period for which alerts are active is too brief for them to be cancelled by a human reviewer; however, if a human reviewer later determines the alert was false a follow-up message can be sent retracting the alert and briefly explaining the cause of the false alert. Social science research shows that the public is accepting of false alerts if they are explained and that false alerts can actually enhance the public's awareness and response to subsequent alerts (Mileti and Sorensen, 1990).

\section{Message Types}

All primary messages are in extensible markup language (XML) format and are published to ActiveMQ topics in the alert layer. Dozens of beta and pilot users make use of the event source product now. Users typically access ShakeAlert products by connecting to alert layer servers using ActiveMQ protocols and subscribing to topics of interest. However, specialized modules can support other messages or protocols for users with specific needs. For example, event results and follow-up products are sent to the USGS National Earthquake Information Center 


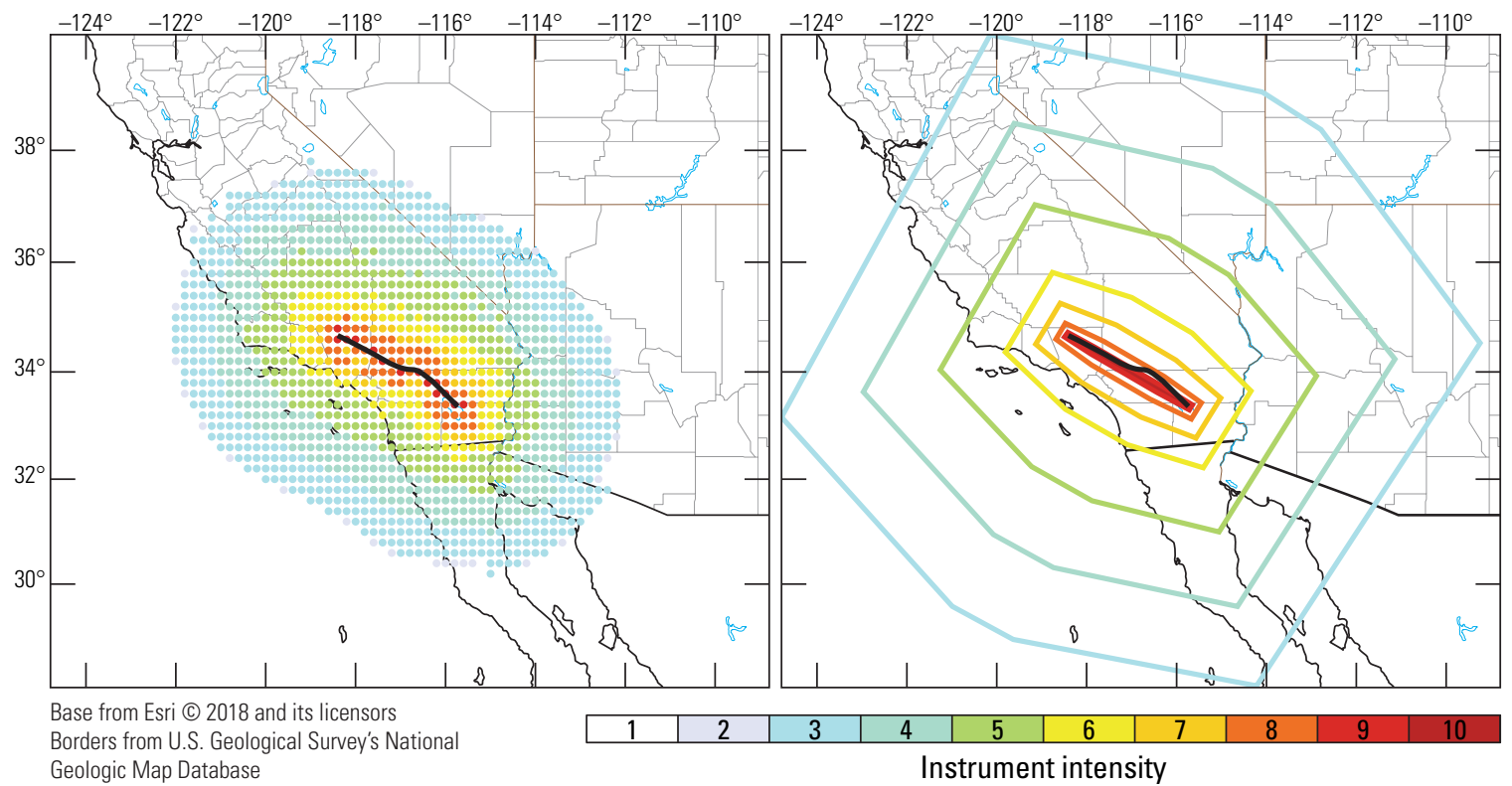

Figure 8. Two maps of the western United States showing examples of the shaking intensity contour (left) and grid map (right) ground-motion products distributed by ShakeAlert. These maps were produced in response to the hypothetical Shake0ut Scenario, which simulates a magnitude-7.8 earthquake event on the San Andreas Fault in southern California. Contour lines and grid map points are colored according to the estimated instrumental Modified Mercalli Intensity (MMI).

via the product distribution layer for inclusion in the USGS Earthquake Hazards Program (EHP) web pages and the ANSS Comprehensive Earthquake Catalog (ComCat). Also, common alert protocol messages are composed and will be sent to FEMA's Integrated Public Alert and Warning System Open Platform for Emergency Networks (IPAWS-OPEN) gateway when public alerting begins. Additional products, message types, formats, and delivery methods can be offered to meet specialized user needs.

After each alert, ShakeAlert will create a report for distribution through the initial alert-distribution pathway describing how the system performed compared to the earthquake solution from the authoritative regional network. In the case of a missed alert, ShakeAlert will manually create and post on USGS EHP web pages a follow-up product containing a general description of what may cause missed alerts and more specific information about the cause of the missed alert, if known.

Here we describe the nature, content, and distribution pathways for these various message types.

ShakeAlert will publish three kinds of primary messages (see appendix 1 for more detail):

- Event source message.-These messages contain the earthquake's hypocenter location, depth, and magnitude. If it is an extensive rupture ( $>M 6.5$ ), this message will also include the faulting extent as a set of line segments or rectangular segments. It also contains other quality metrics as well as the number of reporting stations and observed peak ground motions at triggered stations.
- Contour message.-These messages contain all the information in the event source message plus groundmotion estimates described as a set of nested contours (eight-sided polygons) enclosing areas that are predicted to experience peak ground shaking at each MMI level greater than 2 (fig. 8). MMI 1, denoting "not felt," is not included.

- Map message.-These messages contain all the information in the event source message plus groundmotion estimates described as a grid of points with expected MMI, PGA, and PGV values. Grid spacing is approximately $20 \mathrm{~km}$. Grid size depends on the earthquake's magnitude and the affected area. Users can interpolate between points if they need more precision at a particular location (fig. 8).

ShakeAlert will release two kinds of derived messages:

- Public alert message.-These are common alert protocol formatted messages that contain a single polygon describing the area within which the public should be alerted, out to a prescribed MMI threshold. This message will be sent to the OPEN-IPAWS gateway, which will pass them to cell carriers for broadcast to cell phone subscribers inside the alert area via the Wireless Emergency Alerts (WEA) system. The public alert message may also be used by other users including mass notification companies. 
- QuakeML message.-These messages include event pointsource and magnitude information in an international XML format (QuakeML). This format does not include ground-motion estimates.

Follow-up messages will also be released as needed. Note that these are informational and not alert messages.

- After a true alert.-Following a true alert, ShakeAlert will generate a follow-up message for the public that contains a description of the earthquake that caused the alert in language people can easily understand. This follow-up message will be distributed over the same channels as the original alert.

- After a false alert.-Following a false alert, a follow-up product distributed over the same channels as the original alert will acknowledge that the previous alert was false and will provide an easy-to-understand general explanation of why false alerts are sometimes issued. This message must be sent quickly and therefore cannot wait for a detailed analysis of the problem.

- After a missed alert.-Following a missed alert no public message will be broadcast over public alert channels, but it will be acknowledged on USGS EHP web pages along with an explanation of why the event was missed.

\section{Alert Release Thresholds}

The purpose of ShakeAlert is to issue alerts for potentially damaging earthquakes. Setting the thresholds at which alerts are released to users requires consideration of many variables, including the system's capabilities, earthquake physics, and psychology of end users. The system can detect events as small as M2.0 in areas with dense station coverage but false events are more likely at lower magnitudes. Also, more alerts would be sent at lower magnitude thresholds, because, according to the Gutenberg-Richter relation, there are approximately ten times more earthquakes for each unit you move down the magnitude scale. In most areas, damage is not likely unless an event is $M 5$ or greater and causes shaking of MMI 4 or 5 (see side bar). However, people feel shaking for events with smaller magnitudes and lower intensities. Recent research suggests that sending alerts for lower than "damaging" levels of ground motion can result in more accurate and timely alerts (Minson and others, 2018). To maximize warning time, technical users must act at a low threshold with the understanding that in most cases the earthquake will not grow to an intensity that will cause damage at their location. Waiting to see if the event will grow to a damaging level at a user's location will consume most of the warning time. Applications where the cost of acting is much lower than the cost of the potential damage will see the greatest benefits.
Generally, people expect to receive alerts for events they feel. To do this, the system would need to alert a polygon enclosing the area predicted to experience MMI 2 or greater. MMI 2 is the level at which some people feel shaking but many will not. Also, people are more tolerant of false alerts than missed alerts and many consider false alerts to be an opportunity to practice protective actions and raise awareness (Allen and others, 2017).

Another approach is to alert for MMI 4 or larger - the intensity at which a majority of people will feel ground motion and some damage may result. Although, waiting for the earthquake to grow to that intensity decreases both the warning time and the number of users who will be forewarned for potentially larger levels of shaking. On the other hand, too low a threshold may result in "alert fatigue," causing users to ignore alerts for less frequent damaging events (Kordek, 2013). Balancing these considerations is difficult and thresholds may be adjusted as the ShakeAlert system evolves based on user feedback and changes in the system's capabilities.

Setting thresholds for technical users is less complicated. Technical users are more aware of the applications and limitations of EEW and can set their own thresholds for action based on their particular application's tolerance for false alerts. Therefore, technical users are best served by a lower earthquake magnitude threshold, as long as they do not redistribute these alerts on to the general public, because this could result in an unacceptably high number of false alerts.

ShakeAlert will publish alerts at two different threshold levels. For technical users, alerts will be released for events of M3.5 or greater. These alerts will contain shaking estimates so the user can make their own decision about how to act. Initially, public alerts will be released for events of M5.0 and greater in the area predicted to experience MMI 4 or greater. These alert thresholds and the area to be alerted are being discussed and subject to change based on experience, and may be lowered as public confidence in ShakeAlert develops.

A two-tiered scheme was also adopted by the Japan Meteorological Agency. In Japan, public "forecasts" are sent to registered institutional users if the seismic intensity (SI) ${ }^{6}$ will reach or exceed 3 (about equal to MMI 4) or the event is M3.5 or greater. If the intensity of shaking is expected to reach or exceed SI 5L (about MMI 7) "alarms" are sent via television, radio, and cell broadcast, as well as other means, to any of 190 districts that will experience SI 4 (about MMI 6) or greater shaking. Additional districts can be warned if the earthquake grows in intensity.

${ }^{6}$ The Japan Meteorological Agency uses the shindo seismic intensity scale (SI) which has levels of shaking from 1 to 7 . Levels 5 and 6 were subdivided into lower (L) and upper (U) in 1995. 


\section{Modified Mercalli Intensity}

Table below shows the Modified Mercalli Intensity scale, which describes the intensity of earthquake shaking and the effects of that shaking at a given place.

Modified Mercalli Intensity (MMI) is based on human perception and traditionally designated by Roman numerals (for example, IV, V, and VI), however the ShakeAlert system uses instrumental measurements to estimate "instrumental intensity" and uses Arabic numbers (for example, 4, 5, and 6).

\begin{tabular}{|c|c|c|}
\hline Intensity & Shaking & Description \\
\hline I & Not felt & Not felt except by a very few under especially favorable conditions. \\
\hline II & Weak & Felt only by a few persons at rest, especially on upper floors of buildings. \\
\hline III & Weak & $\begin{array}{l}\text { Felt quite noticeably by persons indoors, especially on upper floors of buildings. } \\
\text { Many people do not recognize it as an earthquake. Standing motor cars may } \\
\text { rock slightly. Vibrations similar to the passing of a truck. Duration estimated. }\end{array}$ \\
\hline IV & Light & $\begin{array}{l}\text { Felt indoors by many, outdoors by few during the day. At night, some awakened. } \\
\text { Dishes, windows, doors disturbed; walls make cracking sound. Sensation like } \\
\text { heavy truck striking building. Standing motor cars rocked noticeably. }\end{array}$ \\
\hline V & Moderate & $\begin{array}{l}\text { Felt by nearly everyone; many awakened. Some dishes, windows broken. } \\
\text { Unstable objects overturned. Pendulum clocks may stop. }\end{array}$ \\
\hline VI & Strong & $\begin{array}{l}\text { Felt by all, many frightened. Some heavy furniture moved; a few instances of } \\
\text { fallen plaster. Damage slight. }\end{array}$ \\
\hline VII & Very strong & $\begin{array}{l}\text { Damage negligible in buildings of good design and construction; slight to } \\
\text { moderate in well-built ordinary structures; considerable damage in poorly built } \\
\text { or badly designed structures; some chimneys broken. }\end{array}$ \\
\hline VIII & Severe & $\begin{array}{l}\text { Damage slight in specially designed structures; considerable damage in } \\
\text { ordinary substantial buildings with partial collapse. Damage great in poorly built } \\
\text { structures. Fall of chimneys, factory stacks, columns, monuments, walls. Heavy } \\
\text { furniture overturned. }\end{array}$ \\
\hline IX & Violent & $\begin{array}{l}\text { Damage considerable in specially designed structures; well-designed frame } \\
\text { structures thrown out of plumb. Damage great in substantial buildings, with } \\
\text { partial collapse. Buildings shifted off foundations. }\end{array}$ \\
\hline$X_{+}$ & Extreme & $\begin{array}{l}\text { Some well-built wooden structures destroyed; most masonry and frame } \\
\text { structures destroyed with foundations. Rails bent. }\end{array}$ \\
\hline
\end{tabular}




\section{Performance Metrics and Standards}

No system is perfect and ShakeAlert will miss some events and produce some false alerts. To minimize such errors, the ShakeAlert system's performance is constantly assessed through the testing and certification process (see Testing and Certification section) to drive improvements, evaluate proposed changes to the system code and configuration, and describe the system's capabilities.

The system performance metrics used in testing and certification evaluations are of two types. The first is an eventassociation metric that compares ShakeAlert's earthquake source parameters (location, magnitude, and origin time) to results from the authoritative ANSS regional seismic networks that are reported to the ANSS Comprehensive Earthquake Catalog (ComCat). The second metric is a comparison of ShakeAlert's predicted ground motions with observed and modeled ground motions from ShakeMap. In the association metric, alerts are determined to be true (true positive), missed (false negative), or false (false positive) based on the following definitions and criteria.

\section{Alerts are true alerts if}

- A matching ComCat event of M3.5 or greater exists,

- The ShakeAlert epicentral location is within $100 \mathrm{~km}$ of the ComCat report, and

- The ShakeAlert origin time is within 15 seconds of the origin time reported to ComCat.

Alerts are determined to be missed alerts if

- A ComCat event meets the alert reporting criteria with no ShakeAlert sent.

Alerts are false alerts if

- A ShakeAlert event has no matching ComCat event.

The initial performance standards that are being applied to ShakeAlert include:

- No more than 1 out of 10 ComCat earthquakes above the target magnitude will be missed and

- No more than 1 out of 10 alerts will be false.

These performance standards are expected to become more stringent in the future.

ShakeAlert has detected hundreds of earthquakes since 2012, when it began operation as a prototype, including the March 29, 2014, M5.1 La Habra mainshock that was detected 4.2 seconds after origin time and the August 24, 2014, M6.0 South Napa earthquake that provided 5-8 seconds of warning to beta users in the San Francisco Bay area. In areas with dense station coverage, the ShakeAlert's first alert is routinely available in less than 5 seconds after origin time.

\section{Alert Distribution and Use}

The role of the USGS is to generate and serve earthquake alerts and encourage their use. Because protecting lives and property from earthquakes is part of its mission, the USGS is committed to generating ShakeAlerts for the public free of charge and will not seek to recover any of the system's development or operational costs through access or license fees.

Alerts are ineffective unless they are communicated to people or used to trigger automatic protective actions. The USGS does not have the mission nor the infrastructure and expertise to deliver mass alerts directly to the public or provide sitespecific technology to take automatic actions. Our strategy for alert distribution and use is to enlist partners with the necessary mission, technical ability, and resources to deliver alerts and perform end-user implementations. For example, within the Federal Government, the FEMA Integrated Public Alert and Warning System (IPAWS) has the mission to provide integrated services and capabilities to Federal, State, territorial, tribal, and local authorities that enable them to alert and warn their respective communities via multiple communication methods.

To be most effective, ShakeAlert notifications must be distributed to thousands of institutional users and millions of individuals with minimum latency and maximum reliability. Technologies to do this are only now becoming available; there are public systems that have this mission and private mass notification companies that are in this business. Unfortunately, most of today's alerting systems were not designed with the low latency requirements of EEW in mind. However, many system operators are working to speed up their alert delivery systems and progress will accelerate as ShakeAlert moves from the prototype stage to routine operations.

\section{Alerts to Institutional Users-Pilot Projects}

The USGS is creating partnerships with end users and commercial "technology enablers" who are critical for the widespread implementation and use of ShakeAlerts. The USGS anticipates that as ShakeAlert becomes available and trusted, an EEW industry will grow to bridge the gap between the alerts generated by ShakeAlert and particular practical implementations customized for end users' needs.

ShakeAlert began soliciting pilot users in April 2017 and many of these users will be capable of practical demonstration in 2018 (see appendix 3). Today there are hundreds of beta and pilot users connected to ShakeAlert servers and sufficient capacity is provisioned to support thousands of continuous, concurrent connections. This is enough to support high-impact technical users and major public alert redistributors but is not intended to support direct connections by individual members of the public. These direct internet connections have very low alert delivery latencies, measured in tens of milliseconds. 


\section{Alerts to the Public}

ShakeAlert is the first public alerting system in the United States to require rapid mass notification within seconds. Here we discuss the challenges that such rapid delivery presents to currently available mass notification technologies.

The USGS plans for ShakeAlerts to be delivered by every practical means. Such multimodal alerting will reach more people and systems more reliably than using any single method. If people receive duplicate alerts by different methods, then the alert's effectiveness is increased because people typically seek confirmation of a hazard before acting.

Many common message delivery technologies are unlikely to ever have the scale and speed needed to rapidly deliver ShakeAlerts to the general population. These include email, text messages (SMS), and reverse 911. Another problem is that current technologies are likely to become slower or fail completely after large earthquakes owing to infrastructure damage, loss of power, and post-earthquake spikes in demand. However, several existing and emerging technologies are candidates for delivering ShakeAlerts to the public.

\section{Mass Alerting via FEMA's Integrated Public Alert and Warning System and Cellular Networks}

Most people expect to receive earthquake alerts on their cell phones. The most effective public mass-alerting platform in the United States is FEMA's Integrated Public Alert and Warning System (IPAWS) (fig. 9). This is the modern internet-based extension of the Cold War-era Emergency Alert System (EAS), which requires broadcasters, cable systems, and satellite service providers to enable the President to address the American public during a national emergency. None of these EAS mechanisms are currently fast enough for effective EEW.

Since it began operation in 2012, more than 33,000 alert and warning messages, including weather warnings and America's Missing: Broadcast Emergency Response (AMBER) alerts, have been sent to the IPAWS gateway by hundreds of Federal, State, territorial, tribal, and local alert authorities for delivery to the public. Each message is authenticated and validated by the IPAWS Open Platform for Emergency Networks (IPAWS-OPEN) gateway and delivered to the public using several distribution methods. The USGS is an approved national alert authority within IPAWS and

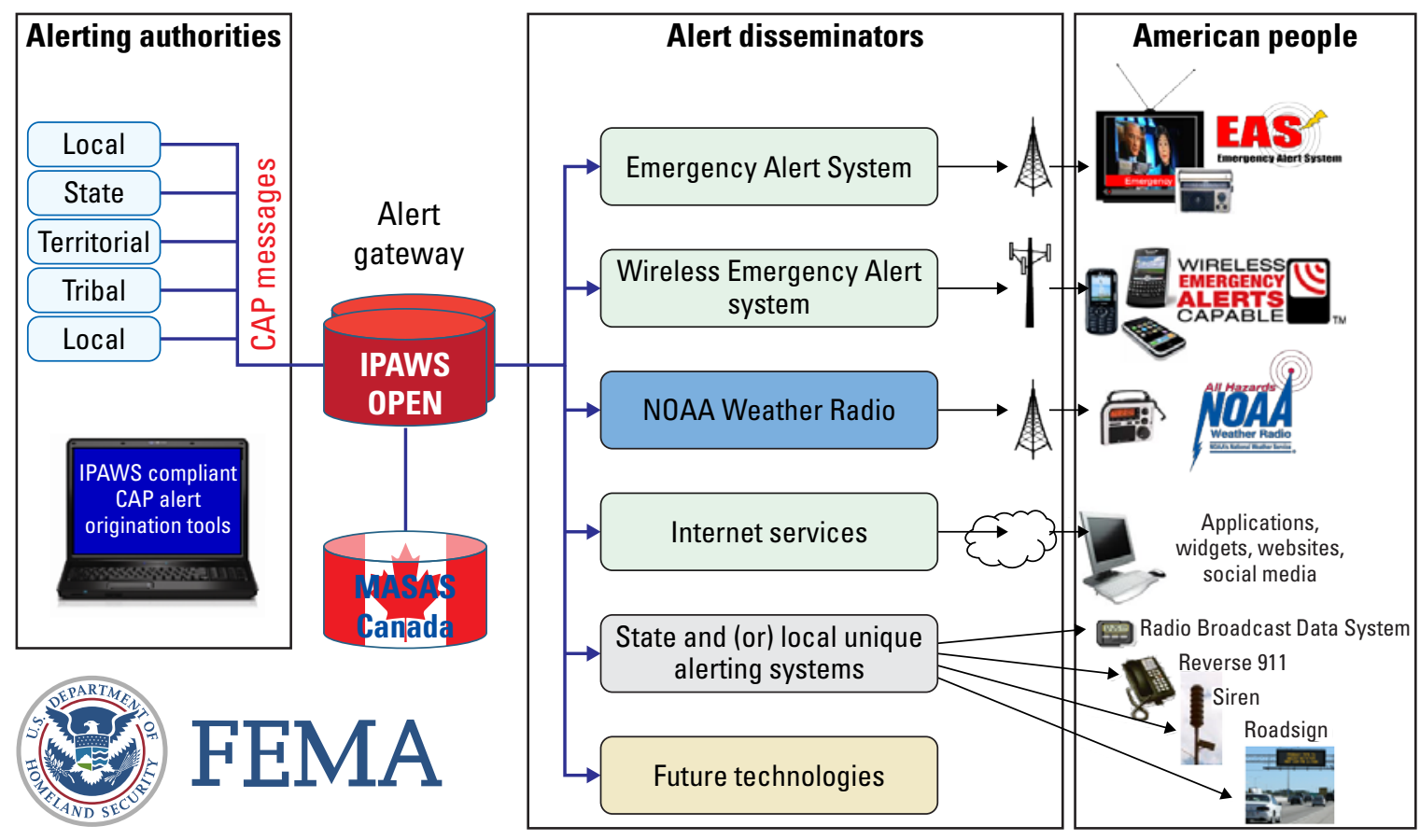

Figure 9. Schematic drawing showing the architecture of the Federal Emergency Management Agency's (FEMA) Integrated Public Alert and Warning System (IPAWS). 
USGS will begin serving alerts for IPAWS distribution as soon as that system is fast enough.

The most effective alert disseminator within IPAWS is the Wireless Emergency Alerts (WEA) system because it uses cellular broadcast technology that is not subject to network overload. WEA can send as many as 90 characters $^{7}$ of text to WEA-capable phones in a defined alert area. Alert authorities send alerts to FEMA's IPAWS gateway, which forwards them to the cellular service providers for delivery. WEA is not currently fast enough for effective EEW alerting, but the Federal Communications Commission (FCC), FEMA, and cellular carriers are working to improve the system for this purpose.

WEA became operational in April 2012. The four major national carriers, AT\&T, Verizon, Sprint, and T-Mobile, ${ }^{8}$ voluntarily participate in WEA. There is no regulatory requirement for how quickly alerts must be delivered and current WEA delivery times vary by carrier, region, and protocol. Carrier delivery times have not been reliably documented, but anecdotal evidence suggests delivery times are unpredictable and can range from tens of seconds to minutes. Current fourth generation long-term evolution (4G LTE) cell networks can deliver cell-broadcast WEA messages faster than the older $3 \mathrm{G}$ service, and next-generation $5 \mathrm{G}$ networks and phones should be even more capable, but are not yet widely available.

IPAWS and EAS are subject to FCC regulations. In 2016, the FCC produced a report for Congress on the feasibility of delivering earthquake alerts in three seconds (Federal Communications Commission, 2016). The FCC concluded that the IPAWS-OPEN gateway's time expenditure could be reduced to less than one second and that alert delivery within a total of three seconds was theoretically achievable using the WEA system if cell carriers made system modifications. It further concluded that rapid delivery over the older EAS system via television and radio is achievable, but only if the EAS system architecture is altered.

To speed up alerts, FEMA has offered to make changes to minimize delays in the IPAWS-OPEN gateway specifically for ShakeAlert. It also plans to measure end-to-end delivery times. The USGS, Cal OES, and university partners are working with the Alliance for Telecommunications Industry Solutions (ATIS), the cell industry's standards organization, to develop new standards to deliver ShakeAlerts quickly.

The cellular industry is currently working on Enhanced Wireless Emergency Alerts (eWEA) to improve WEA's capabilities in response to new FCC mandates and to leverage advances in technology. In 2016 and 2018, the FCC published new rules that, once implemented, will make ShakeAlert message delivery via WEA more practical. The new rules extended the message length from 90 to 360 characters, created a new public safety message type, removed the prohibition against uniform resource locators (URLs) in alert messages,

\footnotetext{
${ }^{7}$ A new Federal Communications Commission (FCC) report and order requires carriers to handle 360 characters in long-term evolution (LTE) networks by May 1, 2019, however, consumers must buy new cell phones with this capability.
}

${ }^{8}$ In April 2018, T-Mobile and Sprint announced their plans to merge. required Spanish

language messages, and

ordered carriers to make

geotargeting of alert areas

more precise. While the

FCC set a 2019 target

for these changes, the

carriers say they may

take years to implement.

The FCC and carriers

continue to study other

WEA issues related to

EEW, such as speed

of delivery and lack of

alert-specific attention

sounds. Also, WEA

behavior is embedded

into the phone's chip set

and is not accessible to

the application layer. If

WEA were implemented

as an application,

then changes could be

implemented without
Wireless Emergency Alerts

Wireless Emergency Alerts

(WEA) are text-like messages

broadcast to modern cell

phones, which are not

affected by network overload.

Authorities send alerts to

FEMA's IPAWS gateway, which

forwards them to cellular

service providers for delivery.

Since its inception in 2012, more

than 33,000 weather, AMBER,

and other alerts have been

delivered. Cell service providers

participate voluntarily and

there is no requirement about

message delivery speed. WEA

is not currently fast enough

for effective EEW, but the FCC,

FEMA, and cellular carriers are working to improve the system. requiring consumers to purchase new phones and alerts could be used by other applications to do things informed by the user's situation. For example, applications could give context-specific instructions to drivers, people in vulnerable structures, and crowded public venues.

ATIS is pursuing a two-phase approach to make WEA practical for ShakeAlerts. In phase one, WEA will be used as it is today, thus avoiding a 2-5 year development cycle. However, this interim step has significant drawbacks. The alert tone is the same for all alerts - weather warnings, AMBER alerts, and ShakeAlerts all sound the same and recipients must read the popup text to know how to respond, consuming precious time. (Some cell phones are capable of announcing the message using text-to-voice technology.) More importantly, because WEA was not originally designed for the speeds needed for EEW, alerts may arrive too late to be effective. Delivery delay times are not well documented. In phase two, a more comprehensive standard will be developed and implemented, which will involve changes to cell system delivery protocols and cell phone handsets with the goal of reducing ShakeAlert delivery times and enabling custom alerting behavior on user devices. This is expected to take several years.

\section{Push Notifications to Cell Phones}

Push notifications are another technology that is used routinely to deliver messages to cell phones. Unlike WEA broadcasts, push notifications are sent to individual phones where they must be received by an application (or "app"). A feasibility study by ATIS concluded that "over-the-top" applications using push notifications are not suitable for EEW (Alliance for Telecommunications Industry Solutions, 2015). 
They noted concerns about high volumes of messages slowing or crashing cell data systems. Other sources suggest that fast, high-volume push notifications are possible. In Japan, the commercial Yurikuru application, which delivers the Japan Meteorological Agency's earthquake forecasts, has more than 5 million downloads. It is supported by in-application advertising but timely delivery is only guaranteed to about 20,000 premium subscribers who pay a subscription fee. Cell phone applicationss can provide features like contextaware alerting or instructions that are not possible with WEA messages. Prototype cell phone applicationss have been written by Caltech, UC Berkeley (MyEEW), and Early Warning Labs (QuakeAlert), but have not been publicly released. Their ability to scale up to large numbers of users is untested; however, in a test of another application, UC Berkeley reported it could deliver messages to 10,000 users in less than one second.

In order to directly measure how push notifications perform as the number of users grows, the USGS has entered into a technology assistance agreement with the City of Los Angeles to support the development of a cell phone application and the underlying server software to drive it. The application will be developed and operated by AT\&T under a contract with the city. Once the application is developed, the capabilities of push notifications will be tested by incrementally adding as many as 50,000 city and county employees. If performance does not suffer, the system will be further tested by incrementally adding residents of the city, which has a population of 4 million.

The USGS's role is to serve alerts and it does not intend to develop or operate its own public cell phone application. Rather, once push notifications are demonstrated to be fast enough for effective EEW, ShakeAlert will depend on partners in the free market to create and support applications. Application developers could adopt various models, including providing them for free as a public service, by paid subscription, or monetized with embedded advertisements. In addition, various government and non-profit organizations may choose to create and support applications for their constituencies or integrate ShakeAlerts with existing applications.

\section{Social Media}

Sending earthquake alerts over current popular social media channels is problematic. Because they are push notifications, existing social media push-notification technologies were not designed with EEW in mind and may not be capable of delivering messages with the volume and speed needed for effective mass alerting. In some cases, users would only see an alert if they were actively using the application at the time of the alert or an incoming alert may be indistinguishable from other notifications. The most significant limitation of current social media platforms (for example, Twitter, Facebook, and Google Now) is that they do not support geotargeting and alerts could not be limited to the area affected by potentially damaging ground motions. Some of these limitations may be reduced or eliminated as technology evolves and EEW becomes more widely accepted.

\section{Mass Notification Companies}

Several companies provide commercial mass notification services to clients, such as State and local agencies, K-12 schools, universities, large companies, and military bases. Through pilot projects, mass notification companies like Everbridge and Regroup are investigating the integration of ShakeAlert with their product offerings. Most of their delivery "modalities," including email, text messaging, and reverse 911, are too slow for effective EEW alerts. However, they also use cell phone applications to deliver alerts to customers.

\section{Digital Radio Broadcasts}

Television and radio broadcast signals can be used to deliver digital information via the Radio Data System protocol. One common application is playlist information delivered to modern car radios.

Cal OES is developing "datacasting" to broadcast ShakeAlert digital messages over America's Public Television Stations (APTS). These encrypted messages are embedded in otherwise unused parts of the broadcast signal. They do not notify viewers by interrupting programming; rather, the messages must be received and decoded by special receivers that can display them, sound alarms, or take actions. In January 2017, Cal OES successfully demonstrated datacasting ShakeAlerts with KVIE in Sacramento, Calif. By connecting a number of voluntarily participating public television stations, this pilot project will be capable of providing high-speed alert delivery in the San Francisco Bay, Los Angeles, Fresno, San Diego and Sacramento areas. By adding additional stations, coverage can be expanded to other areas. Availability of these broadcasts should motivate a market for commercial receivers to notify people and take a wide variety of risk-reduction and hazard-mitigation actions.

The USGS has a cooperative research and development agreement with Global Security Systems, a commercial vendor of Radio Data System technology. In 2016, Global Security Systems demonstrated Radio Data System delivery of ShakeAlerts using their AlertFM product over the Univision station in southern California and public radio station KQED in northern California. Alert delivery took about 6 seconds. Global Security Systems markets receiver-decoder devices that can sound an alert and display a text message as well as close electrical relays to take external automated actions.

\section{Other Alert Delivery Technologies}

In Mexico City, the public receives EEW alerts as a characteristic alert sound and verbal message over a system of more than 12,000 public address speakers (not sirens) operated by the city government. This C5 system (Comando, Control, Cómputo, Comunicaciones y Contacto), which includes surveillance cameras and help buttons, was built to address other public safety concerns and would not have been built for EEW alone. San Francisco, Calif., and some coastal areas in 
the United States have siren or loudspeaker systems, but they are not fast enough for EEW. Furthermore, the generic wail produced by most siren systems cannot inform the public about the specific hazard expected, and complacency and alert fatigue further reduce their effectiveness (National Academies of Sciences, Engineering, and Medicine, 2018).

Communications technology is evolving rapidly. Pilot users are developing or exploring use of existing public announcement systems, Voice over Internet Protocol (VoIP) paging systems, and other alerting paths. The Internet of Things, the wide acceptance of home assistants including Google Home and Amazon Echo ("Alexa"), and devices like Nest and smart meters may ultimately be pathways to deliver EEW and other hazard alerts. The USGS will continue to monitor and encourage the use of new technologies to deliver ShakeAlerts through its pilot outreach efforts.

\section{Communications, Education, and Outreach}

ShakeAlert has organized a comprehensive communication, education, and outreach effort under the guidance of the Joint Committee for Communication, Education, and Outreach (JCCEO). The USGS has a ShakeAlert communication, education, and outreach coordinator on staff and, in 2016, formed the JCCEO to manage the planning and coordination of the communication, education, and outreach component of the ShakeAlert project nationally with broad stakeholder participation. The national umbrella provided by the JCCEO encourages consistent messaging and a uniform human alert interface across regions and technologies. The JCCEO also seeks to integrate ShakeAlert communication, education, and outreach messages with existing general earthquake risk programs and promotes both public and institutional acceptance and implementation of ShakeAlert. ShakeAlert communication, education, and outreach activities also include work with technical end users to develop cooperative agreements and technology assistance agreements. This involves interchange and negotiation to reach agreement on technical requirements, work plans, and timelines.

The JCCEO and its sub-committees and working groups coordinate development of the guidance and resources that will be elemental to successful and sustained user uptake of the system to maximize life-safety and property protection impacts. Over the next several years, as ShakeAlert moves through pilot projects, incremental roll-out, and full system implementation, the JCCEO will make recommendations on system messaging, the human interface, and education and outreach materials that integrate best practices, social science, and user-specific needs. A communication, education, and outreach implementation plan will incorporate such recommendations and will place them in context of rollout and related user-engagement activities. The implementation plan will serve as a roadmap for coordination of more specific plans focused on particular audiences by region, community, or sector.

Extensive communication, education, and outreach for both public and institutional users is needed for ShakeAlert to have maximum beneficial impact. Institutional users as well as the public must be instructed about how they will receive alerts, what actions to take, and the capabilities and limitations of the system. Users and the public should also understand the distinction between alert generation and alert delivery, as well as follow-up messaging, and the time each takes.

Partnerships among government agencies, public communications specialists, and specific user groups such as transportation, utilities, and hospitals will help promote this communication, education, and outreach effort and associated training exercises through clear and consistent messaging. To this end, responsible groups will develop and implement their own comprehensive user-education plans using multiple marketing strategies. ShakeAlert education will also be integrated into classroom curricula related to earth science and public safety, including drop-cover-and-hold exercises in the classroom in response to ShakeAlerts delivered through schools' public address systems.

Decisionmakers in both the public and private sectors will need to be informed of the capabilities of the ShakeAlert system so they can integrate it into their organizations' earthquake mitigation planning. Commercial developers that offer ShakeAlert products and services are expected to facilitate the education process with their clients and are expected to accurately describe the system and use consistent alert signals based on guidance from the JCCEO.

Finally, social science, test marketing methodologies, and user feedback will be used to design both pre-event campaigns and the visual and audible signals that will be used at the devicehuman interface when alerts are received.

The USGS strategy is to encourage and coordinate, but not carry out, these public education and training activities related to ShakeAlert. Earthquake education is already in the portfolio of many State and local agencies and organizations, including the Incorporated Research Institutions for Seismology (IRIS), Southern California Earthquake Center (SCEC), Cascadia Region Earthquake Workgroup (CREW), and Earthquake Country Alliance (ECA). These programs can be effectively leveraged by integrating ShakeAlert messages with their existing earthquake education activities.

\section{ShakeAlert Partners and Users}

The ShakeAlert project has sent live alerts to beta users since 2012 but has instructed them to take no actions because the system was in development. In April 2017, the project began recruiting pilot users to develop projects that demonstrate the use of the ShakeAlert system in real-world applications. Pilot organizations are vetted to ensure they have the institutional resources to complete their proposed project and that projects are viable, tolerant of false alerts, and will pave the way for wider use. Pilot users can take real actions for their own benefit or for the benefit of clients but are currently prohibited from doing general public alerting. For example, pilots cannot commercially distribute a smart phone application, but they are encouraged to develop 
technologies that will in the future allow mass public alerting when the system is demonstrated to be technologically capable of rapid alerting and public communication, education, and outreach is in place.

The ShakeAlert pilot program is focused on five sectors: transportation, utilities, education, health care, and emergency management, and several stakeholder workshops and sector symposia have either been carried out or are planned to further engage these user groups. Lessons learned by pilots as they use ShakeAlerts are contributing to a growing list of useful actions and applications. The future success of the system will be defined in large part by achievements of pilot partners in these sectors.

Many pilots are operational now. For example, the Bay Area Rapid Transit (BART) system was an early adopter and began to use ShakeAlert in August 2012 (McPartland, 2013). BART can reduce train speeds from 80 to 25 miles per hour in about 18 seconds, making derailment during earthquake shaking less likely. The Los Angeles light rail system, LA Metro, is following their lead. Appendix 3 lists current pilot organizations and projects. The list is growing rapidly as ShakeAlert becomes better known and alerts are made available.

\section{Direct Institutional Users}

Direct institutional users are organizations that use ShakeAlert to protect their personnel and infrastructure. They can develop in-house applications to alert employees and activate systems to take actions for their internal use, but they may not alert the public, pass alerts to third parties, or develop or market commercial products or services based on ShakeAlert. In the pilot phase, direct institutional users complete an application describing what they plan to do and sign a non-commercial license agreement. If they work with a commercial third-party technology enabler to accomplish their goals, the third party must also complete a pilot application and sign a commercial license agreement. Upon completion of the pilot phase, an agreement is signed with the USGS that includes a long-term license to connect to ShakeAlert servers. Several pilot users are in this category and others are being sought.

\section{Commercial Partners}

Commercial partners are companies that are developing and offering products and services based on ShakeAlert for paying clients. These may be new products or enhancements to their existing products. Commercial pilots must execute a technology assistance agreement with the USGS and demonstrate that they are capable of delivering ShakeAlerts reliably and without significant delays. They must further demonstrate that their product does not change the ShakeAlert data in a way that degrades ShakeAlerts or is contrary to its mission. They must accurately communicate to clients the capabilities and limitations of the system. Also, the human alert interface must be consistent with ShakeAlert standards in order to maximize the effectiveness of training and education efforts. If a commercial partner demonstrates their ability to perform, then the technology assistance agreement will be amended to include a license to operate.

ShakeAlert may stimulate business opportunities for companies to provide consulting services to help users develop continuity-of-business plans and analyze the cost-benefit of the actions users might take when they receive an alert. Because specific impacts of predicted shaking are site dependent and depend on the infrastructure at a given location, private sector services will be necessary to ensure that warnings are fully utilized by the public and businesses to minimize earthquake damage, injuries, and deaths. Some companies may choose to develop and market stand-alone on-site EEW systems to augment ShakeAlert for particularly vulnerable infrastructure. A local on-site EEW system could provide a faster alert than ShakeAlert when an event is very close to a user's facility and give the added assurance offered by having two independent systems. Such on-site EEW systems are in operation in Japan. The presence of ShakeAlert in the United States will also need to be factored into risk and loss estimation modeling, insurance rate calculations, and emergency response strategies.

\section{System Roles and Governance}

Earthquakes do not respect borders; therefore, ShakeAlert is a multi-State system led by the USGS, a Federal Government bureau. The USGS is also coordinating with international authorities in Canada and Mexico. ShakeAlert is an extension of the ANSS and will be managed like other important projects of the USGS Earthquake Hazards Program (EHP). The USGS EHP is currently overseen by the Senior Science Advisor for Earthquake and Geologic Hazards. The Federal-level oversight of the larger ShakeAlert project will include review by the Scientific Earthquake Studies Advisory Committee (SESAC), the ANSS National Steering Committee, and the USGS Earthquake Program Council. The ANSS has expanded its governance to include a ShakeAlert External Working Group as a subcommittee of the ANSS National Steering Committee, which is a SESAC subcommittee. The external working group is an expert panel providing guidance on the scientific, technical, communication, education, and outreach issues affecting the development, implementation, and utilization of ShakeAlert. Coordination with FEMA, the National Institute of Standards and Technology (NIST), and the National Science Foundation (NSF) is also necessary to fulfill National Earthquake Hazards Reduction Program (NEHRP) responsibilities.

The USGS EHP has overall responsibility for the ShakeAlert system and works closely with cooperating project partners to achieve the goals of the system. Core system management and operations, testing and certification, coordination of communication, education, and outreach activities, and overall project management is performed by USGS project staff, 
known as ShakeAlert Central, which is located in Pasadena and includes a national EEW coordinator. Under the expanded ANSS governance, the ShakeAlert project also has several technical working groups and an internal USGS working group, which provides USGS project oversight and identifies issues to be considered by the external working group.

The ShakeAlert EEW system is being developed as a new product within the ANSS and leverages the existing ANSS investments in seismic and geodetic monitoring. In California, ShakeAlert is operated in cooperation with the California Integrated Seismic Network (CISN), a partnership of the USGS, the California Governor's Office of Emergency Services (Cal OES), the California Geological Survey, Caltech's Seismological Laboratory, and the UC Berkeley Seismological Laboratory. In the Pacific Northwest, ShakeAlert is operated in cooperation with the Pacific Northwest Seismic Network (PNSN), which is a partnership between the USGS, the University of Washington, and the University of Oregon.

The ShakeAlert university partners' work is defined and supported through cooperative agreements with the USGS and coordinated by a number of working groups under the overall guidance of the ShakeAlert Executive Committee.

The development and testing of the ShakeAlert system will continue to be coordinated by ShakeAlert Central and carried out by the USGS EHP, ANSS, and its partner universities through cooperative agreements and grants and through internal USGS projects.

Whereas the USGS EHP will have overall responsibility for the development and operation of the national ShakeAlert system, cooperation and coordination among many stakeholders is needed for success. ANSS regional operators and the ShakeAlert coordinator will harmonize their activities with Federal, State, and local stakeholders. These include NEHRP partner agencies (FEMA, NIST, and NSF) as well as the National Oceanic and Atmospheric Administration (NOAA), State, county, and city emergency management departments, geological surveys, and other organizations with emergency preparedness and response missions.

The JCCEO and its working groups include representatives from the USGS, State emergency management agencies and geological surveys, and other experts in emergency management and hazard communications. As part of their communication, education, and outreach activities, the JCCEO coordinates ShakeAlert's pilot users, social science research, and the development of messaging and educational materials. They have researched and delivered several evidence-based recommendations about risk communications, alert signals and sounds, user interaction, and hazard communication. They also organize user meetings (such as the sector symposia mentioned previously) and recruit and manage commercial and non-commercial pilot users.

\section{State Partners}

The Federal Government expects the benefiting States to participate in and contribute toward ShakeAlert implementation as they do for routine seismic monitoring and other earthquake hazard mitigation activities. The State of California has supported earthquake monitoring since 2001 and made EEW a priority in 2016 by enacting legislation that created the California Earthquake Early Warning Program within Cal OES and the California Earthquake Early Warning Advisory Board to advise the Director of Cal OES. In 2016, California allocated \$10 million for EEW buildout; the funding was used to add CISN stations and to develop and execute a public education campaign. An additional \$15.8 million was allocated in fiscal year 2018-19 to support Cal OES's internal program and install the remaining sensors needed in California. Cal OES has developed an EEW business plan (BlueSky Consulting, 2018) and is exploring models to fund ongoing operation of ShakeAlert, EEW education, and user engagement activities in the State. It is also leading the development of a consensus audio alert sound.

The State of Oregon appropriated funds to purchase 15 seismic stations to enhance and contribute to ShakeAlert. The Oregon Department of Geology and Mineral Industries has also funded 27 new stations and the Eugene Water and Electric Board has purchased equipment for two stations. The Oregon Department of Transportation Wireless Communications Section has entered an intergovernmental agreement with the University of Oregon and the University of Washington (UW) to facilitate microwave data backhaul and seismic station colocation. The State of Washington is strongly supportive of the ShakeAlert initiative and provides some base funding of the PNSN and houses the operation at UW.

The USGS strategy is to coordinate, but not carry out, public education and training related to ShakeAlert, with the expectation that the benefiting States would leverage existing earthquake education programs by integrating ShakeAlert with them. Through the JCCEO, the USGS has guided the formation of State and region-specific committees to ensure these stakeholders participate in ShakeAlert communication, education, and outreach planning. This includes State emergency management departments and geological surveys, as well as commissions, committees, nonprofits, and other associations focused on hazards.

\section{Expanding to Other Regions}

The focus of the USGS is on completing ShakeAlert in Washington, Oregon, and California. Expanding the alert area into the populous areas of Nevada will not be difficult technically but will require additional resources and coordination with another State's stakeholders. The design and cost of implementing ShakeAlert has been estimated for the State of Hawaii (Thelen and others, 2016) and the Anchorage region of Alaska.

In Canada, the USGS is working with its sister organization, Natural Resources Canada, to coordinate cross-border alerts and create a fourth integrated ShakeAlert center in Canada. This will involve sharing algorithm and alert software to run on 
Canadian servers and sharing real-time data, including alerts. We will coordinate our efforts to ensure that cross-border alerts are consistent and do not confuse the public. This project will require higher level coordination of policy related to public earthquake alerting and coordination of the development and distribution of public outreach and education materials with each other and stakeholders.

The USGS is also working with Mexico's Centro Nacional de Prevención de Desastres (CENAPRED, National Center for Prevention of Disasters) and the Centro de Investigación Científica y de Educación Superior de Ensenada (CICESE, Ensenada Center for Scientific Research and Higher Education) in Baja California to ensure that Mexican officials are aware of ShakeAlert and the likelihood that alerts will cross the border. Opportunities are being sought to enhance the Mexican seismic stations for the benefit of populations on both sides of the border.

\section{Continuing Research and Development}

Significant research and development of EEW alert methods has taken place over the last decade to develop the initial methodologies used by ShakeAlert. At present, alerts are generated by a point-source algorithm that estimates the magnitude and location of an earthquake and by a seismicbased finite-fault algorithm that estimates the extent of the fault rupture. Point-source algorithms have successfully provided alerts for small- to moderate-size earthquakes that often match well to ComCat "ground truth" magnitudes and locations. The additional of a finite-fault algorithm is expected to provide improved magnitude and fault rupture extent information for larger earthquakes. However, continued research and development is necessary to drive rapid improvements and fill critical gaps as ShakeAlert transitions from a prototype system to a full public system for the West Coast of the United States. The longer term research objectives summarized below are described in greater detailed by Cochran and others (2018a). These objectives will be pursued under the guidance of the USGS ShakeAlert Chief Scientist through external USGS EHP grants to non-USGS organizations via a competitive proposal process and by internal USGS projects.

Theoretical limitations of EEW systems should be considered when designing an effective system, and those capabilities must be communicated to end users. The work of Meier (2017) and Minson and others (2018) show that it is difficult to provide accurate and timely warnings for high ground-motion thresholds; however, long warning times are possible when low ground-motion thresholds are instead used to issue alerts. Research is required to assess the expected theoretical system performance for different measures of ground motion (PGA, PGV, and others) and for different fault distributions, frequency-magnitude distributions, rupture models, site and basin characteristics, directivity, and so on. Also, predictions from the theoretical analyses should be tested against real-world performance where available.
Verification of algorithm performance is needed to determine if ShakeAlert products meet user needs, including technical end users and the general public. Performance metrics based on the best available science that use representative earthquake datasets as well as synthetic datasets are needed. Users must understand how to maximize their benefit from ShakeAlert; therefore, research is needed to understand the costbenefit based on performance of an ideal (but realistic) system and for the current performance of the ShakeAlert system. Furthermore, social science research is needed to inform decisions about the magnitude and ground-motion thresholds at which alerts should be issued and what the content of those alerts should be (including post-alert follow-up messaging) to maximize their effectiveness.

Continued development of EEW algorithms is needed to further improve the timeliness and accuracy of alerts and the resulting ground motions. Existing algorithms require improved waveform processing methods to better distinguish seismic phases from noise. Also, new algorithms, including those developed for use in other EEW systems worldwide, should be evaluated for their efficacy and possible use in ShakeAlert. For example, a new algorithm was recently added to the Japanese EEW system that predicts expected ground motions directly from observed ground motions without solving for the earthquake source properties (Kodera and others, 2018). The method was introduced to address deficiencies in the existing point-source methods, including lack of warnings issued to more distant regions during large earthquakes and a high false alert rate during very active aftershock sequences.

Research is also needed to evaluate the use of geodetic data to better constrain source extent and slip for large earthquakes. As discussed above, GNSS position measurements with associated uncertainties must be integrated from multiple data streams for real-time use by geodetic algorithms. Also, algorithm development and testing are needed to determine how best to integrate geodetic information with seismically based alerts.

All potential new algorithms will need to be thoroughly evaluated across a wide range of earthquake magnitudes to determine their contributions to the accuracy and timeliness of predicted ground motions. It is expected that a given algorithm may provide accurate alert information only for a specific range of magnitudes or event type (for example, plate interface earthquakes versus shallow crustal earthquakes) and that multiple algorithms may be required to produce more robust alerts. However, information from multiple algorithms must be carefully combined to maximize system performance. For example, a module is being developed that uses Bayesian logic to compare the observed ground motions to those predicted by an algorithm to assess the likelihood that a particular solution is correct (Minson and others, 2017). This is a straightforward check that can suppress false alerts and improve ground-motion estimates by checking that the alerts match ground-motion observations.

The cost-benefit of low-cost sensors, down-hole sensors, and sea-floor geodetic sensors in EEW should be evaluated, as should putting waveform analysis functions on the dataloggers in the field. 


\section{Budget Estimate}

To date, project funding has been of two types: stable base funding from USGS and one-time influxes of capital funds from a variety of sources (appendix 4). The one-time funds have been used to buildout the system infrastructure to its current level but cannot be relied upon for operation and maintenance. Base funding is also used to buildout the system infrastructure by employing a "build-and-operate" strategy of using any funds remaining after development and operational costs are covered for capital buildout. This budget estimates the capital costs of completing the system infrastructure beginning from its state in mid-2018, as well as the stable, year-to-year operation and maintenance funding needed to run the completed system with the reliability its life-safety mission demands.

The estimated one-time cost of completing the ShakeAlert system is $\$ 39.4$ million and the annual operation and maintenance cost of the completed system is estimated to be \$28.6 million per year (table 2). This document also includes an estimate of the added costs for a telemetry improvement plan (appendix 5). Building a highly reliable data telemetry infrastructure would cost another \$20.5 million; however, this cost could be reduced if project partners provide telemetry bandwidth on existing systems. The additional operation and maintenance cost for this improved telemetry system would be $\$ 9.8$ million per year, but this also could be reduced by partners providing bandwidth at low or no cost to the project.

This estimate updates and expands the 2014 plan (Given and others, 2014), which estimated the capital cost to be $\$ 38$ million at that time and the annual cost of operation and maintenance to be $\$ 16$ million. In the four years since that report was published, the USGS and its partners have gained valuable experience as they built out and operated the production prototype, which provided data for the more accurate, higher estimate of project costs presented here.

This 2018 capital budget estimate is higher than the earlier 2014 estimate, despite the capital buildout work that has been done in the intervening four years. The new revised operation and maintenance budget is correspondingly higher as well. There are several reasons for this. First, better estimates have been made to account for regional differences in network buildout costs, changing overhead rates, and inflation in the cost of personnel, equipment, data services, and other items. These better estimates affect both the capital and operation and maintenance budgets. Also, the cost of obtaining and maintaining permits for stations has proven to be significantly higher than originally estimated, primarily because of the need to satisfy National Environmental Policy Act (NEPA), Endangered Species Act (ESA), and National Historic Preservation Act (NHPA) requirements. Federal land management organizations are more aggressively seeking to recover their costs for processing permit applications than in the past. Obtaining permits represents a significant bottleneck in the station buildout, which causes delays and increases costs. Additionally, four years of experience in contracting for station construction has led to more realistic estimates to do that work. This budget also includes a more comprehensive plan for upgrading and maintaining geodetic sensors operated both by the USGS and its partners, many of which are reaching end-oflife. Likewise, the process of planning for robust data telemetry from field sensors to alert centers has revealed the need for greater path and telemetry mode diversity and more purpose-built infrastructure. The cost of building the data processing and alert generation computer infrastructure has been adjusted upward because of the cost of building the alert layer to meet Government cybersecurity requirements under the Federal Information Security Management Act, added data handling and storage capacity for the expanded network, and greater server capacity to handle more compute-intensive algorithms. Also, the proposed investment in ongoing research to improve performance and reliability of ShakeAlert has been increased and additional resources have been allocated for coordination of communication, education, and outreach activities.

The California part of this revised budget was developed in close coordination with Cal OES, as they created their business plan for the California Earthquake Early Warning Program as required by 2016 State legislation (Blue Sky Consulting Group, 2018). The two budgets are compatible, but not identical, because State and Federal budgets include some different assumptions about funding sources, project scope, overhead rates, and taxes.

Some of the funding needed to complete the system may come from sources other than the Federal Government. This has happened in the past; capital funding from non-Federal sources is shown in appendix 4.

It is important to note that this budget assumes that current core funding for the underlying ANSS regional seismic and geodetic networks from Federal and other sources will continue at current levels and will keep up with inflation. It also assumes that the NSF will continue to fund the annual operational and maintenance costs for the UNAVCO Plate Boundary Observatory (PBO) GNSS stations needed to fill out the geodetic network requirements of ShakeAlert.

This budget does not include the investment needed by public or private partners to distribute or use the alerts. It also does not include any costs to State or local governments for activities related to ShakeAlert, including public education and training. However, unlike the earlier plan, this budget includes support for coordinating communication, education, and outreach activities among the stakeholders and developing multi-state education and communications plans and materials. Appendix 5 describes the additional costs for ensuring more robust and reliable telemetry.

\section{Capital Infrastructure Budget}

The capital budget estimate for completing the ShakeAlert system is shown in table 3, broken down by major system components and by ANSS region. The total estimate for all components is $\$ 39.4$ million: $\$ 19.8$ million in California (CISN), $\$ 17.7$ million in Oregon and Washington (PNSN), and \$1.9 million for ShakeAlert Central.

This budget would complete the buildout of the originally envisioned 1,675-station seismic network by upgrading or adding a total of 560 stations: 283 in California and 277 in 
Oregon and Washington. About 865 are currently contributing data and 250 more have been funded and are being built. This budget also includes the one-time capital cost to upgrade about 475 GNSS stations in both USGS and cooperator networks with modern GNSS receivers that have clock corrections for onboard positioning, and improved telemetry where needed.

Capital costs were estimated using the average cost of recent installations for both seismic stations with only strong-motion sensors and stations with broadband sensors. This calculation includes the cost of management, scouting, permitting, environmental assessment, site construction, power systems, field equipment, last-mile telemetry (the link from the station to backbone telemetry), and final testing. To arrive at a gross average cost, it also includes institutional overhead rates, as appropriate. Strong-motion-only stations average \$52,600 and stations that have strong motion plus broadband average $\$ 64,600$. These values were then multiplied by the number of each type of station needed in each region.
A similar process was used for GNSS stations, but various combinations of telemetry and receiver upgrades in the different contributing networks had to be first calculated then multiplied by the number of stations that need each combination of upgrade. The average gross cost per upgrade ranged from $\$ 27,300$ to $\$ 54,700$.

The estimate for ShakeAlert Central is mostly based on replacing aging computer equipment, including production servers and data archives. It also includes updated cybersecurity infrastructure such as firewalls and network routers. USGS overhead rates were applied to arrive at a gross number.

\section{Operations and Maintenance Budget}

The annual recurring cost of long-term operation and maintenance of the ShakeAlert system infrastructure without the telemetry component is $\$ 28.6$ million: \$13.6 million in California (CISN), \$7.0 million in Oregon and Washington (PNSN), and \$8.0 million for ShakeAlert Central (table 4).

Table 2. Summary of estimated capital and operation and maintenance budgets to complete and operate the ShakeAlert system.

[Costs to build and operate a highly reliable telemetry system are not included here, but are shown in appendix 5. GNSS, Global Navigation Satellite System]

\begin{tabular}{lcc}
\hline \multicolumn{1}{c}{ Component } & $\begin{array}{c}\text { Capital costs, } \\
\text { in dollars (\$) }\end{array}$ & $\begin{array}{c}\text { Operation and maintenance, } \\
\text { in dollars (\$) }\end{array}$ \\
\hline Seismic stations & $31,229,353$ & $17,079,668$ \\
GNSS stations & $6,202,386$ & $3,471,170$ \\
ShakeAlert Central & $1,921,500$ & $2,984,730$ \\
Research and development & & $3,202,500$ \\
Communication, education, and outreach & & $1,831,830$ \\
\hline Total & $\mathbf{3 9 , 3 5 3 , 2 3 9}$ & $\mathbf{2 8 , 5 6 9 , 8 9 8}$ \\
\hline
\end{tabular}

Table 3. Summary of capital costs to complete buildout of ShakeAlert infrastructure by Advanced National Seismic System (ANSS) region.

[GNSS, Global Navigation Satellite System]

\begin{tabular}{lcrrr}
\hline \multicolumn{1}{c}{ Component } & $\begin{array}{c}\text { ShakeAlert Central, } \\
\text { in dollars (\$) }\end{array}$ & $\begin{array}{c}\text { California, } \\
\text { in dollars (\$) }\end{array}$ & $\begin{array}{c}\text { Pacific Northwest, } \\
\text { in dollars (\$) }\end{array}$ & $\begin{array}{c}\text { Total West Coast, } \\
\text { in dollars (\$) }\end{array}$ \\
\hline ShakeAlert Central information technology (IT) & $1,921,500$ & & & $1,921,500$ \\
Seismic stations & & $15,997,495$ & $15,231,858$ & $31,229,353$ \\
GNSS stations & & $3,755,844$ & $2,446,542$ & $6,202,386$ \\
\hline Total & $\mathbf{1 , 9 2 1 , 5 0 0}$ & $\mathbf{1 9 , 7 5 3 , 3 3 9}$ & $\mathbf{1 7 , 6 7 8 , 4 0 0}$ & $\mathbf{3 9 , 3 5 3 , 2 3 9}$ \\
\hline
\end{tabular}

Table 4. Summary of annual operations and maintenance budget for the ShakeAlert system by Advanced National Seismic System (ANSS) region.

[GNSS, Global Navigation Satellite System]

\begin{tabular}{lcccc}
\hline \multicolumn{1}{c}{ Category } & $\begin{array}{c}\text { ShakeAlert Central, } \\
\text { in dollars (\$) }\end{array}$ & $\begin{array}{c}\text { California, } \\
\text { in dollars (\$) }\end{array}$ & $\begin{array}{c}\text { Pacific Northwest, } \\
\text { in dollars (\$) }\end{array}$ & $\begin{array}{c}\text { Total West Coast, } \\
\text { in dollars (\$) }\end{array}$ \\
\hline ShakeAlert Central operations & $2,984,730$ & & & $2,984,730$ \\
Research and development & $3,202,500$ & & $3,202,500$ \\
Communication, education, and outreach & $1,831,830$ & & $1,831,830$ \\
Seismic stations & & $11,303,821$ & $5,775,847$ & $17,079,668$ \\
GNSS stations & & $2,281,710$ & $1,189,460$ & $3,471,170$ \\
\hline Total & $\mathbf{8 , 0 1 9 , 0 6 0}$ & $\mathbf{1 3 , 5 8 5 , 5 3 1}$ & $\mathbf{6 , 9 6 5 , 3 0 7}$ & $\mathbf{2 8 , 5 6 9 , 8 9 8}$ \\
\hline
\end{tabular}


The operations and maintenance budget for seismic stations is based on an analysis of the historic average per-station support cost within the ANSS networks. This was then multiplied by the number of new ShakeAlert stations in each region. Note that it assumes current operations and maintenance support from all sources will continue at current levels and support operations and maintenance of prebuildout infrastructure. The estimate includes personnel and travel for field maintenance, commercial telemetry costs, ongoing fees and renewal of site licenses, permits, and environmental approvals, as well as personnel for management, data handling, IT support, and quality control. It also includes equipment replacement costs on a 10-year life cycle for field equipment and a 5-year life cycle for data acquisition computers. Overhead was factored in to arrive at a gross number.

The estimated operations and maintenance budget for GNSS stations was based on an evaluation of the historic average perstation cost adjusted for inflation and takes into account the new telemetry to be added for ShakeAlert and the additional cost of operation, maintenance, and reliable delivery of real-time position streams to meet the more demanding requirements of ShakeAlert. This budget assumes operations and maintenance support for GNSS stations will continue at current levels from all sources, including USGS support. Ten of the GNSS stations are new and will require full support.

The ShakeAlert Central budget includes personnel for project management, IT support, and the testing and certification platform, as well as contracts for cybersecurity and cloud computing. It also includes a computer hardware replacement plan that assumes a 5-year life cycle for replacement of commodity servers at each center to support data handling, processing, monitoring, alert generation, alert services, testing, and development.

The use of cloud services in the ShakeAlert production system has been evaluated and is not believed to be advisable at this time because cloud services would introduce unacceptable fragilities and risks. These risks include greater dependence on the public internet, Government procurement hurdles, and technical and pricing models that change rapidly and are beyond our control. The main attraction of the cloud computing model is its "elasticity", which is the ability to economize by adding or releasing computing resources as demand fluctuates. The base processing load for ShakeAlert production systems is flat and cloud services cannot be added fast enough to handle alert layer spikes without introducing unacceptable delays. Use of cloud services is being pursued in the development and testing environments where there is variable demand that is not time critical.

The research and development budget supports the USGS ShakeAlert Chief Scientist position, internal and external personnel, grants, and contracts to achieve the objectives outlined in the Continuing Research and Development section above. The communication, education, and outreach budget supports the Communication, Education, and Outreach Coordinator position, as well as internal and external personnel and activities under grants and contracts, to achieve the objectives described in the Communications, Education, and Outreach section.

\section{Timeline}

Constructing a timeline for full ShakeAlert implementation is difficult because actual funding levels are not known. ShakeAlert is capable of alerting today but much work remains and funding for robust operation and maintenance is not in place. At current funding levels, some progress can be made, but reliable public alerts in all areas is not possible. Assuming full funding, for both one-time capital buildout and operation and maintenance, we estimate that it will take approximately three years to complete station and telemetry infrastructure, hire and train personnel to maintain and operate the system, and complete public education and training to the point of general public alerting in all areas. The main constraints internally are the time it takes to obtain station site permits and execute Government contracting and hiring.

The USGS will encourage organizations to use ShakeAlerts to take protective actions, but the number of these implementations and how quickly they occur are outside of our direct control. Also, as discussed above, we cannot control when cell systems will have the technical ability to deliver alerts with sufficient speed to be effective for ShakeAlert. Likewise, State partners will primarily perform communication, education, and outreach activities and will establish their own timelines and budgets. Only California has committed funding for this purpose and the type and amount of education required before State authorities are comfortable with public alerting may vary by region.

\section{Conclusion}

The USGS Earthquake Hazards Program, along with its partners in government and industry, is building the ShakeAlert earthquake early warning (EEW) system for the West Coast of the United States motivated by its mission to reduce earthquake impacts. In addition to reducing deaths, injuries, and property damage caused by earthquakes, the system can improve community resilience, provide quick post-event situational awareness, and present new opportunities to educate the public and decisionmakers about earthquake hazards.

The ShakeAlert system can provide as much as tens of seconds of warning to people and automated systems before strong shaking arrives. With just a few seconds, users can initiate a variety of protective actions. School children can drop, cover, and hold on and crowds in theaters and sports venues can be forewarned and given instructions to protect themselves. Workers in factories, construction sites, and hospitals can move away from dangerous areas. Fire station doors can be opened so they do not jam and trap equipment. Heavy equipment, like trains, elevators, and cranes, can stop automatically in safe positions. Spills and damage in water systems can be prevented by activating valves and gates. Finally, ShakeAlerts can be particularly valuable in the aftermath of large earthquakes when aftershocks shake weakened structures, which can endanger rescue and recovery workers who are in hazardous situations. 
EEW has limitations. False and missed alerts are likely, and there may be little or no warning near the earthquake's epicenter, where shaking is strongest. Users that require longer warning times must act at a low threshold of expected shaking, understanding that, in many cases, they will take protective actions for earthquakes that do not grow to an intensity that will cause damage at their location.

Throughout the project, the USGS has leveraged its existing Advanced National Seismic System infrastructure, expertise, and partnerships in California, Oregon, and Washington. The system's seismic sensor network is about 50 percent completed and upgrades to geodetic sensors have begun. As funding allows, stations are being added, telemetry paths are being upgraded, computer infrastructure is becoming more robust, and scientific algorithms and software are being improved and tested. At the same time, the USGS is working with government and industry collaborators to improve alert mass distribution systems and develop new products and services to maximize the benefits of ShakeAlerts. The USGS and its partners are also recruiting end users across many sectors and developing training and education materials to make alerts as effective as possible. Using a phased strategy, the system is becoming more reliable and the alerts it produces are becoming more widely used.

Although the ShakeAlert system is not yet complete, it has reached a level of readiness sufficient to serve live alerts to an expanding number of institutional users on the West Coast. General public alerting will begin as soon as the system and alerts meet appropriate standards, mass alerting technologies are upgraded and tested, and the public is adequately educated about how to respond to alerts.

\section{References}

Allen, R.M., Cochran, E.S., Huggins, T., Miles, S., and Otegui, D., 2017, Quake warnings, seismic culture: Science, v. 358, no. 6367 , p. 1111 .

Alliance for Telecommunications Industry Solutions, 2015, Feasibility study for earthquake early warning system: Alliance for Telecommunications Industry Solutions report ATIS0700020, 37 p., accessed on September 21, 2018, at http://www. atis.org/newsroom/EarthquakeFeasibilityStudy.pdf.

Bakun, W.H., Fischer, F.G., Jensen, E.G., and J. VanSchaack, 1994, Early warning system for aftershocks: Bulletin of the Seismological Society of America, v. 84, no. 2, p. 359-365.

Berberian, M., 2013, Early earthquake detection and warning alarm system in Iran by a telegraph operator-A 116-year-old disaster prevention attempt: Seismological Research Letters, v. 84 , no. 2 , p. 816-819.

Biasi, G.P., and M.G. Alvarez, 2018, Station and telemetry impact metrics for earthquake early warning seismic network performance evaluation [abs.] in 2018 Seismology of the Americas Meeting: Seismological Research Letters, v. 89, no. 2B, p. 717-996.
Blue Sky Consulting Group, 2018, Implementing earthquake early warning in California-A business plan for the California earthquake early warning system: Prepared for the California Governor's Office of Emergency Services, 69 p., accessed on September 14, 2018, at http://www.caloes. ca.gov/EarthquakeTsunamiVolcanoProgramsSite/Documents/ CEEWP\%20Business\%20Plan\%20Final.pdf.

Böse, M., Heaton, T., and Hauksson, E., 2012, Real-time finite fault rupture detector (FinDer) for large earthquakes: Geophysical Journal International, v. 191, no. 2, p. 803-812.

Cochran, E.S., Aagaard, B.T., Allen, R.M., Andrews, J., Baltay, A.S., Barbour, A.J., Bodin, P., Brooks, B.A., Chung, A., Crowell, B.W., Given, D.D., Hanks, T.C., Hartog, J.R., Hauksson, E., Heaton, T.H., McBride, S., Meier, M-A., Melgar, D., Minson, S.E., Murray, J.R., Strauss, J.A., and Toomey, D., 2018a, Research to improve ShakeAlert earthquake early warning products and their utility: U.S. Geological Survey Open-File Report 2018-1131, 17 p., https://doi.org/10.3133/ofr20181131.

Cochran, E.S., Kohler, M.D., Given, D., Guiwits, S., Meier, M-A., Ahmand, M., Henson, I., Andrews, J., and Hartog, J.R., 2018b, Earthquake early warning ShakeAlert systemTesting and certification platform: Seismological Research Letters, v. 89, no. 1, p. 108-117.

Crowell, B.W., Schmidt, D.A., Bodin, P., Vidale, J.E., Baker, B., Barrientos, S., and J. Geng, 2018, G-FAST earthquake early warning potential for great earthquakes in Chile: Seismological Research Letters, v. 89, no. 2A, p. 542-556.

Federal Communications Commission, 2016, The capacity of the Integrated Public Alert and Warning System to deliver sensor-based earthquake early warnings - An engineering analysis: Federal Communications Commission, accessed on September 14, 2018, at https://transition.fcc.gov/bureaus/ pshs/eas/Earthquake_Alert_WhitePaper-120216.pdf.

Federal Emergency Management Agency, 2017, Hazus estimated annualized earthquake losses for the United States: Federal Emergency Management Agency report $\mathrm{P}-366,78 \mathrm{p}$.

Field, E.H., Biasi, G.P., Bird, P., Dawson, T.E., Felzer, K.R., Jackson, D.D., Johnson, K.M., Jordan, T.H., Madden, C., Michael, A.J. and Milner, K.R., 2015, Long-term timedependent probabilities for the third Uniform California Earthquake Rupture Forecast (UCERF3): Bulletin of the Seismological Society of America, v. 105, no. 2A, p. 511-543.

Field, E.H., Dawson, T.E., Felzer, K.R., Frankel, A.D., Gupta, V., Jordan, T.H., Parsons, T., Petersen, M.D., Stein, R.S., Weldon, R.J., II, and Willis, C.J., 2008, The Uniform California Earthquake Rupture Forecast, version 2 (UCERF 2): U.S. Geological Survey Open-File Report 2007-1437, p. 104. 
Fujinawa, Y., and Noda, Y., 2013, Japan's earthquake early warning system on 11 March 2011-Performance, shortcomings, and changes: Earthquake Spectra, v. 29, no. S1, p. S341-S368.

Given, D.D., Cochran, S.E., Heaton, T., Hauksson, E., Allen, R., Hellweg, P., Vidale, J., and Bodin, P., 2014, Technical implementation plan for the ShakeAlert production system-An earthquake early warning system for the West Coast of the United States, U.S. Geological Survey OpenFile Report 2014-1097, 25 p., https:/dx.doi.org/10.3133/ ofr20141097.

Grapenthin, R., Johanson, I.A., and Allen, R., 2014, Operational real-time GPS-enhanced earthquake early warning: Journal of Geophysical Research, v. 119.

Heaton, T.H., 1985, A model for a seismic computerized alert network: Science, v. 228, no. 4702, p. 987-990.

Hutton, K., Woessner, J., and Hauksson, E., 2010, Earthquake monitoring in southern California for seventy-seven years (1932-2008): Bulletin of the Seismological Society of America, v. 100, no. 2, p. 423-446.

Jaiswal, K.S., Petersen, M.D., Rukstales, K., and W.S. Leith, 2015, Earthquake shaking hazard estimates and exposure changes in the conterminous United States: Earthquake Spectra, v. 31, no. S1, p. S201-S220.

Johnson, L.A., Rabinovici, S., Kang, G.S., and Mahin, S.A., 2016, California Earthquake Early Warning System Benefit Study: Pacific Earthquake Engineering Research Center report no. 2016/06, 90 p.

Kodera, Y., Yamada, Y., Hirano, K., Tamaribuchi, K., Adachi, S., Hayashimoto, N., Morimoto, M., Nakamura, M., and M. Hoshiba, 2018, The Propagation of Local Undamped Motion (PLUM) method-A simple and robust seismic wavefield estimation approach for earthquake early warning: Bulletin of the Seismological Society of America, v. 108 , no. 2, p. 983-1003.

Kohler, M.D., Cochran, E.S., Given, D., Guiwits, S., Neuhauser, D., Hensen, I., Hartog, R., Bodin, P., Kress, V., Thompson, S., Felizardo, C., Brody, J., Bhada, R., and Schwarz, S., 2018, Earthquake early warning ShakeAlert system - West coast wide production prototype: Seismological Research Letters, v. 89 , no. 1 , p. 99-107.

Kordek, M.E., 2013, Alert fatigue by other names-Review of contributing fields regarding the 'cry wolf' effect: Scholar Archive, no. 910, accessed on September 14, 2018, at https://digitalcommons.ohsu.edu/etd/910.
Kuyuk, H.S., and Allen, R.M., 2013, Optimal seismic network density for earthquake early warning-A case study from California: Seismological Research Letters, v. 84, no. 6, p. 946-954.

Kuyuk, H.S., Allen, R.M., Brown, H., Hellweg, M., Henson, I., Neuhauser, D., 2014, Designing a network-based earthquake early warning algorithm for California-ElarmS-2: Bulletin of the Seismological Society of America, v. 104, no. 1, p. 162-173.

Lee, W.H.K., and J.M. Espinosa-Aranda, 1998, Earthquake early warning systems - Current status and perspectives in Zschau, J., and A. Küppers (eds.), Early Warning Systems for Natural Disaster Reduction: Springer-Verlag Berlin Heidelberg, p. 409-423.

McPartland, J., 2013, Using earthquake early warning in the Bay Area Rapid Transit system [abs.]: Abstract S43C-02 presented at 2013 Fall Meeting, American Geophysical Union, San Francisco, Calif., 9-13 December.

Meier, M-A., 2017, How "good" are real-time ground motion predictions from Earthquake Early Warning systems?: Journal of Geophysical Research, v. 122, p. 5561-5577.

Mileti, D.S., and J.H. Sorensen, 1990, Communication of emergency public warnings - A social science perspective and state-of-the-art assessment: Prepared for the Federal Emergency Management Agency, 162 p., accessed on September 16, 2018, at https://doi.org/10.2172/6137387.

Minson, S.E., Meier, M-A., Baltay, A.S., Hanks, T.C., and Cochran, E.S., 2018, The limits of earthquake early warning-Timeliness of ground motion estimates: Science Advances, v. 4, no. 3.

Minson, S.E., Murray, J., Langbein, J., and Gomberg, J., 2014, Real-time inversions for finite fault slip models and rupture geometry based on high-rate GPS data: Journal of Geophysical Research, v. 119, no. 4, p. 3201-3231.

Minson, S.E., Wu, S., Beck, J.L., and Heaton, T.H., 2017, Combining multiple earthquake models in real time for earthquake early warning: Bulletin of the Seismological Society of America, v. 107, no. 4, p. 1868-1882.

Nakamura, Y., and J. Saita, 2007, UrEDAS, the Earthquake Warning System - Today and tomorrow in Gasparini, P., Manfredi, G., and J. Zschau, eds., Earthquake Early Warning Systems: Springer-Verlag Berlin Heidelberg, 252 p.

National Academies of Sciences, Engineering, and Medicine, 2018, Emergency alert and warning systems - Current knowledge and future research directions: The National Academies Press, Washington, D.C., accessed on September 16, 2018, at https://doi.org/10.17226/24935. 
Porter, K.A., and J.L. Jones, 2018, How many injuries can be avoided in the HayWired scenario through earthquake early warning and drop, cover, and hold on?, chap. Q of Detweiler, S.T., and Wein, A.M., eds., The HayWired earthquake scenario-Engineering implications: U.S. Geological Survey Scientific Investigations Report 2017-5013-I-Q, 429 p., https://doi.org/10.3133/sir20175013v2.

Ruhl, C.J., Melgar, D., Grapenthin, R., and Allen, R.M., 2017, The value of real-time GNSS to earthquake early warning: Geophysical Research Letters, v. 44, p. 8311-8319.

Strauss, J.A., and Allen, R.M., 2016, Benefits and costs of earthquake early warning: Seismological Research Letters, v. 87 , no. 3 , p. $765-772$.

Thelen, W.A., Hotovec-Ellis, A.J., Bodin, P., 2016, Feasibility study of earthquake early warning (EEW) in Hawaii: U.S. Geological Survey Open-File Report 2016-1172, 33 p., https://doi.org/10.3133/ofr20161172.
U.S. Geological Survey, 1999, An assessment of seismic monitoring in the United States; requirement for an Advanced National Seismic System: U.S. Geological Survey Circular 1188, 55 p., https://doi.org/10.3133/ cir1188.

U.S. Geological Survey, 2017, Advanced National Seismic System - Current status, development opportunities, and priorities for 2017-2027 (ver. 1.1, July 2017): U.S. Geological Survey Circular 1429, 32 p., https://doi. org/10.3133/cir1429.

U.S. Government Accountability Office, 2016, EarthquakesAdditional actions needed to identify and mitigate risks to Federal buildings and implement an early warning system: U.S. Government Accountability Office report GAO-16-680, $114 \mathrm{p}$. 


\section{Appendixes 1-5}




\section{Appendix 1. ShakeAlert Primary Messages}

ShakeAlerts can be thought of as a service that publishes messages to ActiveMQ topics when predetermined criteria and thresholds are met. Institutional users connect to alert servers and subscribe to the topic or topics containing the message types they want. If needed to support high-impact users, the ShakeAlert project may produce and publish additional messages in other formats. In special cases, ShakeAlert may support message delivery via protocols other than ActiveMQ. For example, the contents of event source message are reformatted into the QuakeML format and published to the product distribution layer, making them available to Advance National Satellite System (ANSS) monitoring centers, including the National Earthquake Information Center. Also, common alert protocol messages are composed and sent to the Federal Emergency Management Agency's (FEMA) Integrated Public Alert and Warning System Open Platform for Emergency Network (IPAWS-OPEN) gateway for public alerting.

Large earthquakes may occur on long faults that take tens of seconds to minutes to rupture. The first alert message for an event is published quickly, before a large rupture has finished. Therefore, updates are published as more sensor data becomes available and the estimated magnitude and rupture length evolves. The rate at which updates are sent may be regulated in some cases (for example, for public alerts) to prevent overwhelming the capabilities of the delivery technology.

\section{Event Source Message}

Event source messages are primary messages that describe the earthquake source. This message is descriptive, not prescriptive; that is, it is not an alert. Its contents must be interpreted and additional logic must be applied by the user to decide if action should be taken. Event source message characteristics include:

- Topic: eew.sys.dm.data

- Message label: <event_message>

- Summary of content elements:

- $<$ core_info $>$

- Latitude, longitude, and depth of epicenter, including uncertainty estimate

- Magnitude and uncertainty estimate

- Number of reporting stations

- < fault_info $>$ (only if available)

- Finite-fault description from FinDer or geodetic methods

- Two-dimensional connected line segments or
- Three-dimensional connected rectangular segments

- $<$ gm_info $>$ (only if available)

- Observed peak ground motions at triggered stations

- Format: extensible markup language (XML); an XML schema definition [XSD] file describes the XML format elements

- Frequency of updates can be more than once per second. Dozens of updates may occur as the event evolves.

\section{Contours Message}

Contour messages contains all the information in event source messages in addition to ground-motion predictions described as a set of nested contours (polygons) enclosing areas of specified Modified Mercalli Intensity (MMI) levels.

- Topic: eew.sys.gm-contour.data

- Message label: <event_message>

- Summary of content elements:

- All the information in the <core_info $>$ event source message element

- < gmcont_pred $>$

- A set of nested polygons enclosing areas that are expected to exceed MMI values from 2 to the maximum for the event; polygons have 8 vertices

- Format: XML (an XSD file describes the format elements)

- Frequency of updates can be more than once per second. Dozens of updates may occur as the event evolves.

\section{Map Message}

Map messages contain all the information in the event source message in addition to ground-motion predictions described as a grid of points with expected MMI values. Grid spacing is approximately 20 kilometers. Grid size depends on the earthquake's magnitude and the affected area. Users can interpolate between points if they need more precision at a particular location.

- Topic: eew.sys.gm-map.data

- Message label: <event_message> 
- Summary of content elements:

- All the information in the $<$ core info $>$ event source message element

- <gmmap_pred $>$

- List of grid points with predicted peak ground acceleration, peak ground velocity, and MMI level.

- Format: XML (an XSD file describes the format elements)

- Frequency of updates can be more than once per second. Dozens of updates may occur as the event evolves. 


\section{Appendix 2. ShakeAlert Reporting Region}

The reporting region for ShakeAlert is defined by the polygons shown in figure 2.1; polygon vertices are defined in table 2.1. The reporting region is based on Advanced National Seismic System (ANSS) authoritative regions, but has been extended off the Pacific Northwest coast. The reporting region has also been extended into Canada to latitude $50^{\circ} \mathrm{N}$ with the concurrence of Natural Resources Canada. The actual area for which alerts will be published at each rollout phase has not yet been determined.

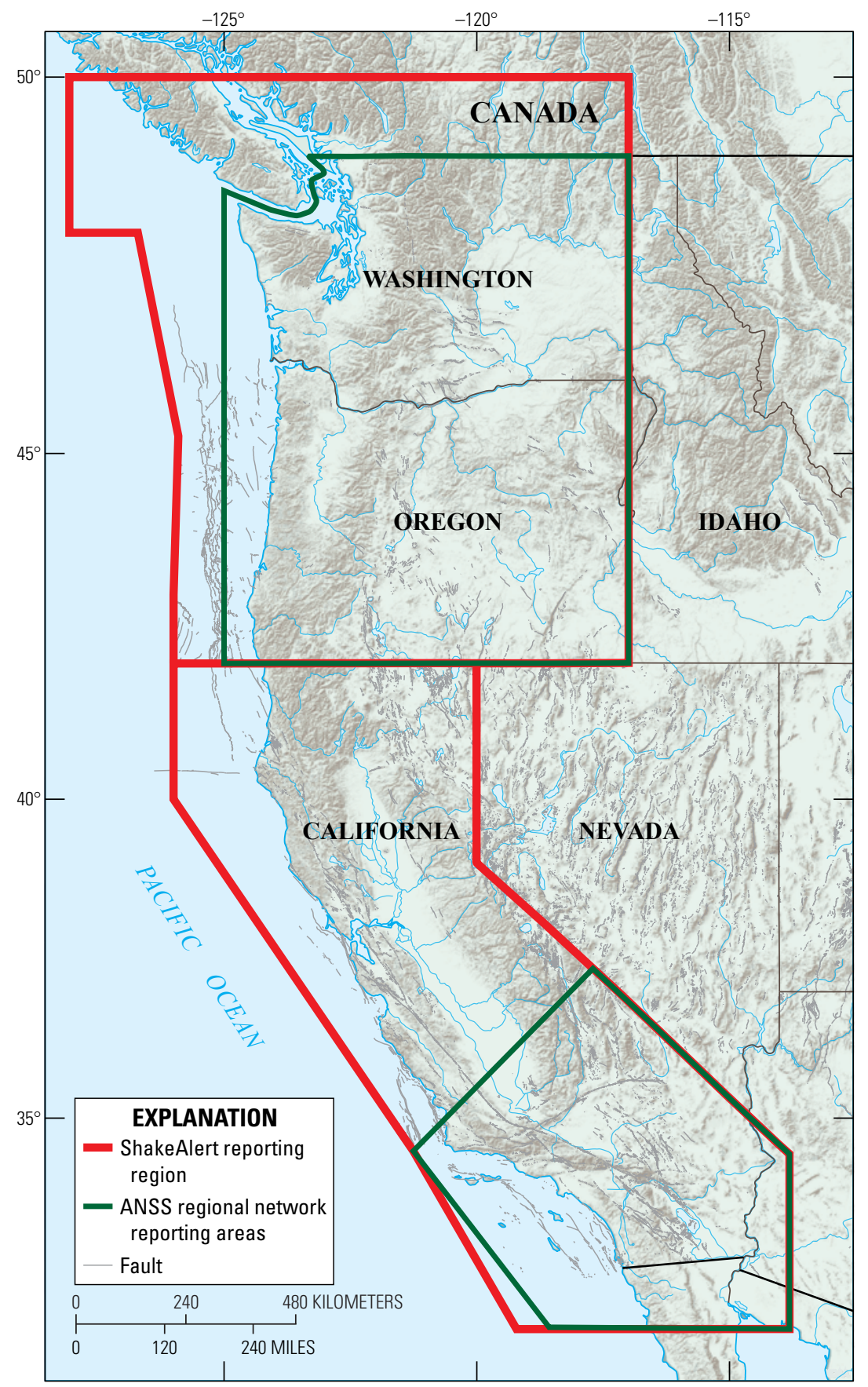

Base from Esri (C) 2018 and its licensors
Table 2.1. Vertices that define the ShakeAlert reporting region.

\begin{tabular}{cc}
\hline California & Pacific Northwest \\
\hline $37.430,-117.760$ & $42.000,-122.700$ \\
$39.000,-120.000$ & $42.000,-121.417$ \\
$42.000,-120.000$ & $42.000,-120.000$ \\
$42.000,-125.000$ & $42.000,-117.000$ \\
$42.000,-126.000$ & $49.000,-117.000$ \\
$40.000,-126.000$ & $50.000,-117.000$ \\
$34.500,-121.250$ & $50.000,-128.100$ \\
$31.500,-119.264$ & $47.996,-128.100$ \\
$31.500,-113.893$ & $47.996,-126.777$ \\
$34.500,-114.000$ & $45.352,-125.934$ \\
$37.430,-117.760$ & $43.000,-126.000$ \\
& $42.000,-126.000$ \\
& $42.000,-125.167$ \\
& $42.000,-122.700$ \\
\hline
\end{tabular}

Figure 2.1. Map of the ShakeAlert reporting region (outlined in red) and Advanced National Seismic System (ANSS) regional network reporting areas (outlined in green) in the western United States and Canada. 


\section{Appendix 3. List of Current ShakeAlert Pilot Users and Technology Partners (as of August 1, 2018)}

\begin{tabular}{|c|c|c|c|}
\hline User $^{1}$ & Technology partner & Sector & Application \\
\hline Bay Area Rapid Transit (BART) & None & Transportation, rail & Slow down trains \\
\hline California Institute of Technology (Caltech) & Everbridge & Education & Alert personnel \\
\hline Chevron Corporation & None & Manufacturing energy & Alert personnel, situational awareness \\
\hline City of Los Angeles & AT\&T & City government & $\begin{array}{l}\text { Alert employees via cell application, extend } \\
\text { to public }\end{array}$ \\
\hline City of Los Angeles & Early Warning Labs & City government & Alert people in city hall \\
\hline Early Warning Labs ${ }^{2}$ & None & Earthquake safety services & Develop hardware actuators for clients \\
\hline Esri $^{2}$ & None & $\begin{array}{l}\text { Information technology, geo- } \\
\text { graphic information systems }\end{array}$ & Integrate with map and alert products \\
\hline Eugene Water and Electric Board (EWEB) & None & Water system & $\begin{array}{l}\text { Close valves, gates, trip hydroelectric } \\
\text { generation units }\end{array}$ \\
\hline Everbridge $^{2}$ & None & Mass notification & $\begin{array}{l}\text { Integrate with emergency notification } \\
\text { product }\end{array}$ \\
\hline International School of the Peninsula (ISTP) & $\begin{array}{l}\text { University of } \\
\text { California, Berkeley }\end{array}$ & Education & Alert personnel and students \\
\hline Jet Propulsion Laboratory (JPL) & None & Research & $\begin{array}{l}\text { Alert personnel at Deep Space Network, } \\
\text { open fire station doors }\end{array}$ \\
\hline $\begin{array}{l}\text { Humboldt State University public radio station } \\
\text { (KHSU) }\end{array}$ & None & Public entertainment, media & Develop alerting over public radio stations \\
\hline Los Angeles County Department of Health Services & To be determined & Health care & Alert personnel, extend to other facilities \\
\hline $\begin{array}{l}\text { Los Angeles County Metropolitan Transportation } \\
\text { Authority (LA Metro) }\end{array}$ & Early Warning Labs & Transportation, rail & $\begin{array}{l}\text { Alert personnel including train and bus } \\
\text { operators }\end{array}$ \\
\hline Los Angeles Unified School District (LAUSD) & Early Warning Labs & School district & $\begin{array}{l}\text { Alert students in } 3 \text { schools, develop } \\
\text { curriculum }\end{array}$ \\
\hline NBCUniversal & Early Warning Labs & Entertainment media & $\begin{array}{l}\text { Alert personnel, radio, Voice over Internet } \\
\text { Protocol (VoIP), open fire station doors }\end{array}$ \\
\hline Northridge Hospital Medical Center & $\begin{array}{l}\text { Global Security } \\
\text { Systems (GSS) }\end{array}$ & Health care & Alert personnel via radio and pager \\
\hline Oregon Department of Transportation (ODOT) & None & Transportation & Activate warning lights on bridges \\
\hline Pacific Gas and Electric Company (PG\&E) & None & Utility & Alert personnel \\
\hline Regatta condominium complex & Early Warning Labs & $\begin{array}{l}\text { Residential } \\
\text { high-rise building }\end{array}$ & Alert residents, open doors \\
\hline Regroup Mass Notification ${ }^{2}$ & None & Mass notification & $\begin{array}{l}\text { Integrate with emergency notification } \\
\text { product }\end{array}$ \\
\hline RH2 Engineering ${ }^{2}$ & None & Water system controls & Develop hardware actuators for clients \\
\hline Northeast Sammamish Sewer and Water District & RH2 Engineering & Water utility & Close valves, stop pumps \\
\hline Santa Monica Community College & Early Warning Labs & Education & Alert personnel \\
\hline SCADA Solutions, Inc. ${ }^{2}$ & None & Utility control systems & Develop hardware actuators for clients \\
\hline SkyAlert $^{2}$ & None & Earthquake safety services & Develop hardware actuators for clients \\
\hline University of California, Berkeley Police Department & None & Education and public safety & Alert personnel, extend to football stadium \\
\hline University of Oregon & None & Education, utility & Alert personnel, protect power equipment \\
\hline $\begin{array}{l}\text { University of Southern California Department of } \\
\text { Public Safety }\end{array}$ & None & Education and public safety & Alert personnel, extend to medical center \\
\hline Varius, Inc. ${ }^{2}$ & None & Water system controls & Develop hardware actuators for clients \\
\hline $\begin{array}{l}\text { Washington State Department of Transportation } \\
\text { (WSDOT) }\end{array}$ & None & Transportation & Alert personnel, extend to ferry operations \\
\hline
\end{tabular}

${ }^{1}$ This list is growing rapidly.

${ }^{2}$ Company that plans to develop and market commercial products based on ShakeAlert. 


\section{Appendix 4. Funding History}

The history of funding to build, develop, and operate a West Coast earthquake early warning system is shown in tables 4.1 and 4.2. ShakeAlert has not yet received the capital funding needed to complete the system's infrastructure buildout. Also, it does not yet have the stable, long-term funding needed to operate the system reliably. Therefore, the U.S. Geological Survey (USGS) has employed a build-and-operate strategy, using any funding that remains after operational and development costs are covered to advance the capital buildout of infrastructure. Stable year-toyear base funding has increased over the life of the ShakeAlert project but has never reached the required level. Initially, increases in base funding can be used to incrementally improve system infrastructure, but over time that funding must shift to support operation and maintenance of the expanded system. There have also been occasional one-time or short-term supplemental funding from various sources that have been used for capital buildout of infrastructure, additional research and development, and to support management salary. Such sources include the California Governor's Office of Emergency Services (Cal OES), the State of Oregon, the Gordon and Betty Moore Foundation, and Los Angeles/Long Beach Urban Area Security Initiative (UASI) funds from the Department of Homeland Security.

Table 4.1. Historical Federal (U.S. Geological Survey [USGS]) funding for the ShakeAlert system.

\begin{tabular}{|c|c|c|c|}
\hline Fiscal year(s) & Project & $\begin{array}{l}\text { Base funding, } \\
\text { in dollars (\$) }\end{array}$ & $\begin{array}{c}\text { Capital funding, } \\
\text { in dollars (\$) }\end{array}$ \\
\hline $2006-12$ & EHP & $2,093,851$ & \\
\hline 2009-11 & ARRA & & $4,436,110$ \\
\hline $2012-15$ & EHP & $1,575,000$ & \\
\hline $2008-14$ & MHDP & $2,342,150$ & \\
\hline 2014 & MHDP & $1,500,000$ & \\
\hline 2015 & MHDP & $1,500,000$ & $5,000,000$ \\
\hline 2016 & ShakeAlert & $8,200,000$ & \\
\hline 2017 & ShakeAlert & $10,200,000$ & \\
\hline 2018 & ShakeAlert & $12,900,000$ & $10,000,000$ \\
\hline Total & & $45,311,001$ & $14,436,110$ \\
\hline
\end{tabular}

Table 4.2. Historical Non-Federal funding for the ShakeAlert system.

[LA/LB UASI, Los Angeles/Long Beach Urban Area Security Initiative, which provided funds from the Department of Homeland Security's Federal Emergency Management Agency; Cal OES, California Governor's Office of Emergency Services; Caltech, California Institute of Technology; UC Berkeley, University of California, Berkeley; USGS, U.S. Geological Survey; FY, fiscal year]

\begin{tabular}{lllc}
\hline Timeframe & \multicolumn{1}{c}{ Source } & \multicolumn{1}{c}{ Recipient(s) } & $\begin{array}{c}\text { Funding', } \\
\text { in dollars (\$) }\end{array}$ \\
\hline $2012-15$ & Gordon and Betty Moore Foundation & $\begin{array}{l}\text { USGS, UC Berkeley, Caltech, and } \\
\text { University of Washington }\end{array}$ & $6,500,000$ \\
$2014-16$ & LA/LB UASI & Caltech & $5,600,000$ \\
$2016-18$ & Gordon and Betty Moore Foundation & $\begin{array}{l}\text { UC Berkeley, Caltech, and University } \\
\text { of Washington }\end{array}$ & $3,600,000$ \\
\hline $2016-17$ & Cal OES & USGS, UC Berkeley, and Caltech & $10,000,000$ \\
$2015-18$ & Oregon & University of Oregon & $1,000,000$ \\
\hline $2018-19$ & Cal OES & To be determined & $15,750,000$ \\
\hline Total & & & $\mathbf{4 2 , 4 5 0 , 0 0 0}$ \\
\hline
\end{tabular}

${ }^{1}$ Note that these are all one-time funds that cannot be relied upon for long-term operation of the ShakeAlert system. 


\section{Appendix 5. Telemetry Improvement Plan}

The ShakeAlert project evaluated available and emerging telecommunications technologies and developed a telemetry improvement plan that would provide robust data return, which is summarized here. The estimated one-time cost of completing this plan is $\$ 20.5$ million and the annual operation and maintenance cost would be $\$ 9.8$ million per year. These costs could be substantially reduced if States and other partners provide data communications at low or no cost.

Robustness and resilience are achieved by using spatial diversity: that is, geographically overlapping independent communication services (for example, cellular, radio over Internet Protocol [IP radio], satellite, and internet) as well as U.S. Geological Survey-owned infrastructure (microwave and radio) and partner-owned infrastructure (for example, State-owned microwave). This reduces single points of failure in data delivery, and makes it less likely that adjacent stations will be knocked offline by a failure of one telemetry technology. Key microwave "backbone" links are engineered with redundant radio and power systems. Major regional collection nodes are designed with redundant backhauls, either of which can maintain dataflow if the other slows or fails. Dynamic routing in IP-based systems such as microwave, IP radio, satellite, and terrestrial internet can adapt to failures by rerouting dataflow.

One emerging technology that could be useful for ShakeAlert telemetry is FirstNet, which is a $\$ 7$ billion Federal project to build a nationwide, high-speed, broadband network dedicated to public safety. All 50 States and 5 territories have opted into the plan, and AT\&T has been awarded the contract to build and operate the system for 25 years. As FirstNet evolves, the ShakeAlert project will explore how it can be used to move data from field stations to alert centers and from alert center to users; however, practical use may be years away.

Organizations that operate their own communications systems, such as the military, utilities, and State, local, and county agencies, are valuable partners. Not only can they transport data from field stations to ShakeAlert processing centers, but alerts can be delivered to them over their own networks. Therefore, ties with current partners are being strengthened and new ones are being sought. Some candidate systems' cost recovery structures can put them at a price disadvantage compared to commercial services, while others are competitive. The public safety mission of ShakeAlert, as well as its direct value to these partners, can be an incentive for them to provide bandwidth at no or reduced costs.
The final mix and distribution of technologies will be determined by funding as well as the cost, capability, and geographic availability of the various telemetry options. There will also be regional adaptations owing to differences in topography, vegetation, population, and available infrastructure.

Estimated costs would also be reduced if non-cash resources are provided to the project by public or private partners. For example, our initial estimate of capital costs for backbone telemetry in California was reduced by $\$ 10$ million because the California Governor's Office of Emergency Services (Cal OES) agreed to provide high-availability telemetry bandwidth on its Public Safety Communications system as part of California's support of earthquake early warning. The cost of telemetry in Washington and Oregon could be similarly reduced if those States agreed to the same or similar terms.

The estimated capital cost of the robust three-state telemetry improvement plan is $\$ 20.5$ million: $\$ 8.8$ million in California and $\$ 11.7$ million in Oregon and Washington (table 5.1). The estimated operation and maintenance costs would be $\$ 9.8$ million per year. Both the capital and operation and maintenance costs of telemetry improvement could be substantially reduced if States and other partners provide data communications at no or reduced cost.

The budget for the proposed improved telemetry system covers detailed system engineering, site permitting, radiofrequency licensing, upgrade of obsolete equipment, and installation of new infrastructure, such as towers. With full funding, completing the telemetry improvement would take at least three years. The capital cost of telemetry improvement could be amortized over a reasonable time, where it replaces alternatives that incur monthly charges; however, those costs are not known well enough to reliably project at this time.

More study of the strengths and weaknesses of different field telemetry technologies could inform practical network design decisions. Interesting work has been done to evaluate the effects of altered station distribution during telemetry outages (Biasi and Alvarez, 2018), but the fragilities of telecommunications systems both to bring in field data and deliver alerts are not well understood. More work to examine the effects of differing telemetry technologies and configurations on increased data transmission resilience for ShakeAlert will be pursued as resources permit.

Table 5.1. Summary of capital and operation and maintenance budget estimates to complete the three-state telemetry improvement plan for the ShakeAlert system by Advanced National Seismic System (ANSS) region.

\begin{tabular}{lccc}
\hline \multicolumn{1}{c}{ Component } & $\begin{array}{c}\text { California, } \\
\text { in dollars (\$) }\end{array}$ & $\begin{array}{c}\text { Pacific Northwest, } \\
\text { in dollars (\$) }\end{array}$ & $\begin{array}{c}\text { West Coast total, } \\
\text { in dollars (\$) }\end{array}$ \\
\hline Capital cost & $8,835,552$ & $11,691,287$ & $20,526,839$ \\
Operation and maintenance cost & $3,616,491$ & $6,152,226$ & $9,768,717$ \\
\hline Total & $\mathbf{1 2 , 4 5 2 , 0 4 3}$ & $\mathbf{1 7 , 8 4 3 , 5 1 3}$ & $\mathbf{3 0 , 2 9 5 , 5 5 6}$ \\
\hline
\end{tabular}


Publishing support provided by the Menlo Park Publishing Service Center, California

Manuscript approved on September 24, 2018

Edited by Monica Erdman

Layout and design by Cory Hurd 


\section{$\frac{2}{2}$}

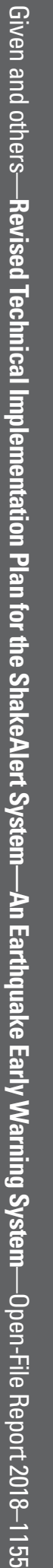

